\title{
(ब)
}

AUTARQUIA ASSOCIADA À UNIVERSIDADE DE SÃO PAULO

\section{ABLAÇÃO SELETIVA DE UM FILME DE NITRETO DE TITÂNIO EM SUBSTRATO DE CARBONETO DE TUNGSTÊNIO UTILIZANDO LASER DE PULSOS ULTRACURTOS}

EDUARDO SPINELLI OLIVEIRA

Dissertação apresentada como parte dos requisitos para obtenção do Grau de Mestre em Ciências na Área de Tecnologia Nuclear - Materiais

Orientador:

Prof. Dr. Wagner de Rossi 


\title{
INSTITUTO DE PESQUISAS ENERGÉTICAS E NUCLEARES
}

Autarquia associada à Universidade de São Paulo

\section{ABLAÇÃO SELETIVA DE UM FILME DE NITRETO DE TITÂNIO EM SUBSTRATO DE CARBONETO DE TUNGSTÊNIO UTILIZANDO LASER DE PULSOS ULTRACURTOS}

\author{
Eduardo Spinelli Oliveira
}

Dissertação apresentada como parte dos requisitos para obtenção do Grau de Mestre em Ciências na Área de Tecnologia Nuclear Materiais

Orientador:

Prof. Dr. Wagner de Rossi

Versão Corrigida

Versão Original disponível no IPEN

São Paulo 
À minha amada esposa Dani,

Que me apoiou em todos os momentos, muitas vezes abrindo mão de seu tempo e seus sonhos para que eu pudesse completar este trabalho. 


\section{AGRADECIMENTOS}

Ao Instituto de Pesquisas Energéticas e Nucleares e ao Centro de Lasers e Aplicações pela estrutura concedida para realização deste trabalho.

Aos meus pais Raimundo e Maria, que me proporcionaram a melhor educação ao seu alcance e me ensinaram alguns dos segredos da vida, fazendo de mim o homem que sou hoje.

À minha irmã Adriana, pelo cuidado com todos, indiscriminadamente, passando tranquilidade nos momentos difíceis.

Ao meu irmão George, pela força em todos os momentos da vida e por enxergar mais em mim do que eu mesmo.

Aos meus "Primos", que sempre me apoiaram e estiveram na torcida pelo meu sucesso, vocês sabem quem vocês são.

À todos os amigos e colegas de trabalho, que tanto incentivaram a conclusão deste projeto.

À todos os colegas do Centro de Lasers e Aplicações, sempre dispostos a ajudar e compartilhar experiências, em especial ao Dr. Marcelo Bertolete, que prestou grande ajuda técnica e me incentivou a ir em frente quando diversos fatores me empurravam para trás.

À todos os funcionários e colaboradores do Centro de Lasers e Aplicações, pelo cuidado e zelo pelo bem estar de todos, em especial aos Professores Dr. Marcus Paulo Raele e Dr. Ricardo Elgul Samad pelo apoio e conhecimento compartilhado a todos os momentos.

Ao Prof. Dr. Rui Vilar do Instituto Técnico Superior de Lisboa que dispôs de seu tempo em visita ao IPEN para esclarecer importantes dúvidas sobre os materiais utilizados neste trabalho.

Um agradecimento especial ao meu orientador neste trabalho Prof. Dr. Wagner de Rossi que, com muita calma e paciência compartilhou seu conhecimento, seu tempo e seu laboratório, confiando no trabalho de um aluno já a muito fora do meio acadêmico, muito obrigado. 
Sempre em frente, se cair levante, se não puder levantar, arraste-se. 


\title{
ABLAÇÃO SELETIVA DE UM FILME DE NITRETO DE TITÂNIO EM SUBSTRATO DE CARBONETO DE TUNGSTÊNIO UTILIZANDO LASER DE PULSOS ULTRACURTOS
}

\author{
Eduardo Spinelli Oliveira
}

\section{RESUMO}

Revestimentos superficiais são aplicados à muitas ferramentas de usinagem na indústria metalúrgica com o intuito de melhorar a eficiência de corte e aumentar sua vida útil. Neste trabalho foram realizados testes para remoção do recobrimento de nitreto de titânio alumínio (TiAIN) em pastilhas de carboneto de tungstênio (WC-Co), utilizando um feixe laser de pulsos ultracurtos. Após a determinação dos limiares de dano do filme e do substrato foram ablacionados na superfície do recobrimento, traços utilizando duas condições de ablação. Inicialmente operou-se no regime de baixa fluência do filme, e posteriormente no regime de baixa fluência do substrato, muito abaixo do limiar do filme, aplicandose alta sobreposição de pulsos. Um sistema de espectroscopia de emissão atômica induzida por laser (LIBS) foi montado para monitoramento dos materiais presentes no plasma gerado pelo laser, porém o sistema não apresentou sensibilidade suficiente para leitura da baixa intensidade do plasma proveniente do processo e não foi utilizado. Após a análise dos traços por microscopia eletrônica, perfilometria óptica e espectroscopia por fluorescência de Raios-X, não foi possível determinar um processo seguro para realizar a remoção seletiva do filme em questão, porém, devido aos dados obtidos e observações dos resultados em alguns traços, novas possibilidades foram levantadas, abrindo a discussão para a realização de trabalhos futuros. 


\title{
SELECTIVE ABLATION OF A TITANIUM NITRIDE FILM ON TUNGSTEN CARBIDE SUBSTRATE USING ULTRASHORT LASER PULSES
}

\author{
Eduardo Spinelli Oliveira
}

\begin{abstract}
Surface coatings are applied to many cutting tools in the metallurgical industry in order to improve cutting efficiency and extend its useful life. In this work, tests were performed to remove the coating of titanium aluminum nitride (TiAIN) on tungsten carbide (WC-Co) pellets, using an ultrashort laser pulses beam. After determination of the damage thresholds of the film and the substrate, were ablated on the surface of the coating lines using two ablation conditions, it was initially operated on the low fluence regime for the film, and later on the low fluence regime of the substrate, far below the threshold of the film, applying high overlapping pulses. A laser induced breakdown spectroscopy (LIBS) system was set up to monitor the materials present in the plasma generated by the laser, but the system did not present sufficient sensitivity to read the low intensity of the plasma generated in the process and was not used. After the analysis of the traces by electron microscopy, optical profilometer and X-ray fluorescence spectroscopy, it was not possible to determine a safe process to carry out the selective removal of the film in question, however, due to the data obtained and observations of the results in some traces, new possibilities were raised, opening the discussion for future work.
\end{abstract}




\section{SUMÁRIO}

Página

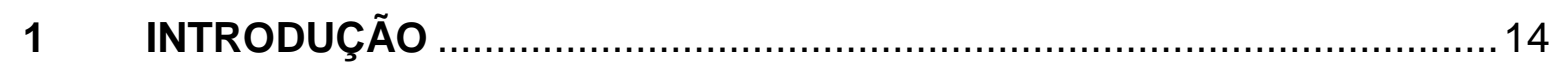

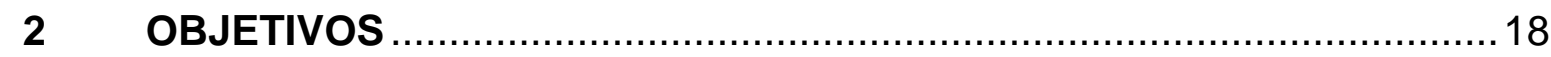

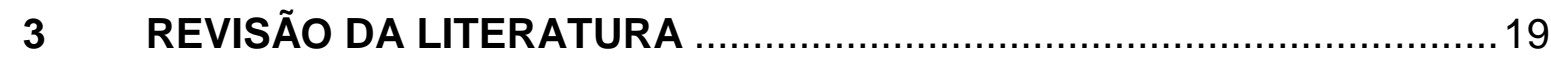

3.1 Ablação seletiva a laser ....................................................................19

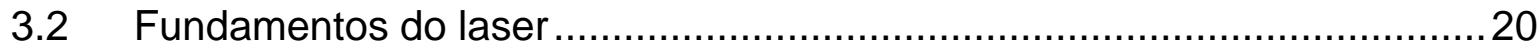

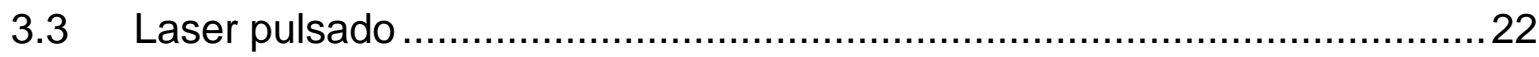

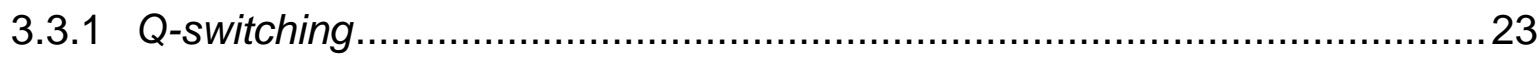

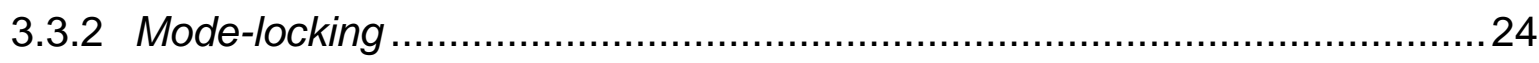

3.3.3 Amplificação de pulso Chirped (CPA) ……….....................................26

3.4 Características de um feixe laser ………….....................................2

3.4.1 Características métricas de um feixe laser focalizado ……………….......27

3.4.2 Distribuição de energia num feixe laser focalizado....................................29

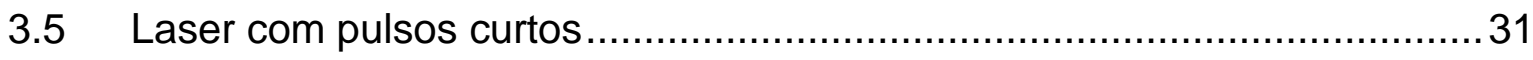

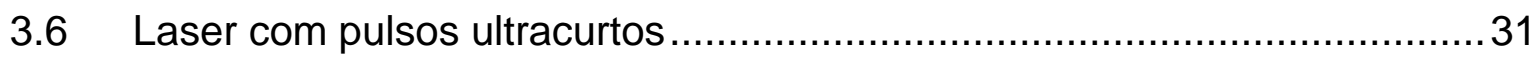

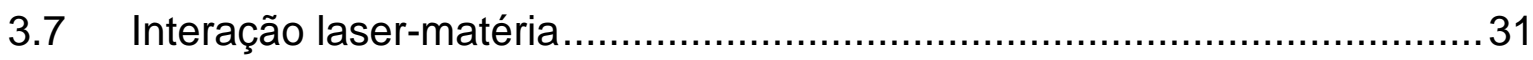

3.7.1 Processo de absorção da energia do laser ................................................33

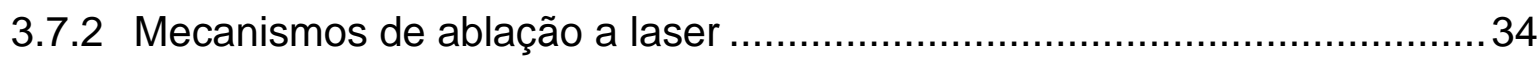

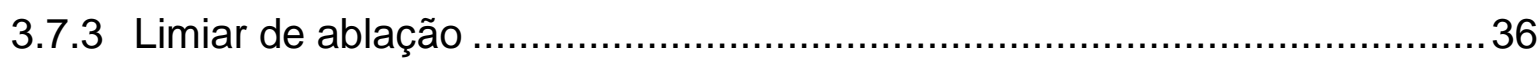

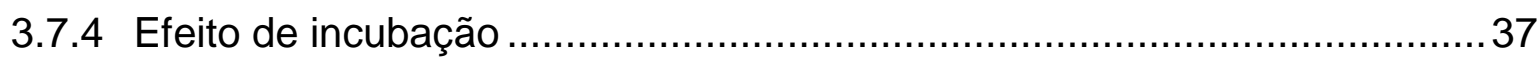

3.7.5 Método D-Scan para determinação do limiar de ablação ........................... 38

3.8 Espectroscopia de emissão atômica induzida por laser (LIBS) ………........39 
3.8.1 Utilização do laser com pulsos de femtossegundos na LIBS

4 METODOLOGIA

4.1 Laser com pulsos de femtossegundos .......................................... 44

4.2 Sistema LIBS para controle da ablação seletiva .................................45

4.3 Teste do sistema LIBS numa pastilha triangular .............................. 49

4.4 Pastilha quadrada para os testes da ablação seletiva ...........................50

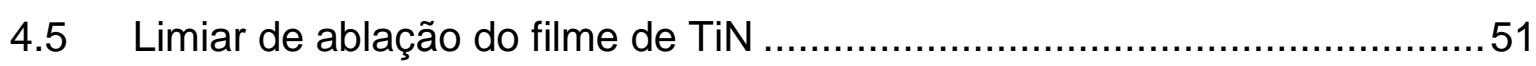

4.6 Limiar de ablação do substrato de WC ........................................... 52

4.7 Determinação dos parâmetros para ablação seletiva.............................52

4.8 Ablação por meio de baixa fluência no filme de TiAIN .............................54

4.9 Teste de redução do limiar de ablação do filme de TiN a partir dos efeitos de incubação............................................................. 55

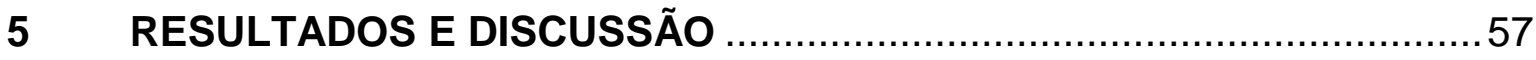

5.1 Sistema de controle da ablação (LIBS) ......................................... 57

5.2 Teste do sistema LIBS na pastilha triangular ....................................... 60

5.3 Composição do filme e do substrato da pastilha quadrada .......................62

5.4 Limiar de ablação do filme de TiAIN ................................................ 65

5.5 Limiar de ablação do substrato de WC-Co ...................................... 68

5.6 Ablação por meio de baixa fluência no filme de TiN .............................. 70

5.7 Teste de redução do limiar de ablação do filme de TiN a partir dos

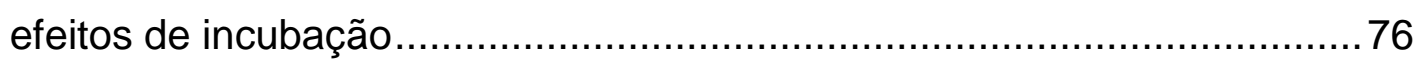

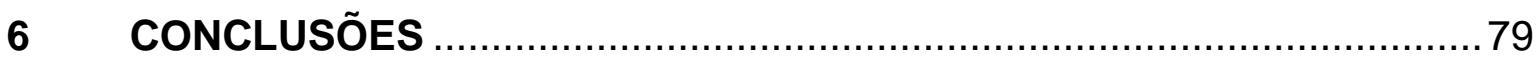

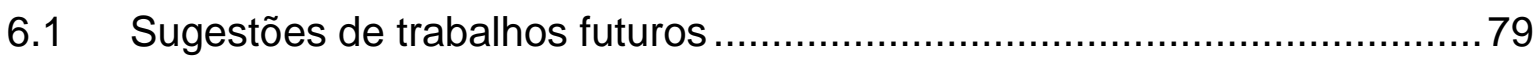

APÊNDICE A - Traços gravados no filme de TiN para determinação do limiar de ablação pelo método D-Scan. Sobreposição decrescente de pulsos de cima para baixo, variando de $\mathrm{N}=4913$ à $\mathrm{N}=1 \ldots \ldots \ldots \ldots .80$

APÊNDICE B - Rebaixos ablacionados para teste do sistema de LIBS .........81

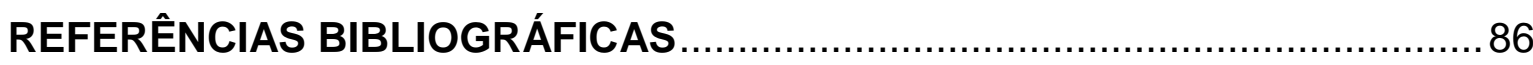




\section{LISTA DE TABELAS}

TABELA 1 - Variação de fluência e sentido de usinagem dos canais no teste de montagem do LIBS

TABELA 2 - Composição do filme da pastilha utilizada para o teste do sistema LIBS.

TABELA 3 - Composição do substrato da pastilha utilizada para o teste do sistema LIBS 61

TABELA 4 - Profundidade e rugosidade, em função da quantidade de passes, dos rebaixos ablacionados para teste do sistema LIBS 62

TABELA 5 - Composição do filme da pastilha de usinagem. 63

TABELA 6 - Composição do substrato da pastilha de usinagem. 63 


\section{LISTA DE FIGURAS}

FIGURA 1 - Estruturas do tipo escadas utilizadas em sensores MEMS, gravadas em SiC por "escrita direta" utilizando laser de femtossegundos [16].....19 FIGURA 2 - Cabeça de mármore helenístico antes da limpeza a laser (à esquerda) e após o tratamento (à direita) [17].

FIGURA 3 - Diagrama de transições eletrônicas durante o bombeamento de um meio de ganho para geração de um feixe laser [22].

FIGURA 4 - Esquema simplificado de montagem dos componentes básicos de um laser [21].

FIGURA 5 - Elementos de um tubo laser de $\mathrm{HeNe}$ [22].

FIGURA 6 - Evolução temporal de ganho e perdas em um laser com sistema $\mathrm{Q}$-switched ativo. $\mathrm{O} Q$-switching é ativado em $\mathrm{t}=0$. A potência de saída começa a subir exponencialmente, mas atinge o máximo somente após $\approx 0,2$ us [25].

FIGURA 7 - Modulação de fase de uma série de modos de deslocamento longitudinais, gerando um pulso laser [27].

FIGURA 8 - Sistema mode-locking numa cavidade laser linear [21].

FIGURA 9 - Esquema de funcionamento de um sistema de amplificação de pulso Chirped [29].

FIGURA 10 - Características métricas de um feixe laser focalizado [30].

FIGURA 11 - Perfil típico da distribuição de energia de um feixe Gaussiano. Representação em uma e duas dimensões (à direita) e um modelo 3D (à esquerda) [32].

FIGURA 12 - Intensidade normalizada do feixe, I/I0, como função da distância radial $\rho$ em diferentes distâncias axiais. (a) $z=0$; (b) $z=z 0$; (c) $z=2 z 0$ [33] .......30 FIGURA 13 - Escala de tempo relacionando os processos secundários gerados na ablação a laser [36].

FIGURA 14 - Comparação do dano causado por um laser com pulsos de nanossegundos e um de femtossegundos [37].

FIGURA 15 - Estrutura eletrônica de bandas de metais, semicondutores e dielétricos [39].

FIGURA 16 - a) Esquema da varredura diagonal da amostra; b) perfil gravado na amostra [44]. 
FIGURA 17 - Esquema simplificado com os principais componentes de um sistema LIBS.

FIGURA 18 - Esquema representativo da evolução temporal de um plasma de LIBS. Os quadros ilustram o tipo de espectro que se pode observar nos diferentes momentos [47].

FIGURA 19 - Evolução temporal do espectro do plasma induzido por laser numa amostra metálica [48].

FIGURA 20 - Arranjo óptico do sistema de entrega do feixe [50].

FIGURA 21 - Traços ablacionados na chapa de titânio GP2CP. Representação do posicionamento das lentes para teste de captação do sinal de emissão do plasma para o sistema LIBS.

FIGURA 22 - Montagem das lentes para captação do sinal para o LIBS.

FIGURA 23 - Montagem do equipamento LIBS, à direita conjunto de lentes para captação do sinal do plasma e à esquerda espectrômetro e computados para tratamento dos dados.

FIGURA 24 - Tela do software de análise espectral com os picos coletados no canal 1 do Conjunto 1

FIGURA 25 - Pastilha de usinagem utilizada para teste do sistema LIBS. 50

FIGURA 26 - Pastilha de mercado utilizada como amostra.

FIGURA 27 - Perfil do traço 10 ablacionado no filme com sobreposição de pulsos de $\mathrm{N}=18$. No detalhe, a região de transição do filme para o substrato no início do traço, desde a formação dos LIPSS até a remoção total do filme. ....53 FIGURA 28 - Detalhe dos LIPSS formados pelo laser no filme, estruturas verticais formadas transversalmente ao traço.

FIGURA 29 - Representação da variação do diâmetro do feixe no decorrer da varredura diagonal do traço 10 gravado para o $D$-scan.

FIGURA 30 - Gráfico comparativo dos limiares de ablação do filme de TiAIN e do substrato de WC-Co em função da sobreposição de pulsos. 56

FIGURA 31 - Perfil 3D dos canais ablacionados no Conjunto 1

FIGURA 32 - Intensidades relativas dos sinais captados pelo espectrômetro de acordo com a redução da fluência do laser. Lentes de captação paralelas ao sentido de usinagem atrás do feixe.

FIGURA 33 - Gráfico da intensidade relativa do sinal do plasma captada para cada configuração de posicionamento das lentes do LIBS. 
FIGURA 34 - Evolução da intensidade do pico referente ao titânio em cada passe ablacionado.

FIGURA 35 - Análise da espessura do filme de TiN.

FIGURA 36 - Mapa de rugosidade da superfície da pastilha de usinagem.

FIGURA 37 - Perfis gravados na pastilha de usinagem pelo método D-Scan, para determinação do limiar de ablação do filme de TiAIN.

FIGURA 38 - Onze primeiros traços gravados no D-Scan para determinação do limiar de ablação do filme de TiAIN.

FIGURA 39 - Perfil do traço 9 gravado na superfície da pastilha para determinação do limiar de ablação pelo método D-Scan. No detalhe, região da largura máxima do perfil.

FIGURA 40 - Acima, vista frontal com escala de profundidade do traço 9 ablacionado para realização do D-Scan no filme de TiAIN. Abaixo, secção longitudinal no centro do traço.

FIGURA 41 - Gráfico do limiar de ablação em função da sobreposição de pulsos para o filme de TiAIN, obtido pelo método de D-Scan.

FIGURA 42 - Perfis gravados no substrato pastilha de usinagem pelo método

D-Scan para determinação do limiar de ablação.

FIGURA 43 - Perfil do traço 13 gravado na superfície da pastilha para determinação do limiar de ablação pelo método D-Scan. No detalhe, região de largura máxima do perfil.

FIGURA 44 - Gráfico do limiar de ablação em função da sobreposição de pulsos para o substrato de WC, obtido pelo método de D-Scan.

FIGURA 45 - Traços gravados para teste de ablação com fluência próxima à de limiar do filme de TiAIN.

FIGURA 46 - Imagem do traço 21 com indicação do percurso do laser, linha vermelha, e da região transversal ao traço onde foi realizada uma análise por EDS, linha amarela.

FIGURA 47 - Detalhe da análise EDS realizada no traço 21, onde é possível identificar a redução dos componentes do filme na região de varredura do laser.

FIGURA 48 - Imagens geradas no MEV dos canais ablacionados em função da variação da sobreposição de pulsos. 
FIGURA 49 - Perfil gerado no perfilômetro óptico referente ao traço 21 ablacionado com fluência por pulso de $0,6 \mathrm{~J} / \mathrm{cm} 2$ e sobreposição de $N=111$. Imagem 3D da superfície (acima), e seção transversal do traço com o perfil de profundidades (abaixo).

FIGURA 50 - Gráfico das profundidades em cada um dos 25 canais ablacionados no filme de TiAIN, com sobreposição de pulsos variando de $\mathrm{N}=2340$ (traço 1) até $\mathrm{N}=94$ (traço 25).

FIGURA 51 - Traços gravados utilizando fluência abaixo do limiar de ablação do substrato, portando muito abaixo do limiar do filme, porém com alta sobreposição de pulsos.

FIGURA 52 - Traços para teste de ablação com alta sobreposição de pulsos. ....77 FIGURA 53 - Rebaixo ablacionado em 1 passe numa pastilha de usinagem para teste do sistema de LIBS.

FIGURA 54 - Rebaixo ablacionado em dois passes numa pastilha de usinagem para teste do sistema de LIBS.

FIGURA 55 - Rebaixo ablacionado em três passes numa pastilha de usinagem para teste do sistema de LIBS.

FIGURA 56 - Rebaixo ablacionado em quatro passes numa pastilha de usinagem para teste do sistema de LIBS.

FIGURA 57 - Rebaixo ablacionado em cinco passes numa pastilha de usinagem para teste do sistema de LIBS. 


\section{INTRODUÇÃO}

Filme fino é um termo utilizado para designar camadas de materiais que vão desde frações de nanometros até vários micrometros de espessura, embora ainda haja uma discussão quanto ao limite dessa espessura [1]. A tecnologia dos filmes de recobrimento vem sendo cada vez mais utilizada, principalmente em tecnologias de armazenamento de dados (óptico e magnético), telecomunicações, displays, células de combustível, células fotovoltaicas, sensores, atuadores, além de recobrimentos com diversas funções (ópticas, decorativas, proteção ambiental, proteção ao desgaste mecânico, como barreiras de difusão, redução do coeficiente de atrito), dentre outros [1].

$\mathrm{Na}$ indústria metalúrgica, grande parte das ferramentas utilizadas para usinagem convencional recebem um revestimento superficial visando a melhoria de propriedades mecânicas e físicas específicas como dureza, ductilidade ou resistência à abrasão, para execução dos trabalhos de conformação e corte de metais [2]. Na fabricação de pastilhas de usinagem (insertos), uma combinação muito comum é a utilização de um substrato de metal duro (WC-Co) recoberto com um filme de nitreto de titânio (TiN), configuração que é foco de muitos estudos para melhoria dos processos de usinagem [3-5].

Os principais métodos para obtenção de filmes finos são a modificação da superfície do substrato por altas temperaturas (tratamento térmico), e a deposição física ou química de vapor (PVD - do inglês: Physical Vapour Deposition, ou CVD - do inglês: Chemical Vapour Deposition). Para diversas aplicações é necessário controlar ou impedir o crescimento do filme, ou até mesmo, eliminar a camada em determinadas regiões da superfície, como por exemplo, para fabricação de células fotovoltaicas [6]. Um dos métodos utilizados para remoção de filmes depositados em áreas específicas é a ablação seletiva por laser que, com o avanço das técnicas de controle e equipamentos cada vez mais precisos, vem ganhando espaço nos processos industriais de fabricação [7]. 
Em alguns casos no entanto, a ablação seletiva deve ser realizada de forma que sejam preservadas as características físicas e químicas dos materiais, como por exemplo na fabricação de células fotovoltaicas, onde não deve haver contato entre as camadas depositadas [6]. Para esse fim, lasers de pulsos curtos se mostraram ineficientes, uma vez que os efeitos térmicos provenientes do processo de ablação geram a difusão dos materiais entre as camadas, reduzindo a eficiência do produto na geração de energia [8].

A capacidade de pulsos laser ultracurtos de ablacionar quantidades muito pequenas de qualquer tipo de material, pode ser utilizada para remoção seletiva de filmes depositados sobre um substrato [9]. Camadas de poucas dezenas de nanometros podem ser retiradas por cada pulso laser, e o processo pode ser repetido até que todo o material de cobertura seja removido. Este processo pode ser de grande precisão e possui inúmeras aplicações [8, 10-13] como limpeza de superfícies, recuperação de objetos, usinagem de máscaras de semicondutores, descontaminação, e retirada de recobrimentos de ferramentas de corte.

A diferença entre as propriedades físicas do filme e do substrato determinam a possibilidade do processo, bem como sua precisão e complexidade. Se o material do recobrimento absorve o comprimento de onda do laser e pode ser removido com uma densidade de energia, fluência, menor do que àquela necessária para causar dano ao substrato, então o processo é relativamente simples e não há a necessidade de um controle extremamente preciso. A densidade de energia, do pulso é ajustada para estar um pouco acima daquela necessária para eliminar o filme, porém abaixo do limite para causar dano ao substrato; um excesso de pulsos sobre a superfície do substrato não irá afetá-lo.

Em outra análise, se a fluência necessária para remover o recobrimento é próxima ou maior que a fluência mínima para causar dano ao substrato, chamada de fluência de limiar, então um controle mais preciso e realimentado pelo processo deve existir para evitar dano excessivo ao substrato.

O controle do processo pode ser feito através da medida em tempo real do espectro do plasma emitido pela interação com o pulso laser focalizado, observando a evolução das emissões características do filme e do substrato, que pode ser feito pela técnica de espectroscopia de emissão atômica induzida por 
laser (LIBS, do inglês: Laser-induced Breakdown Spectroscopy) [11]. Esta análise permite determinar com precisão quando o material do revestimento está acabando e quando o material do substrato começa a ser ablacionado pelo laser [11].

O processo para remoção de recobrimentos em pastilhas de usinagem depende das propriedades físicas do filme e do substrato; depende de como o calor flui de um material para o outro, de suas propriedades térmicas e de como os limiares de ablação são modificados por defeitos gerados pela interação com o laser. Enfim, um estudo completo é muito complexo e não foi o objetivo deste trabalho, contudo, para dar início a este estudo, uma aplicação específica foi escolhida, a remoção de um filme de TiAIN depositado em substrato de metal duro (WC-Co) de ferramentas de corte.

Para remoção de filmes de TiAIN depositados sobre um substrato de WC-Co, a ablação realizada por lasers de pulsos com largura temporal de nanossegundos não é aconselhável, pois nesse caso, o trabalho se dá por meio de processos térmicos, onde uma grande parte do material é ejetado na forma de vapor, e outra parte é fundida e ressolidificada, permanecendo nos arredores da superfície ablacionada. Além deste inconveniente, uma zona afetada pelo calor (ZAC) também é formada na vizinhança da região irradiada pelo laser. A espessura desta ZAC depende principalmente da energia utilizada, da largura temporal do pulso laser, e das propriedades térmicas do material processado. A formação destas camadas, de regiões ressolidificadas e de ZAC, com formação de fases cristalinas diferentes daquelas do metal original, levam a uma modificação das propriedades físicas e metalúrgicas da pastilha de usinagem, que pode não ser mais adequada à utilização como ferramenta de corte [14].

Uma opção para realizar a ablação seletiva sem provocar estes efeitos negativos, é a utilização de lasers de pulsos ultracurtos, com larguras temporais da ordem de poucas dezenas ou centenas de femtossegundos ( $1 \mathrm{fs}=10^{-15} \mathrm{~s}$ ). Como a duração temporal destes pulsos é menor que o tempo de interação elétron-fonon do material, grande parte do processo de ablação ocorre antes que haja transferência significativa de calor para a rede cristalina. Em dielétricos, o material é ejetado principalmente por repulsão coulombiana, enquanto que para metais, o material irradiado é ejetado principalmente por explosão de fase, sem que haja acúmulo significativo de calor na região de interação [6, 9]. 
A simples utilização de pulsos ultracurtos, contudo, principalmente para metais, não garante a interação não térmica com o laser, e somente a utilização de parâmetros adequados de pulso podem levar a um processo com mínimo acúmulo de calor. Assim, há a necessidade de se encontrar as condições adequadas de ablação que levem a um acúmulo mínimo de calor na região de interação com o pulso laser e, ao mesmo tempo, garantam a remoção completa do filme depositado sobre o substrato no inserto de usinagem. 


\section{OBJETIVOS}

Este trabalho teve como objetivo desenvolver uma metodologia para utilização de laser de pulsos ultracurtos na remoção controlada de filmes de TiAIN depositados em substrato de WC-Co. 


\section{REVISÃO DA LITERATURA}

\subsection{Ablação seletiva a laser}

A ablação seletiva a laser tem como objetivo principal a remoção de camadas de determinado material depositadas, propositalmente ou não, sobre um substrato, podendo ir desde a fabricação de microestruturas aplicadas em sensores para sistemas microeletromecânicos (MEMS, do inglês: Microelectromechanical Systems) como é possível ver na FIGURA 1, até a remoção de camadas de contaminantes em obras de arte como retratado na FIGURA 2 [15].

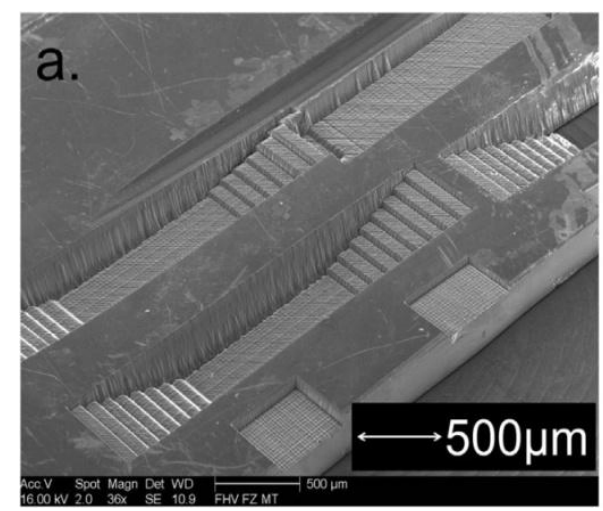

FIGURA 1 - Estruturas do tipo escadas utilizadas em sensores MEMS, gravadas em SiC por "escrita direta" utilizando laser de femtossegundos [16].

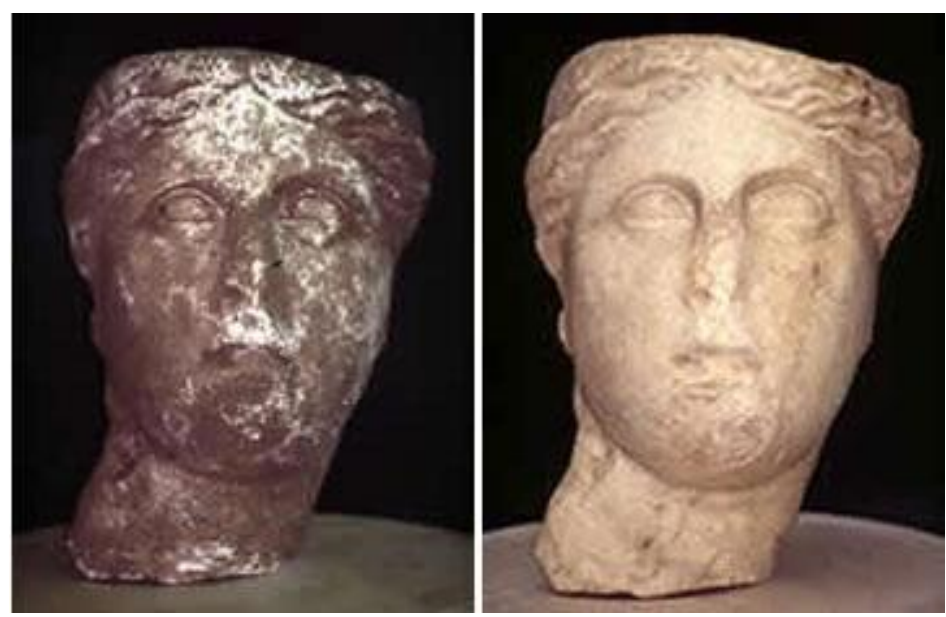

FIGURA 2 - Cabeça de mármore helenístico antes da limpeza a laser (à esquerda) e após o tratamento (à direita) [17]. 
Para que a ablação seletiva tenha sucesso, é necessário conhecer as propriedades físicas tanto do material do substrato como da camada que se deseja remover, e a precisão do processo está diretamente relacionada às características do laser, como taxa de repetição e duração dos pulsos, energia e fluência. Combinando a tecnologia laser de pulsos ultracurtos, que oferece maior precisão e grande aplicação na microusinagem, com sistemas de movimentação de alta precisão, é possível gerar microestruturas complexas, assim como obter grande precisão na remoção seletiva de materiais [15].

\subsection{Fundamentos do laser}

O primeiro sistema laser desenvolvido utilizava um cristal de rubi como meio de ganho, e foi fabricado por Theodore Maiman em 1960 [18], baseado nas teorias de emissão estimulada discutidas por Albert Eistein [19] muitos anos antes, e pode ser operado até os dias de hoje. Muitos sistemas foram desenvolvidos em seguida, inclusive o laser de $\mathrm{CO}_{2}$ em 1963 [20], um dos mais poderosos e amplamente utilizados lasers industriais até os dias atuais.

Para geração de um feixe laser são necessários basicamente três componentes:

- o material gerador, chamado de meio de ganho, que fará a amplificação da luz pelo processo de emissão estimulada. O meio de ganho pode ser sólido, líquido ou gasoso;

- uma fonte capaz de fornecer energia suficiente ao meio de ganho, provocando neste a emissão estimulada de fótons. Esse processo é chamado de bombeamento, e a fonte pode ser uma descarga elétrica, uma lâmpada ou outro laser;

- dois espelhos que formarão uma cavidade óptica, onde o feixe de luz da emissão estimulada será concentrado viajando de um a outro, formando um ressonador [21].

A geração de um feixe laser se dá pelo fornecimento de energia ao meio de ganho, a fim de excitar seus elétrons e um nível energético mais elevado. Na FIGURA 3 é possível ver um diagrama simplificado das transições dos elétrons nos níveis de energia durante o bombeamento. Esses elétrons excitados decaem por meio de transições não radiativas até atingirem um estado metaestável. Ao decaírem dessa condição para o nível energético mais baixo, 
liberam a energia excedente na forma de fótons, emissão espontânea, até atingirem seu estado fundamental [22].

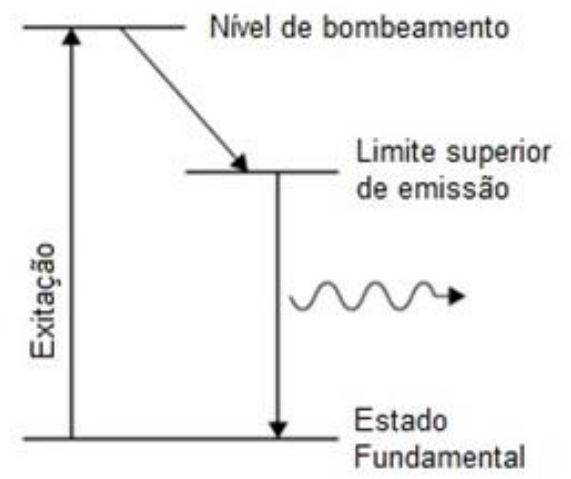

Emissão em três niveis

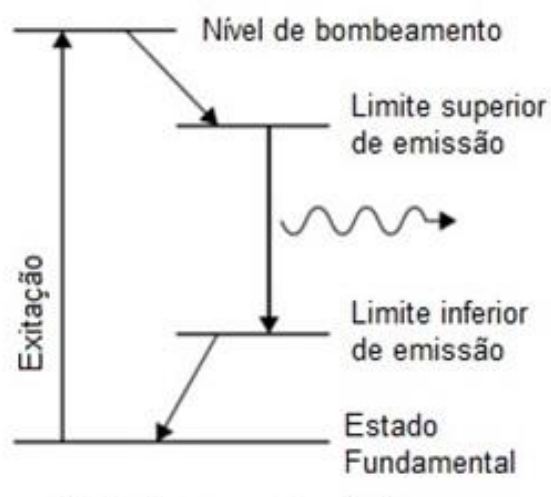

Emissão em quatro niveis

FIGURA 3 - Diagrama de transições eletrônicas durante o bombeamento de um meio de ganho para geração de um feixe laser [22].

Para que se obtenha um feixe laser, é necessário que o bombeamento seja contínuo e suficiente para provocar uma inversão de população, que é quando a maioria dos elétrons do material gerador estão no nível metaestável e, ao decaírem para seu estado fundamental emitem um fóton, que por sua vez pode estimular outro átomo no mesmo nível metaestável a liberar um novo fóton com a mesma energia do inicial, emissão estimulada, dando início ao processo [21].

A grande maioria destes fótons estimulados são perdidos em colisões no interior do meio de ganho, no entanto, alguns viajam paralelamente ao eixo óptico da cavidade laser, onde são presos pelos espelhos posicionados em cada extremidade. Na FIGURA 4 pode-se ver um esquema simplificado deste processo. De um lado há um espelho totalmente refletor, enquanto que do outro um parcialmente refletor, o que permite que uma pequena proporção dos fótons passem através dele dando origem ao feixe laser. Os fótons que não passam pelo espelho são refletidos de volta para o interior da cavidade, e continuam o processo de emissão estimulada [21]. Na FIGURA 5 tem-se uma ilustração da estrutura básica típica de um laser de Hélio-Neodímio (HeNe). 


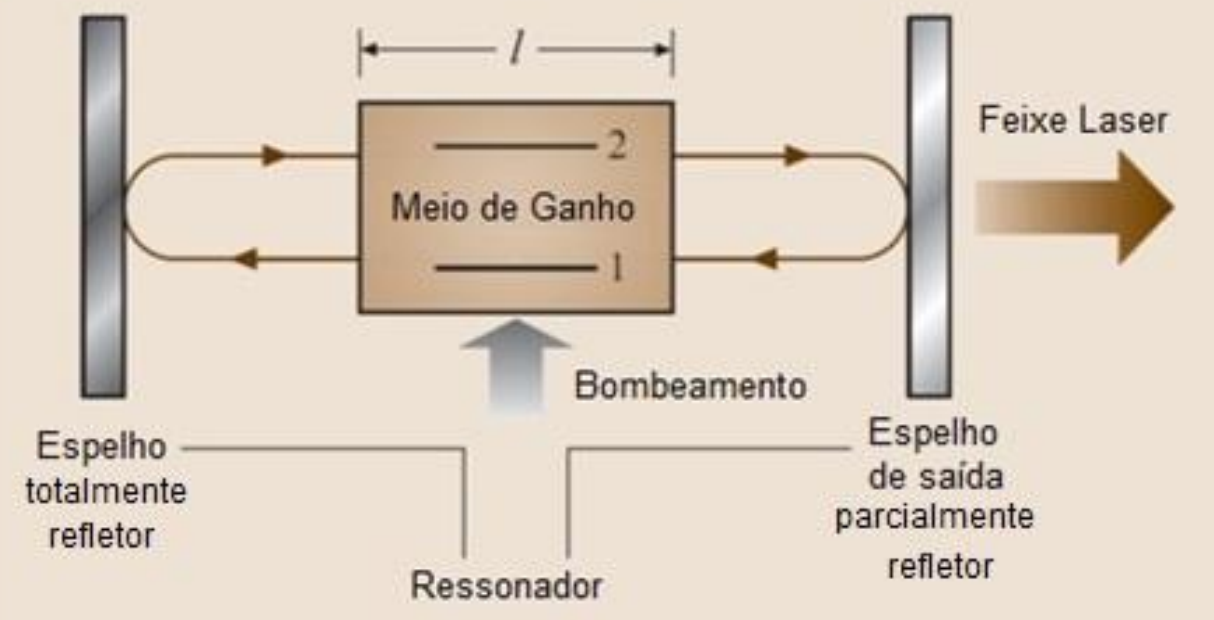

FIGURA 4 - Esquema simplificado de montagem dos componentes básicos de um laser [21].

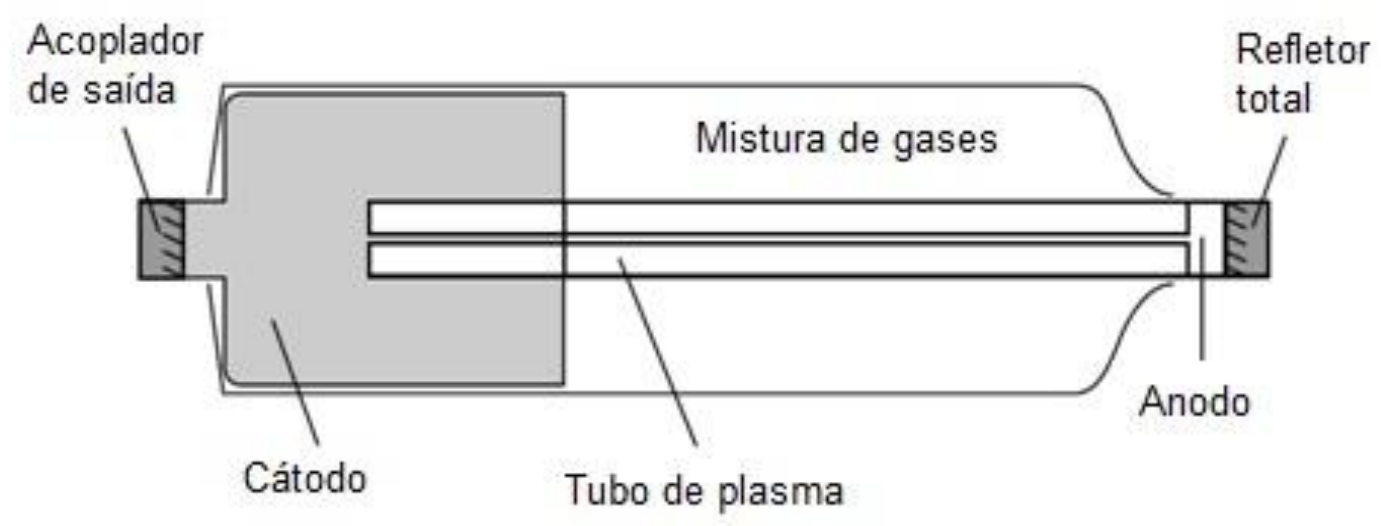

FIGURA 5 - Elementos de um tubo laser de $\mathrm{HeNe}$ [22].

Se o material gerador é continuamente bombeado, eventualmente o equilíbrio é estabelecido entre o número de átomos no estado metaestável e o número de fótons emitidos, o que resulta na emissão de um feixe laser contínuo [22].

\subsection{Laser pulsado}

Ao irradiar um material com um pulso contínuo de laser, o acúmulo da energia depositada irá provocar um grande aquecimento do material que, por sua vez, irá influenciar diretamente na precisão do processo de ablação [21].

Pela modulação da saída da cavidade do laser, é possível gerar flashes de luz, chamados de pulsos ópticos, que depositam certa quantidade de 
energia por vez no material, permitindo assim que parte do efeito térmico produzido se dissipe antes da chegada do próximo pulso [21].

Ao focalizar estes pulsos em diâmetros muito pequenos, aumenta-se muito a intensidade da energia depositada e, reduzindo o tempo de duração de cada pulso, é possível conseguir intensidades locais muito mais altas, mesmo utilizando pulsos com energias modestas [21].

Além do bombeamento pulsado, existem vários métodos para geração de pulsos laser com largura temporal muito mais curta, e sua escolha depende dos requisitos necessários ao pulso. Dentre as principais técnicas estão o Qswitching e o Mode-locking [21].

\subsubsection{Q-switching}

Esta técnica foi aplicada pela primeira vez por McClung et al. em 1962 [23], conseguindo a produção de pulsos abaixo da ordem dos nanossegundos (1 $\left.\mathrm{ns}=10^{-9} \mathrm{~s}\right)$. Utilizando um laser com $Q$-switching é possível gerar potências de pico muitas vezes maiores do que as potências médias produzidas por pulsos contínuos, variando de megawatts ( $M W$ ) até gigawatts (GW). Estes lasers têm provado ser particularmente úteis em diversas aplicações, incluindo corte, soldagem e limpeza, ou como uma fonte de bombeamento para outros sistemas [24].

O Q-switching mantém uma alta taxa de colisões/perdas, entre os elétrons excitados dentro da cavidade do laser, o que gera uma quantidade muito grande de elétrons no nível de energia metaestável. Em seguida, essas colisões são reduzidas rapidamente para níveis muito baixos, o que resulta em uma alta taxa de emissão estimulada, saturando o ganho no interior cavidade do laser e atingindo a energia máxima do pulso, que é liberado como um pulso de saída. No gráfico da FIGURA 6 é possível acompanhar a evolução temporal do ganho e das perdas no interior da cavidade do laser durante a operação de sistema $Q$ switched ativo [24]. 


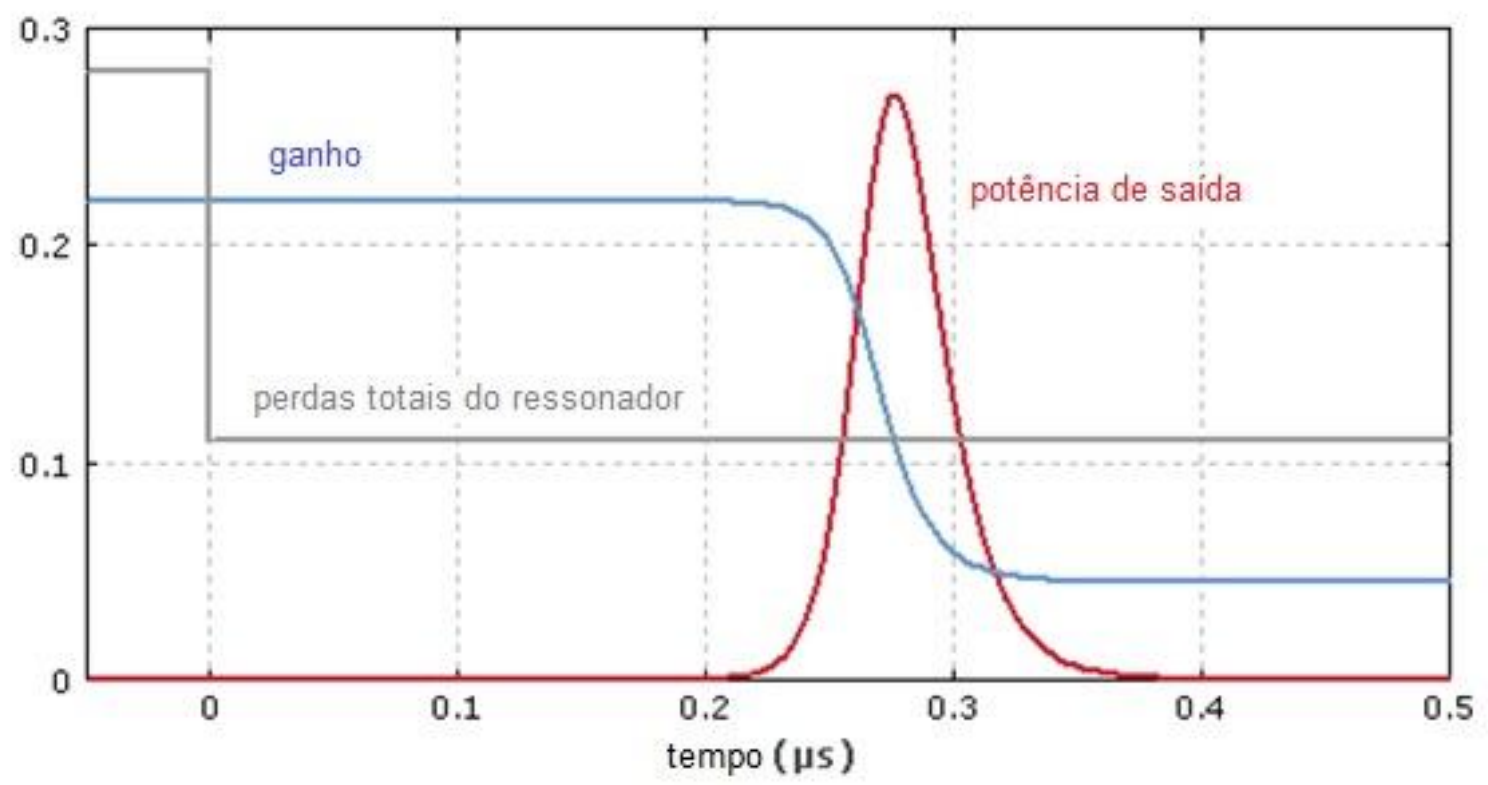

FIGURA 6 - Evolução temporal de ganho e perdas em um laser com sistema $Q$ switched ativo. $O Q$-switching é ativado em $\mathrm{t}=0$, quando a potência de saída começa a subir exponencialmente, atingindo o máximo somente após $\approx 0,2 \mu \mathrm{s}$ [25].

O controle das perdas no interior da cavidade pode ser conseguido por meio de um $Q$-switching ativo ou passivo. O controle ativo requer a utilização de um dispositivo de modulação, o qual é acionado por uma fonte externa, enquanto que o sistema passivo é automodulado, por meio da utilização de um absorvedor saturável. Nesta técnica, as perdas são minimizadas quando a energia no meio de laser atinge uma intensidade suficientemente elevada [24].

O sistema $Q$-switching é o mais comumente empregado porém, devido à limitação do processo, para geração de pulsos com duração temporal variando de picossegundos $\left(10^{-12} \mathrm{~s}\right)$ à femtossegundos $\left(10^{-15} \mathrm{~s}\right)$, classificadas como lasers de pulsos ultra-curtos, o sistema Mode-locking, combinado com a amplificação de pulsos Chirped (CPA) são normalmente utilizados [24].

\subsubsection{Mode-locking}

A utilização desta técnica permite a geração de pulsos laser ultracurtos, e foi demonstrado por Hargrove et al. em 1964 [26]. Esse método consiste na modulação de fase dos fótons que viajam entre os espelhos da cavidade do laser, obrigando-os a operar com uma relação fixa entre si. 
Para sincronizar as oscilações dos fótons no ressonador, é adicionado um modulador no interior da cavidade do laser, que permite a passagem de pulsos ultracurtos sincronizados enquanto bloqueia os pulsos mais longos. Quando o equilíbrio é estabelecido neste processo, a menor duração de pulso é atingida [21]. A FIGURA 7 ilustra este tipo de modulação .

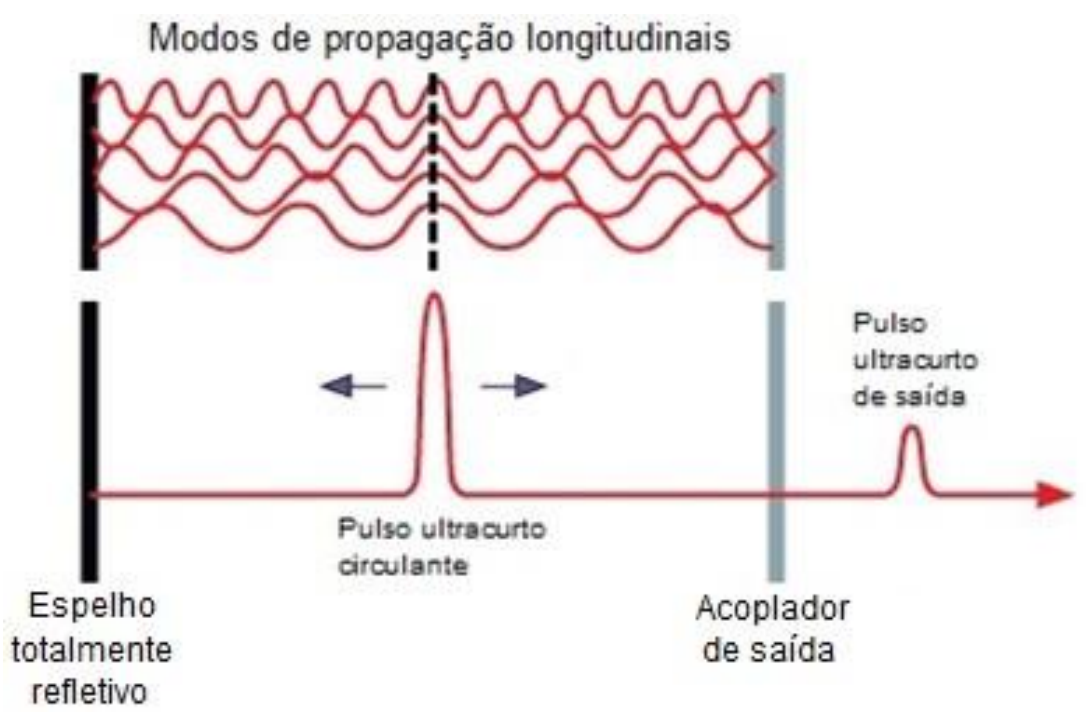

FIGURA 7 - Modulação de fase de uma série de modos de deslocamento longitudinais, gerando um pulso laser [27].

A duração do pulso produzido depende do número de modos de oscilação no interior da cavidade do laser, portanto os meios de ganho com uma grande largura de banda são capazes de gerar os pulsos mais curtos, tipicamente na faixa de 1 ns para lasers a gás e abaixo de 10 fs para lasers de estado sólido [21]. Na FIGURA 8 é possível ver um esquema simplificado da montagem de um sistema de mode-locking no interior da cavidade laser.

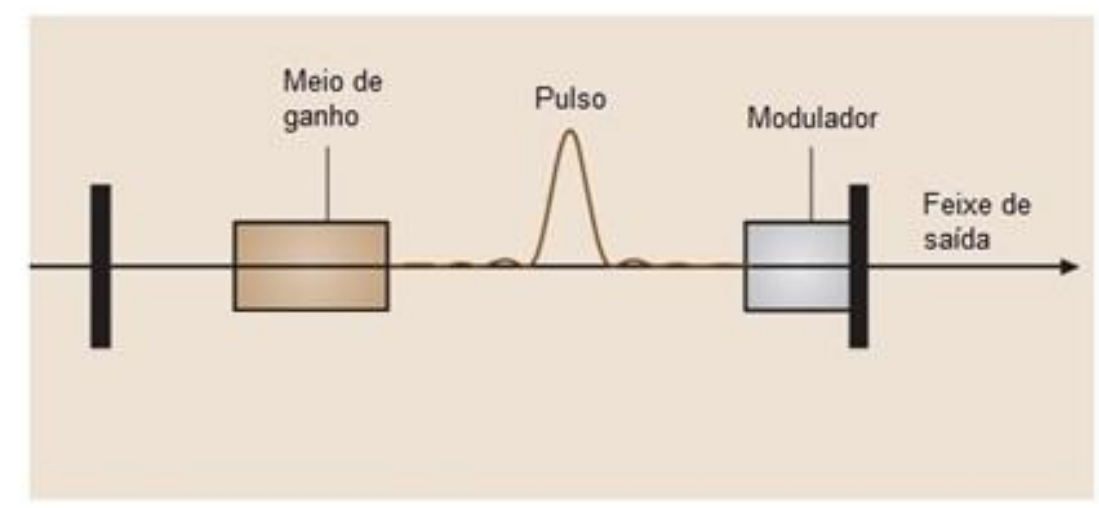

FIGURA 8 - Sistema mode-locking numa cavidade laser linear [21]. 
Os sistema Mode-locking pode ainda ser ativo, onde o modulador é comandado por uma fonte externa, ou passivo, que explora algum efeito óptico não linear, como a saturação de um absorvedor saturável ou a mudança nãolinear do índice de refração de um meio óptico (efeito Kerr) [21].

\subsubsection{Amplificação de pulso Chirped (CPA)}

Para pulsos laser ultracurtos com altas taxas de repetição, a energia produzida pode ser da ordem de nanojoules (nJ), o que é muito baixo para o processamento da maioria dos materiais, consequentemente esses pulsos devem ser amplificados. No entanto, os pulsos amplificados resultantes apresentam alguns problemas, tais como efeitos de distorção não linear do pulso, devido às intensidades extremamente elevadas (acima dos terawatts), e danos para o meio de ganho ou outros componentes ópticos. Esses problemas podem ser superados utilizando a amplificação de pulso Chirped [28]. Na FIGURA 9 é possível ver um esquema de funcionamento desse sistema.

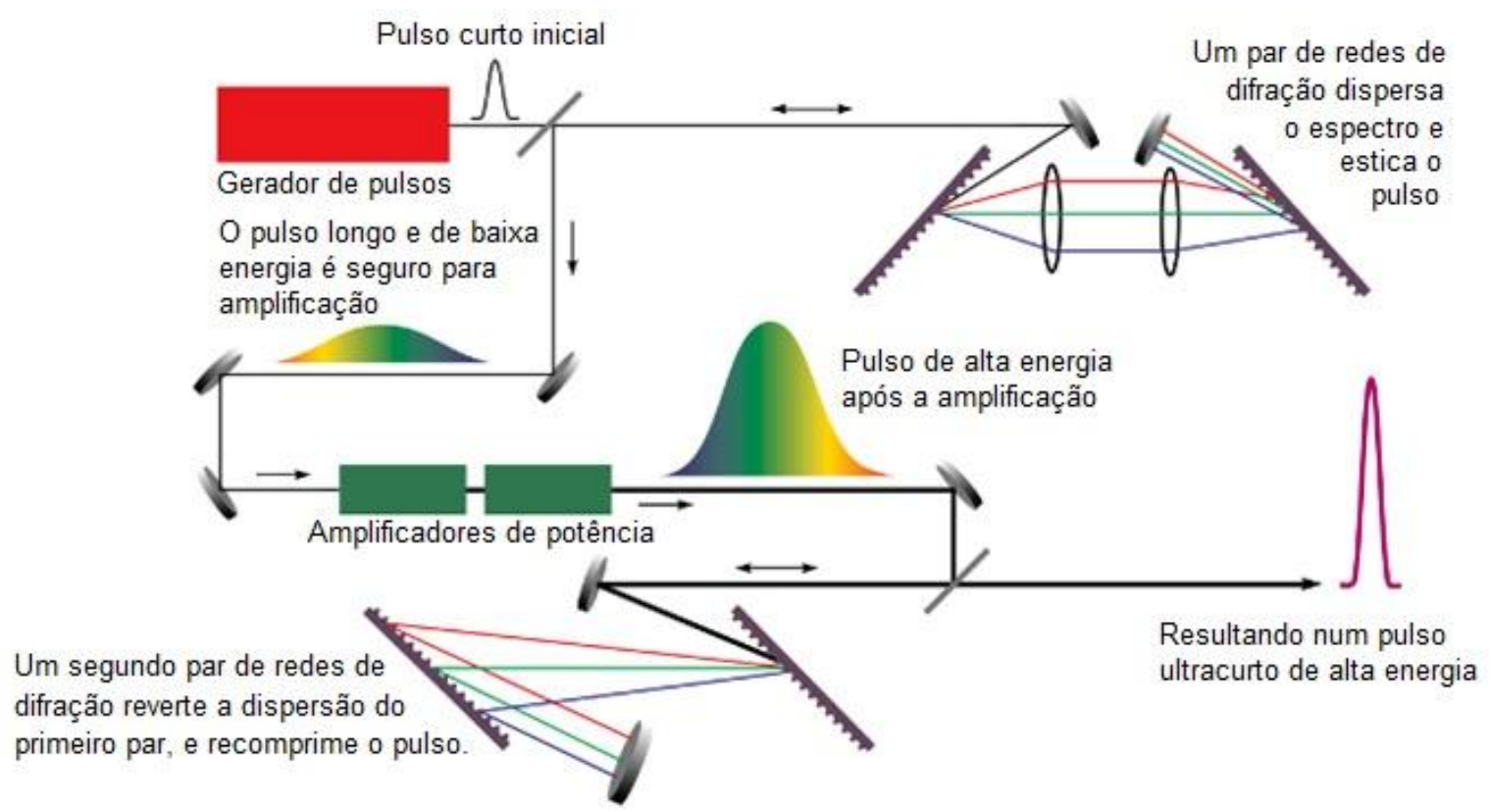

FIGURA 9 - Esquema de funcionamento de um sistema de amplificação de pulso Chirped [29].

Nesta técnica, primeiramente os pulsos são temporalmente esticados, reduzindo consideravelmente a intensidade de pico e evitando danos ao 
componentes da cavidade óptica. O pulso alargado é encaminhado ao amplificador de energia que o concentra a níveis mais elevados e mais adequados para o processamento de materiais. Após a amplificação o pulso passa por um compressor, que encurta temporalmente o pulso, que volta a ter altas intensidades antes de ser emitido. Este método só é aplicável em pulsos extremamente curtos, na casa dos femtosegundos a alguns picossegundos [28].

\subsection{Características de um feixe laser}

Algumas características exclusivas de um feixe laser são o que os tornam uma valiosa ferramenta em diversas aplicações, dentre essas características pode-se destacar o fato de o laser ser monocromático e unidirecional.

Num feixe laser, quase todos os fótons estão em frequências muito próximas, diferente do que ocorre em fontes de luz convencionais, onde os fótons cobrem, geralmente, uma grande faixa do espectro. O pequeno desvio existente no espectro de um feixe laser deve-se às emissões espontâneas que ocorrem inevitávelmente durante o processo de emissão estimulada no meio de ganho [21].

A unidirecionalidade do laser é uma de suas caracterísitcas mais importantes. Num feixe laser todos os fótons viajam numa mesma direção, apresentando apenas uma pequena divergência, sendo esta característica que permite focaliza-lo numa área extremamanete pequena, limitada apenas pela difração apresentada pelo feixe. Essa focalização concentra toda a energia numa pequena quantidade de matéria, o que é extremamanete importante em aplicações como o processamento de materiais [21].

Um outro ponto muito importante num feixe laser pulsado, é a resolução temporal do pulso, ou seja, a duração de cada pulso, ou então, quanto tempo cada pulso leva para depositar sua energia no alvo [21].

\subsubsection{Características métricas de um feixe laser focalizado}

Um feixe laser pode ser focalizado numa área muito pequena, limitada pela difração para cada comprimento de onda. Tal característica é o que permite conseguir densidades muito elevadas de energia numa pequena região alvo, fazendo com que a maioria dos materiais sejam imediatamente fundidos, 
vaporizados ou sublimados, processos chamados de ablação. O raio mínimo do ponto focal de um feixe laser focalizado, região chamada de cintura do feixe, pode ser estimado pela Equação 1 [21].

$$
w_{0}=\frac{4 M^{2} \lambda f}{\pi \phi}
$$

Onde $w_{0}$ é o raio mínimo do ponto focal, $M^{2}$ é o fator de qualidade do feixe, $\lambda$ é o comprimento de onda do laser, $f$ é o comprimento focal da lente utilizada e $\phi$ é o diâmetro do feixe na entrada da lente [21].

Além de calcular o diâmetro da cintura de um feixe, é possível também determinar as dimensões de outros parâmetros, como a profundidade de foco (ou parâmetro confocal), a divergência total, e até estimar o diâmetro teórico do feixe em função da distância em relação à cintura [21]. Na FIGURA 10 estão ilustradas tais características.

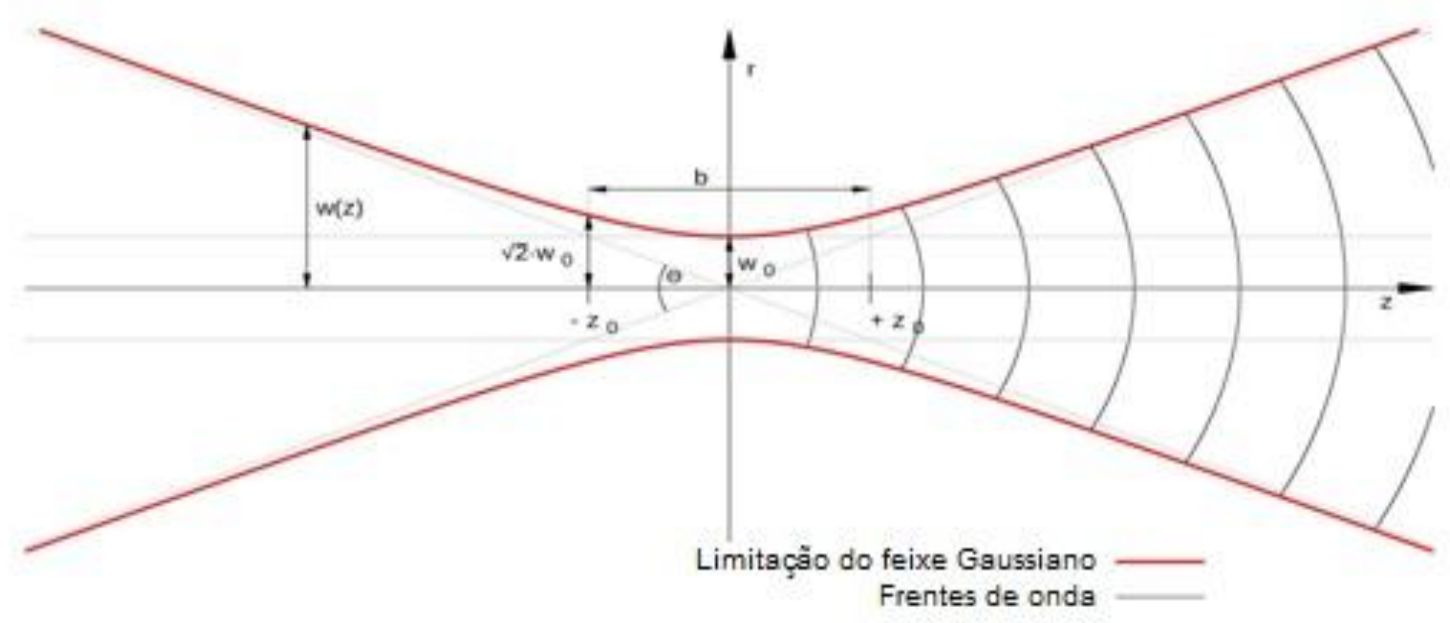

FIGURA 10 - Características métricas de um feixe laser focalizado [30].

O parâmetro confocal $(b)$ é dado pela distância em relação à cintura onde o raio do feixe é $\sqrt{2}$ vezes o raio mínimo do ponto focal, e pode ser determinado pela Equação 2 [31].

$$
b=\frac{2 \pi w_{0}^{2}}{\lambda}
$$


A divergência total do feixe $(\Theta)$ pode ser estimada pela Equação 3, enquanto que o diâmetro teórico do feixe em função da distância em relação à cintura $(w(z))$ pode ser obtido pela Equação 4 [21].

$$
\begin{gathered}
\Theta=\frac{2 \lambda}{\pi w_{0}} \\
\mathrm{w}(\mathrm{z})=w_{0} \sqrt{1+\left(\frac{z}{z_{R}}\right)^{2}}
\end{gathered}
$$

Onde $z$ é a distância em relação à cintura do feixe onde se deseja estimar o diâmetro e $z_{R}$ é a metade do parâmetro confocal. O diâmetro $2 w(z)$ concentra concentra cerca de $86 \%$ da energia do feixe.

\subsubsection{Distribuição de energia num feixe laser focalizado}

A densidade de energia no interior de um feixe laser segue uma distribuição Gaussiana, por isso são também chamadados de feixes Gaussianos. A FIGURA 11 ilustra a distribuição de energia numa secção transversal de um feixe laser.

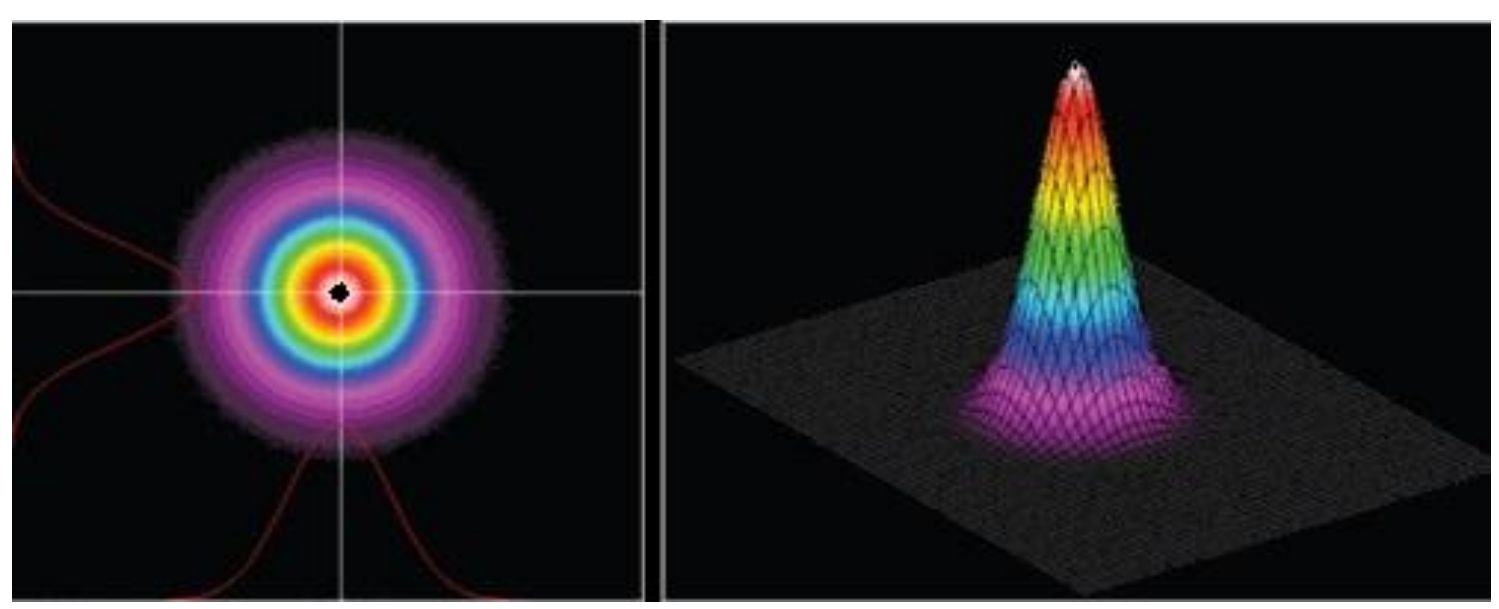

FIGURA 11 - Perfil típico da distribuição de energia de um feixe Gaussiano. Representação em uma e duas dimensões (à direita) e um modelo 3D (à esquerda) [32]. 
A intensidade óptica $I$ no interior de um feixe Gaussiano é uma função das posições radial e axial $\rho$ e $z$ respectivamente, assim, $I(\rho, z)$ pode ser determinada pela Equação 5 [21].

$$
I(\rho, \mathrm{z})=I_{0}\left(\frac{w_{o}}{w(z)}\right)^{2} e^{-\frac{2 \rho^{2}}{[w(z)]^{2}}}
$$

Onde $\mathrm{I}_{0}$ é a intensidade máxima do feixe, e $\rho$ é a distância radial em relação ao eixo do feixe. O raio do feixe $\mathrm{w}(\mathrm{z})$ aumenta com a distância axial $\mathrm{z}$ conforme ilustrado na FIGURA 12.
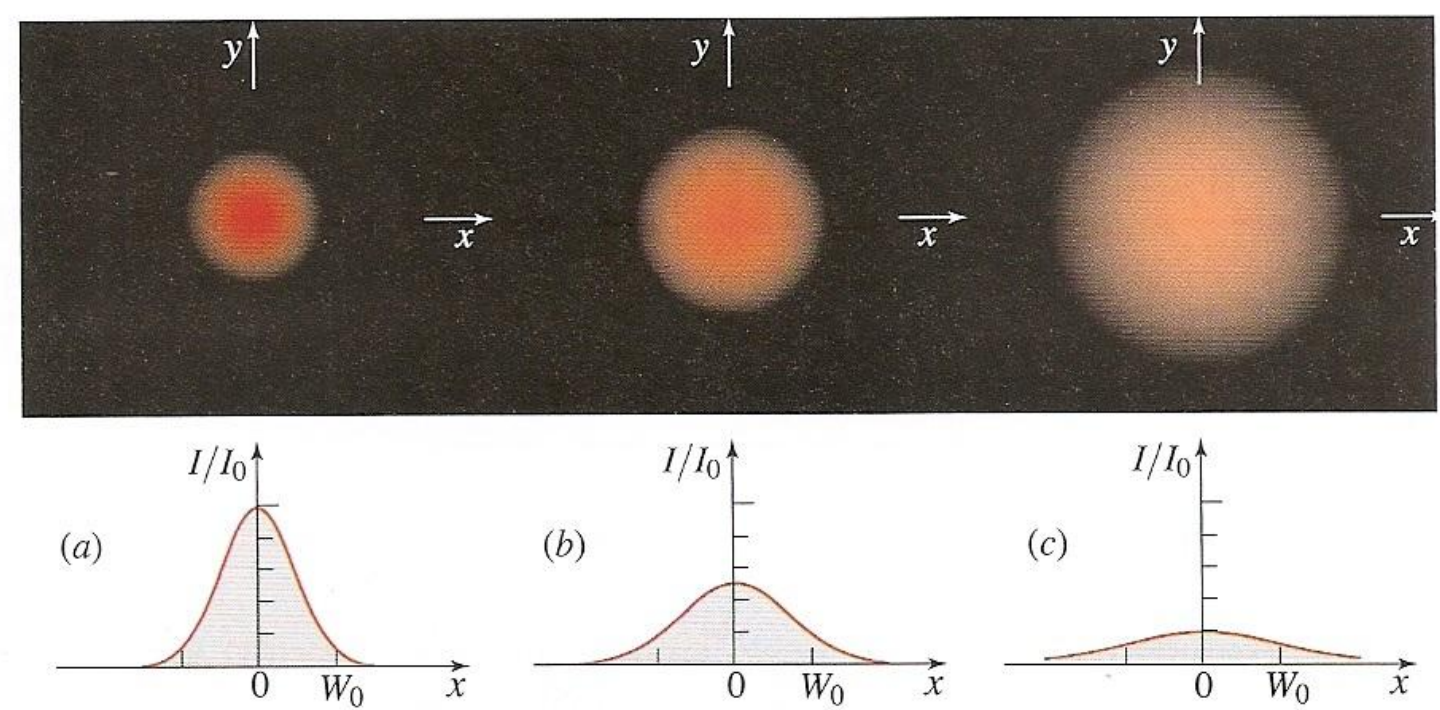

FIGURA 12 - Intensidade normalizada do feixe, I/I0, como função da distância radial $\rho$ em diferentes distâncias axiais. (a) $z=0$; (b) $z=z 0$; (c) $z=2 z 0$ [33].

É possível determinar a fluência de energia entregue por um pulso laser, ou seja, a densidade de energia na região irradiada, a partir do diâmetro do feixe no ponto de incidência utilizando a Equação 6.

$$
F=\frac{E}{A}
$$

Onde $F$ é a fluência gerada pelo pulso, $E$ é a energia do pulso e $A$ é a área da região irradiada. 


\subsection{Laser com pulsos curtos}

Do ponto de vista prático, a duração de um pulso laser consiste, basicamente, no tempo que este leva para depositar sua energia no material irradiado. No caso de lasers com pulsos curtos, este tempo gira na casa de nanossegundos ou acima de algumas dezenas de picossegundos; durante este tempo, o material irradiado absorve a energia do laser que, na maioria dos casos, se propaga pela rede cristalina do material na forma de calor. Esse aquecimento pode gerar diversos danos termomecânicos no material irradiado, como fusão, formação de rebarbas e microtrincas, mudanças na morfologia e características mecânicas como dureza e tenacidade, efeitos que limitam a aplicabilidade desse tipo de laser em determinados processos [34].

\subsection{Laser com pulsos ultracurtos}

No caso de lasers com pulsos ultracurtos, com duração na ordem dos femtossegundos, o tempo de deposição da energia do pulso é inferior ao tempo necessário para que os elétrons excitados pelo feixe transmitam a energia absorvida para a rede cristalina, o que causaria o aquecimento do material, minimizando assim os efeitos térmicos verificados na região ablacionada [34].

\subsection{Interação laser-matéria}

Ao irradiar um material com um feixe laser, a energia é absorvida pelos elétrons das camadas mais superficiais, que a transmitem para a rede cristalina por meio de colisões [35].

No caso de pulsos de nanossegundos, o tempo de deposição da energia do laser é superior ao tempo necessário para a transferência da energia dos elétrons para a rede, assim o equilíbrio térmico entre o subsistema eletrônico e a rede atômica do material se dá durante o pulso laser, causando assim seu aquecimento. Na FIGURA 13 é possível ver uma escala relacionando o tempo necessário para o desenvolvimento dos processos envolvidos na ablação a laser [34]. 


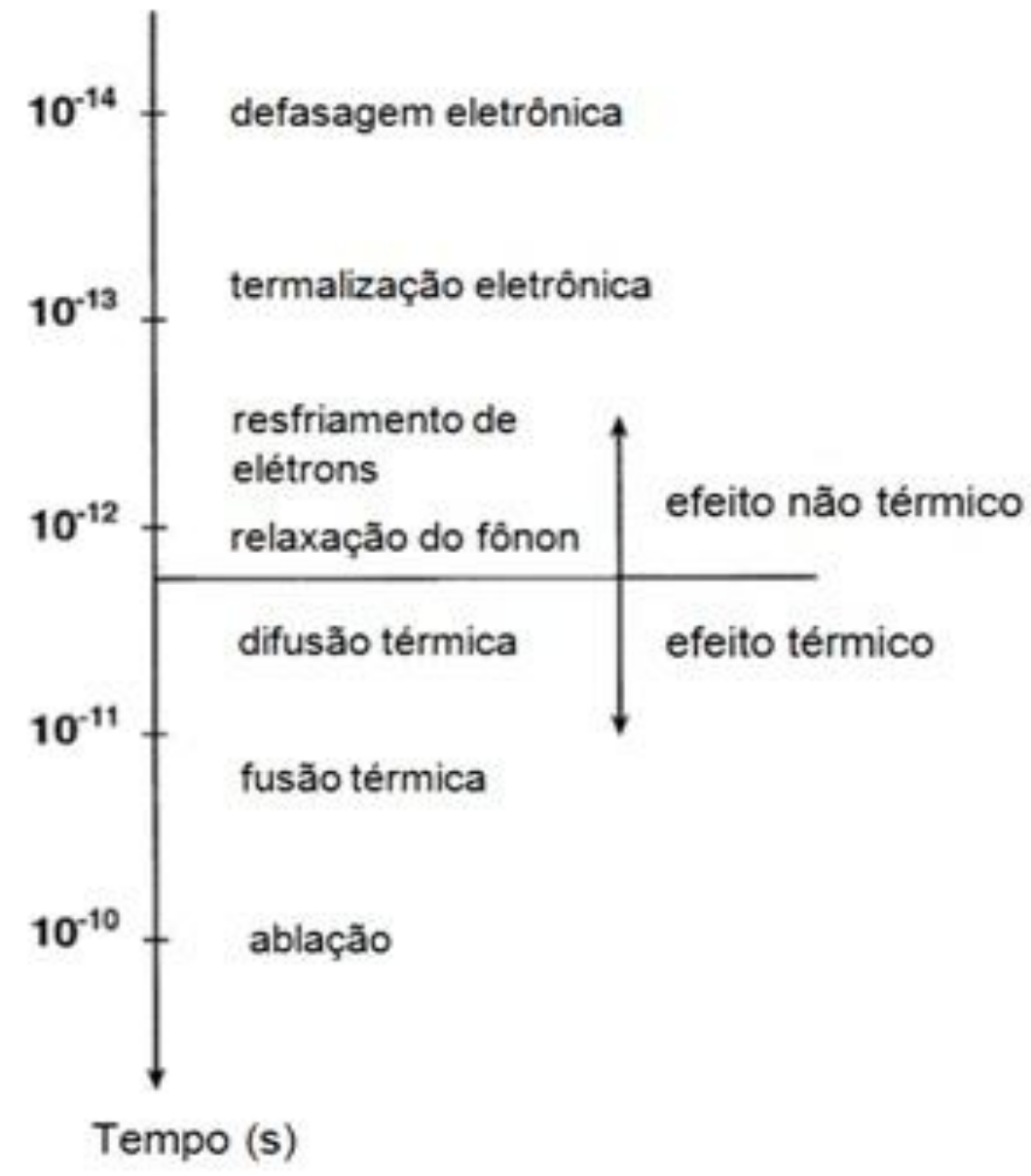

FIGURA 13 - Escala de tempo relacionando os processos secundários gerados na ablação a laser [36].

No caso de lasers de femtossegundos, a absorção eletrônica e o aquecimento da rede devem ser analisados separadamente. Inicialmente, toda a energia do laser é absorvida por elétrons de uma camada muito superficial, e a excitação e ejeção desses elétrons leva à ionização da superfície, com consequente ejeção do material remanescente por repulsão Coulombiana, ou explosão de fase, uma vez que existe um grande desequilíbrio entre as temperaturas dos elétrons excitados, que apresentam temperaturas de milhares de graus, enquanto a rede do material permanece praticamente à temperatura ambiente [34]. Na FIGURA 14 tem-se uma ilustração da diferença do tipo de dano causado por um laser de nanossegundos e um de femtossegundos. 


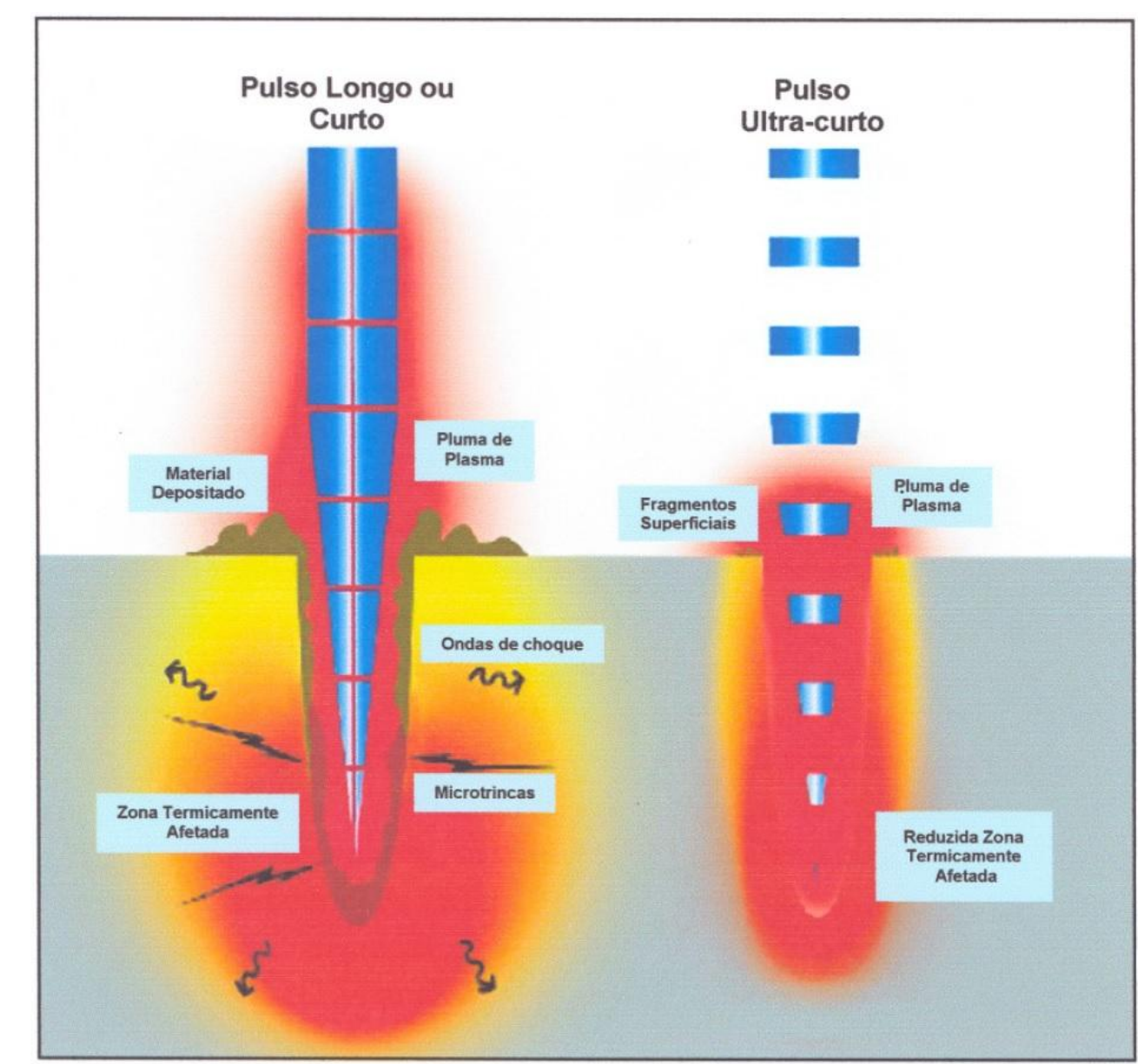

FIGURA 14 - Comparação do dano causado por um laser com pulsos de nanossegundos e um de femtossegundos [37].

O acúmulo de energia na região irradiada causa a ablação do material, que pode se dar por um processo térmico, fusão e vaporização, comuns quando a absorção de energia é linear, ou então por processos não térmicos, sublimação ou repulsão Coulombiana, normalmente quando a absorção é não linear [34].

\subsubsection{Processo de absorção da energia do laser}

Ao incidir na superfície de um material, parte da energia do laser é refletida e parte é absorvida, e a predominância entre um e outro fenômeno se dá principalmente pelas propriedades do material, no caso da absorção linear, ou então pela intensidade extremamente alto do pulso, processo de absorção não linear [38]. 


\subsubsection{Absorção linear}

Ao atingir um material, a energia do laser é absorvida por uma fina camada superficial, e a intensidade do pulso diminuirá exponencialmente com a profundidade de penetração. Este decaimento depende do coeficiente de absorção do material e determina a profundidade de penetração. Isto pode ser descrito pela Equação 7 [21].

$$
I=I_{0} e^{-\alpha Z}
$$

Em que $I_{0}$ é a intensidade incidente, $\alpha$ é o coeficiente de absorção do material e $I$ é a intensidade transmitida após viajar uma distância $Z$ dentro do material.

Utilizando esta equação é possível determinar o comprimento de onda do laser com maior ou menor absorção para diferentes materiais.

\subsubsection{Absorção não linear}

A absorção não linear ocorre quando dois ou mais fótons são absorvidos simultaneamente, excitando um elétron diretamente para um nível eletrônico superior. Quando é aplicada intensidade suficiente num feixe laser, é possível desencadear 0 processo de absorção mesmo em materiais transparentes como vidros, excitando elétrons diretamente entre os intervalos de bandas eletrônicas [31].

\subsubsection{Mecanismos de ablação a laser}

A ablação a laser depende de muitos fatores, como as propriedades físicas do material a ser ablacionado, a duração dos pulsos laser e a fluência utilizada na região irradiada [31].

Para lasers com pulsos curtos, na faixa de nanossegundos, os processos envolvidos são basicamente térmicos, com a fusão e posterior evaporação do material, enquanto que para lasers de pulsos ultracurtos, na faixa de femtossegundos, os efeitos térmicos podem ser minimizados, dando lugar a outros mecanismos [31]. 
Os materiais podem ser classificados em três grupos principais: metais, semicondutores e dielétricos. Cada uma dessas classes apresenta diferentes mecanismos de ablação devido principalmente às diferenças em suas estruturas eletrônicas de banda, que influenciam fortemente no modo como os elétrons do material irão absorver a energia fornecida pelo laser, além do efeito que essa absorção irá desencadear na rede eletrônica. Na FIGURA 15 é possível ver um diagrama simplificado das diferentes bandas eletrônicas por tipo de material.

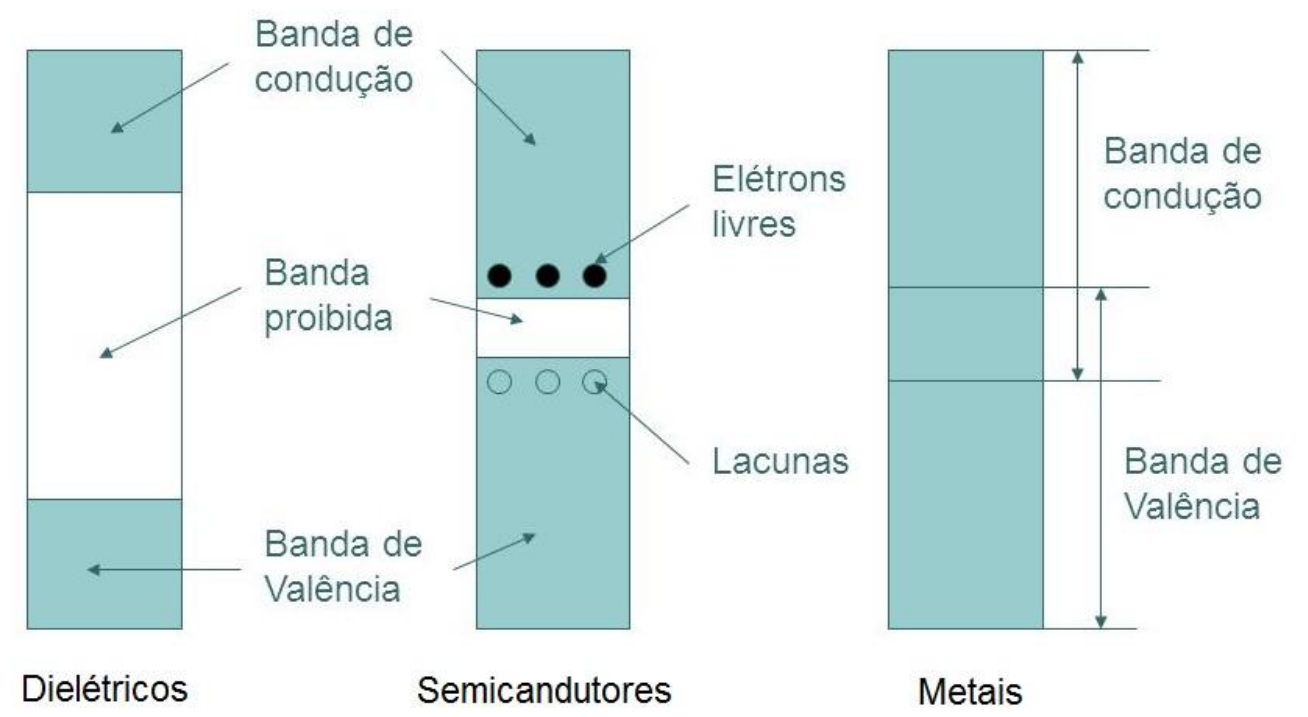

FIGURA 15 - Estrutura eletrônica de bandas de metais, semicondutores e dielétricos [39].

\subsubsection{Mecanismos de ablação em metais}

Nos metais a energia do pulso laser é absorvida pelos elétrons livres presentes na superfície do material pelo efeito Bremsstrahlung inverso, seguida de um rápido relaxamento energético do subsistema eletrônico e transferência de energia para a rede por difusão térmica devido ao acoplamento elétron-fônon [34].

No caso de pulsos ultracurtos, a energia absorvida pelos elétrons causa um forte desequilíbrio entre as sua temperatura, que pode chegar a milhares de graus, e da rede, que permanece praticamente em temperatura ambiente. Esta condição, chamada de modelo de duas temperaturas (TTM do inglês: Two-Temperature Model), permanece durante um tempo inferior ao necessário para que ocorra o equilíbrio térmico entre os elétrons excitados e a rede, fazendo com que o material ionizado seja ejetado por explosão de fase, promovida pela grande diferença de temperatura entre uma fina camada do 
material e seu interior, podendo também ocorrer a repulsão Coulombiana, causada pela alta ionização superficial do material. Todo esse processo ocorre antes que elétrons excitados possam transferir sua energia para a rede, minimizando os efeitos térmicos na superfície ablacionada [34].

\subsubsection{Mecanismos de ablação em dielétricos}

No caso de materiais semicondutores e dielétricos, onde a existência de elétrons livres é muito pequena, a alta intensidade do feixe focalizado deve ser suficiente para promover a absorção multifotônica nos elétrons ligados, os quais são levados em grande quantidade à banda de condução, criando assim (e também por um processo subsequente de ionização por avalanche) uma situação localizada semelhante à de um metal, promovendo muitos pares elétron-vacância.

A ablação é iniciada quando a densidade do plasma gerado pelos elétrons livres alcança um valor crítico, desencadeando um processo de repulsão Coulombiana, preferencialmente, devido ao acúmulo de cargas positivas numa fina camada superficial do material que é então ejetada, podendo também ocorrer processos de explosão de fase como nos metais [34].

\subsubsection{Limiar de ablação}

O limiar de ablação de um material é a menor fluência de energia necessária para causar algum dano à região irradiada [31]. O processo mais comum para determinação desse limiar, técnica da regressão do diâmetro do dano ou dano zero, foi introduzida por Liu em 1982 [40], um processo bastante trabalhoso, que requer um controle muito preciso dos parâmetros do laser e uma ótima estabilização do processo.

Neste método, ablações pontuais são efetuadas no material de interesse variando-se a fluência do laser. Então é feita a medição do diâmetro dos perfis gravados que são relacionados com a fluência de limiar do material por meio da Equação 8 [40].

$$
\mathrm{D}^{2}=2 w_{0} \ln \left(\frac{F_{0}^{p i c o}}{F_{t h}}\right)
$$


Onde $D^{2}$ é o diâmetro ao quadrado do perfil gravado, $w_{0}$ é o raio da cintura do feixe, $F_{0}^{\text {pico }}$ é a fluência do pulso e $F_{t h}$ é a fluência de limiar do material.

Inserindo os dados obtidos no controle do diâmetro do dano na 8, é possível determinar a fluência de limiar extrapolando-se a curva gerada pela plotagem dos dados para $D=0$.

Durante 0 processamento experimental com lasers de pulsos ultracurtos, verificou-se que o limiar de ablação de um material diminui conforme o aumento do número de pulsos sobrepostos, evento chamado de efeito de incubação. O método dano zero pode ser utilizado da mesma maneira variando a sobreposição de pulsos em cada ponto ablacionado para determinação de tal efeito [41].

\subsubsection{Efeito de incubação}

Após a incidência de um pulso laser na superfície de um material, este, mesmo que não possua energia suficiente para causar dano visível, promove mudanças estruturais na distribuição eletrônica da região irradiada devido aos campos elétricos extremamente altos característicos de pulsos laser ultracurtos [41].

Tais mudanças criam níveis intermediários de energia entre as bandas de condução e de valência, além de centros de cor na estrutura do material, que facilitam a absorção multifotônica diminuindo o limiar de ablação [42, 43].

Nos metais, a dependência do limiar de ablação em relação à sobreposição de pulsos e, consequentemente, ao efeito de incubação do material, é descrita pela Equação 9 [43], ao passo que para dielétricos, essa relação é descrita pela Equação 10 [42].

$$
\mathrm{F}_{\mathrm{th}}(N)=\mathrm{F}_{\mathrm{th}(1)} N^{S-1}
$$

Onde $\mathrm{F}_{\text {th }}(N)$ é a fluência de limiar em função de $N, \mathrm{~F}_{\text {th(1) }}$ é a fluência de limiar para um único pulso, $N$ é a quantidade de pulsos sobrepostos e $S$ é o parâmetro de incubação para metais, que pode ser obtido ajustando-se os dados experimentais com a curva da Equação 9. 


$$
\mathrm{F}_{\mathrm{th}}(N)=\mathrm{F}_{\mathrm{th}(\infty)}+\left(\mathrm{F}_{\mathrm{th}(1)}-\mathrm{F}_{\mathrm{th}(\infty)}\right) \mathrm{e}^{-\mathrm{k}(\mathrm{N}-1)}
$$

Onde $\mathrm{F}_{\mathrm{th}(\infty)}$ é a fluência de limiar para infinitos pulsos e $k$ é o parâmetro de incubação para dielétricos.

\subsubsection{Método D-Scan para determinação do limiar de ablação}

Uma ótima alternativa para determinação do limiar de ablação é um método desenvolvido nos laboratórios do Centro de Lasers e Aplicações do Instituto de Pesquisas Energéticas e Nucleares (CLA-IPEN), chamado de D-Scan [44], que apresenta resultados com boa precisão e confiabilidade, apesar da simplicidade com que pode ser executado.

Este método consiste na varredura transversal e longitudinal da amostra, de forma simultânea, conforme ilustrado na FIGURA 16(a), indo de um ponto anterior até um ponto posterior à cintura do laser. Esse processo permite, em determinados níveis de intensidade do laser, a gravação de um perfil simétrico na amostra, conforme ilustrado na FIGURA 16(b). A partir das dimensões do perfil gravado e dos parâmetros utilizados na varredura, é possível determinar com boa precisão os limiares de ablação para os regimes de baixa e alta fluência [44, 45].

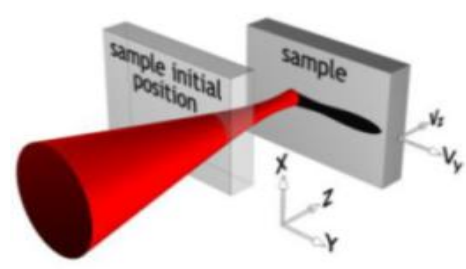

(a)

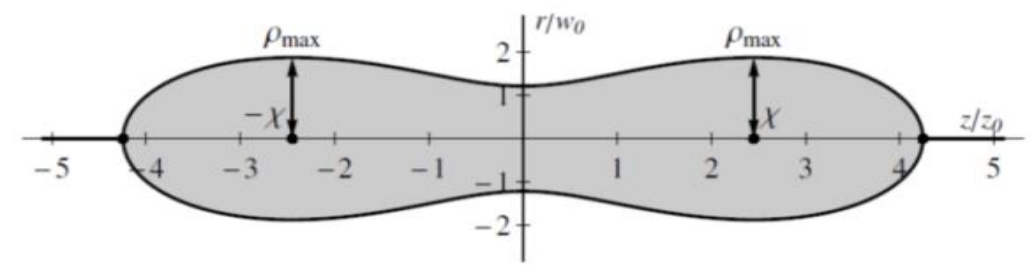

(b)

FIGURA 16 - a) Esquema da varredura diagonal da amostra; b) perfil gravado na amostra [44].

A partir do tratamento das equações que definem a distribuição radial de intensidade num feixe Gaussiano, e o diâmetro do feixe dependente da distância em que se encontra da cintura, é possível realizar na superfície de uma amostra a gravação de um perfil com dimensões dependentes da posição da amostra (na coordenada $z$ da FIGURA 16) em relação ao feixe [41]. 
A determinação do limiar de ablação por este método é realizada a partir da Equação 11 [44], derivada da equação de distribuição radial de intensidade num feixe Gaussiano [46].

$$
F_{t h}=\frac{E_{o}}{e \pi \rho_{\max }^{2}} \approx 0,117 \frac{E_{o}}{\rho_{\max }^{2}}
$$

Onde $\mathrm{F}_{\text {th }}$ é a fluência de limiar de ablação do material, $\mathrm{E}_{0}$ é a energia do laser e $\rho_{\max }$ é o raio máximo do perfil gravado.

\subsection{Espectroscopia de emissão atômica induzida por laser (LIBS)}

LIBS (do inglês: Laser-Induced Breakdown Spectroscopy) é um método de espectroscopia de emissão atômica (AES do inglês: Atomic Emission Spectroscopy) que consiste em vaporizar ou atomizar uma amostra, gerando assim uma nuvem de espécies atômicas livres, um plasma ionizado onde esses íons, ao retornarem ao seu estado energético fundamental, liberam seu excesso de energia na forma de luz com espectros característicos para cada espécie química. A luz emitida é coletada e enviada a um monocromador, onde é dispersada em seus vários comprimentos de onda. Após a análise da intensidade luminosa de cada um desses componentes, é possível determinar os elementos presentes no plasma, e num processamento mais detalhado é possível até determinar a concentração de cada um deles [47].

Apesar da simplicidade do sistema, os processos físicos e químicos envolvidos na formação do plasma bem como na sua captação e análise, podem representar fatores complicadores quando existe a necessidade de se ablacionar quantidades muito pequenas de material. Na FIGURA 17 é possível ver um esquema simplificado de um sistema LIBS. 


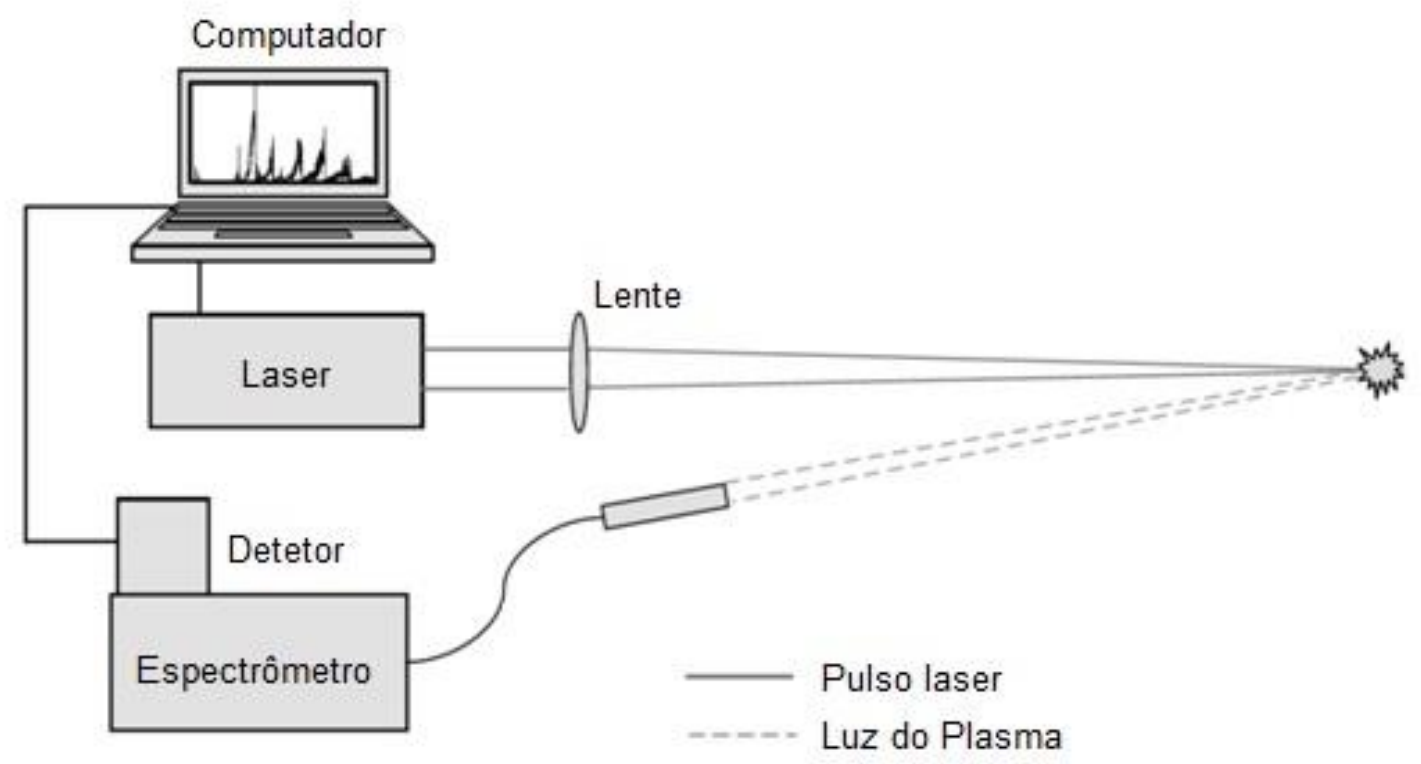

FIGURA 17 - Esquema simplificado com os principais componentes de um sistema LIBS.

Um fator muito importante na utilização do LIBS é o controle da janela de análise. Nos primeiros momentos da formação de um plasma a ionização é alta e, a medida que a recombinação de elétrons-íons prossegue formam-se átomos neutros e, em seguida, moléculas. Ao longo desse processo existe um continuum de fundo que decai mais rapidamente do que as linhas espectrais [47].

Na FIGURA 18 é possível acompanhar a evolução temporal de um plasma iniciado sem ambiente controlado a 1 atm, por um pulso de 5 a $10 \mathrm{ns,}$ centrado em $1064 \mathrm{~nm}$ a partir de um laser Nd: YAG [47]. Para pulsos muito mais longos (laser de $\mathrm{CO}_{2}$ por exemplo) ou pulsos muito mais curtos (pico ou femtossegundos) a escala de tempo irá expandir ou contrair. A medida que a pressão ambiente diminui, o tempo de vida do plasma diminui também, uma vez que há menos captura e reciclagem da energia absorvida no volume de plasma [47]. Os plasmas formados por pulsos de energias modestas usadas para LIBS, são tipicamente menos de $10 \%$ ionizados no tempo observável mais precoce, momento de ignição [47]. 


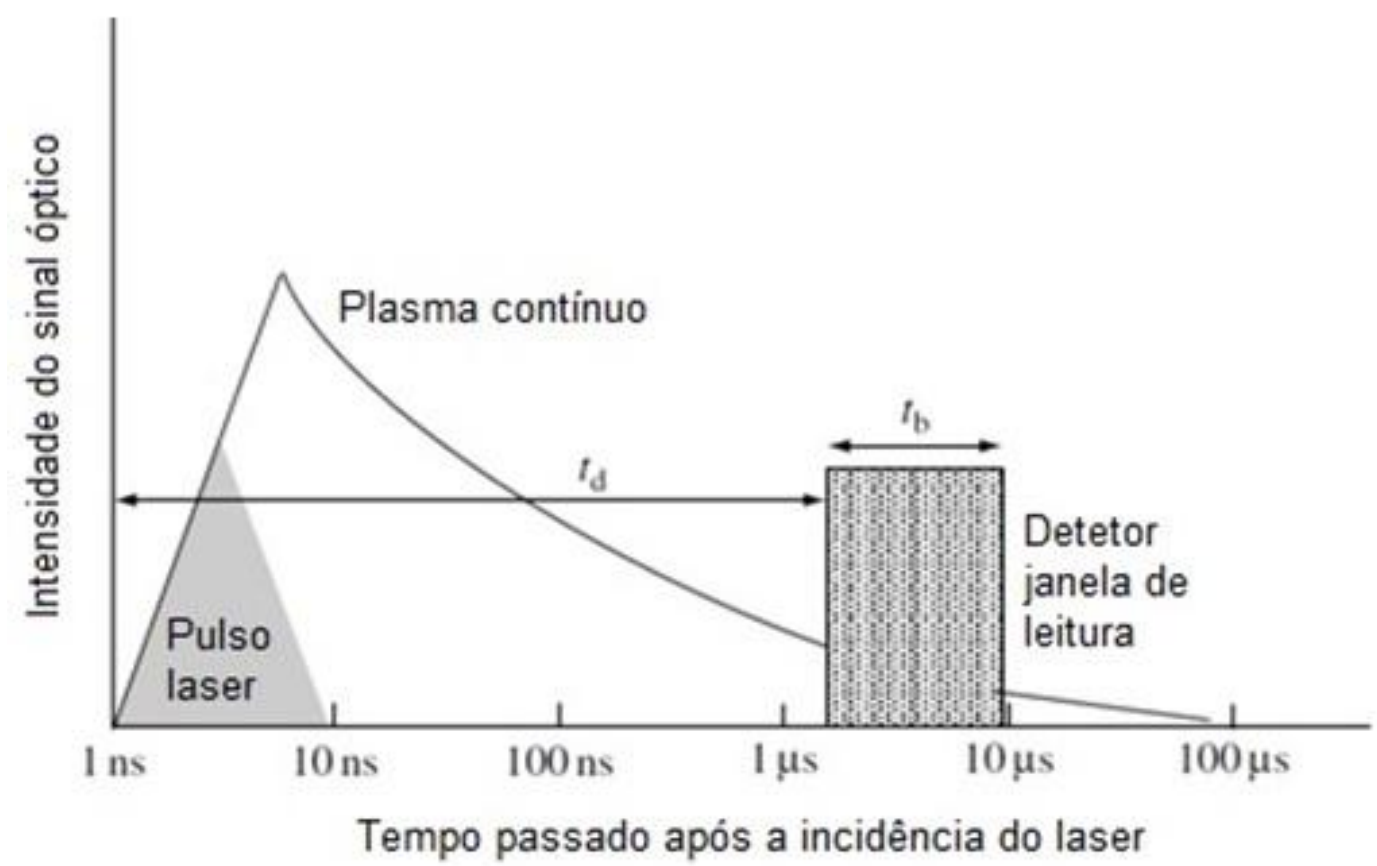

FIGURA 18 - Esquema representativo da evolução temporal de um plasma de LIBS [47].

O continuum deve-se principalmente ao efeito de bremsstrahlung e recombinações. No bremsstrahlung os fótons são emitidos por elétrons acelerados ou desacelerados em colisões. Uma recombinação ocorre quando um elétron livre é capturado em um nível de energia iônica ou atômica e emite seu excesso de energia cinética na forma de um fóton [47]. A resolução temporal da luz plasmática no LIBS permite a discriminação em favor da região onde os sinais de interesse predominam. Na FIGURA 19 pode-se verificar o espectro obtido de acordo com a variação do atraso da janela de análise do sistema LIBS. Este atraso, permite que ocorra o decaimento da radiação de fundo antes da coleta do sinal, permitindo que os elementos presentes se destaquem no espectro [48]. 


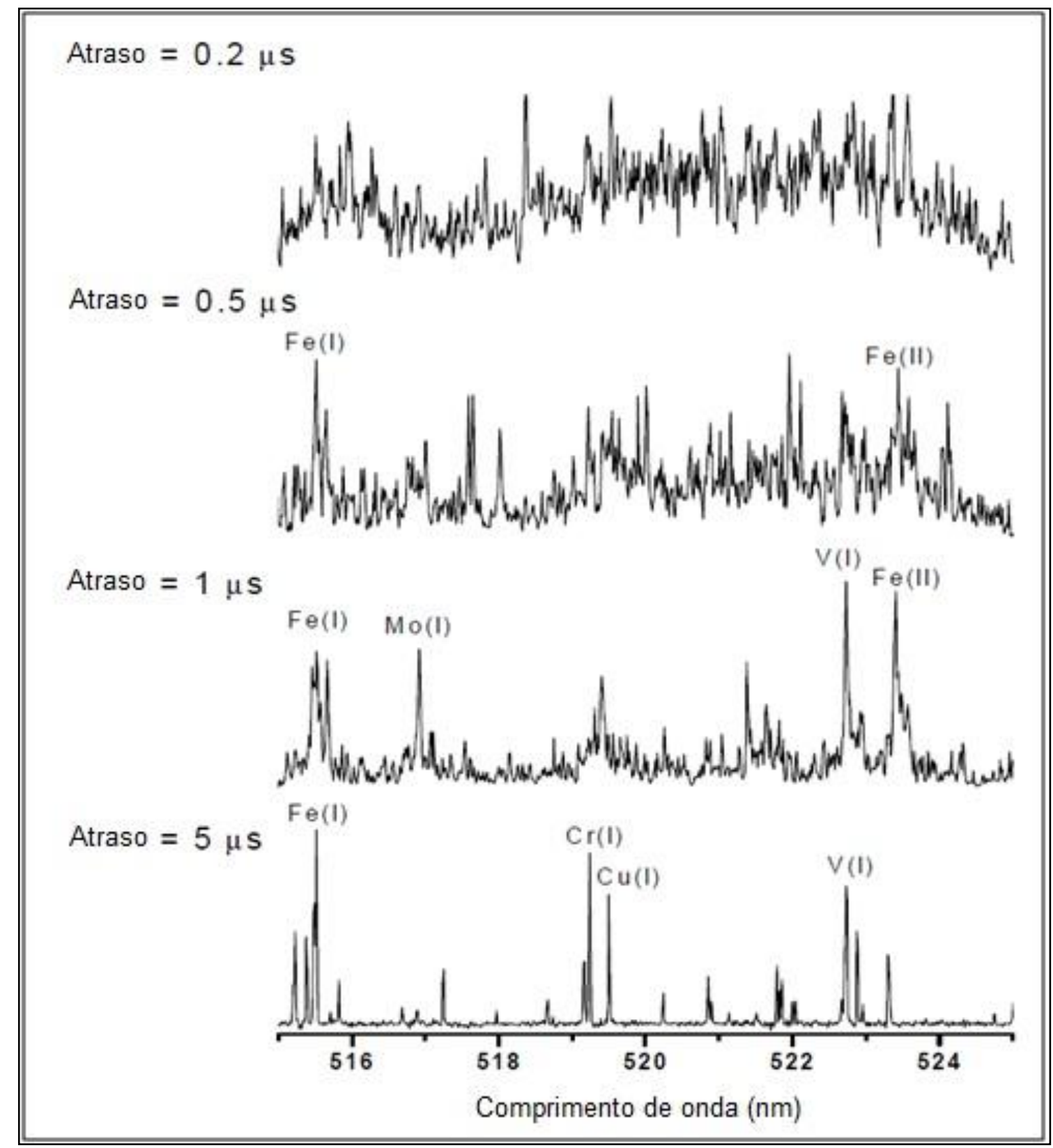

FIGURA 19 - Evolução temporal do espectro do plasma induzido por laser numa amostra metálica [48].

\subsubsection{Utilização do laser com pulsos de femtossegundos na LIBS}

Com a crescente disponibilidade de lasers de femtossegundo no mercado, muitas experiências LIBS vêm sendo realizadas com pulsos ultracurtos. Uma vez que a irradiação da superfície é terminada antes da total expansão do plasma, não há o efeito de blindagem, comum com os pulsos mais longos, gerando uma diminuição na energia depositada e consequentemente, na ablação da amostra e na cratera formada. Atualmente ainda não há nenhuma evidência conclusiva de como isto afeta os resultados analíticos [49]. 
Não há diferenças consideráveis na configuração do equipamento em relação a um LIBS convencional, porém, além do controle da energia do laser, que é praticamente o único parâmetro monitorado nos sistemas convencionais, num fs-LIBS é necessário um controle preciso de outras características do pulso, como a duração e o perfil temporal em escala de femtossegundo, gerando a necessidade de uma quantidade maior de equipamentos de controle [49]. 


\section{METODOLOGIA}

\subsection{Laser com pulsos de femtossegundos}

Todos os experimentos foram realizados no laboratório de lasers de altíssima intensidade e no laboratório de aplicações industriais, ambos localizados no Centro de Lasers e Aplicações (CLA) do Instituto de Pesquisas Energéticas e Nucleares (IPEN).

O laser utilizado consiste de um sistema de Ti: Safira de femtossegundo, amplificado por varredura de frequência (Femtopower Compact Pro CE-Phase HP/HR da marca Femtolasers) que gera continuamente pulsos de 25 fs (FWHM), centrados em $775 \mathrm{~nm}$ com $40 \mathrm{~nm}$ de largura de banda, taxa de repetição máxima de $4 \mathrm{kHz}$ e energia máxima por pulso de $750 \mu \mathrm{J}$.

Após a geração do feixe laser no laboratório de lasers de altíssima intensidade, ele é direcionado para o laboratório de aplicações industriais, percorrendo aproximadamente $30 \mathrm{~m}$ até um sistema de guiamento composto por obturadores, expansores, polarizadores, espelhos e todo um sistema óptico que permite o controle da dispersão a da intensidade do feixe, que é focalizado sobre a amostra por uma lente com comprimento focal de $40 \mathrm{~mm}$, gerando um diâmetro no foco (cintura) de aproximadamente $15 \mu \mathrm{m}$. Na FIGURA 20 pode-se ver o arranjo óptico do sistema de entrega do feixe. 


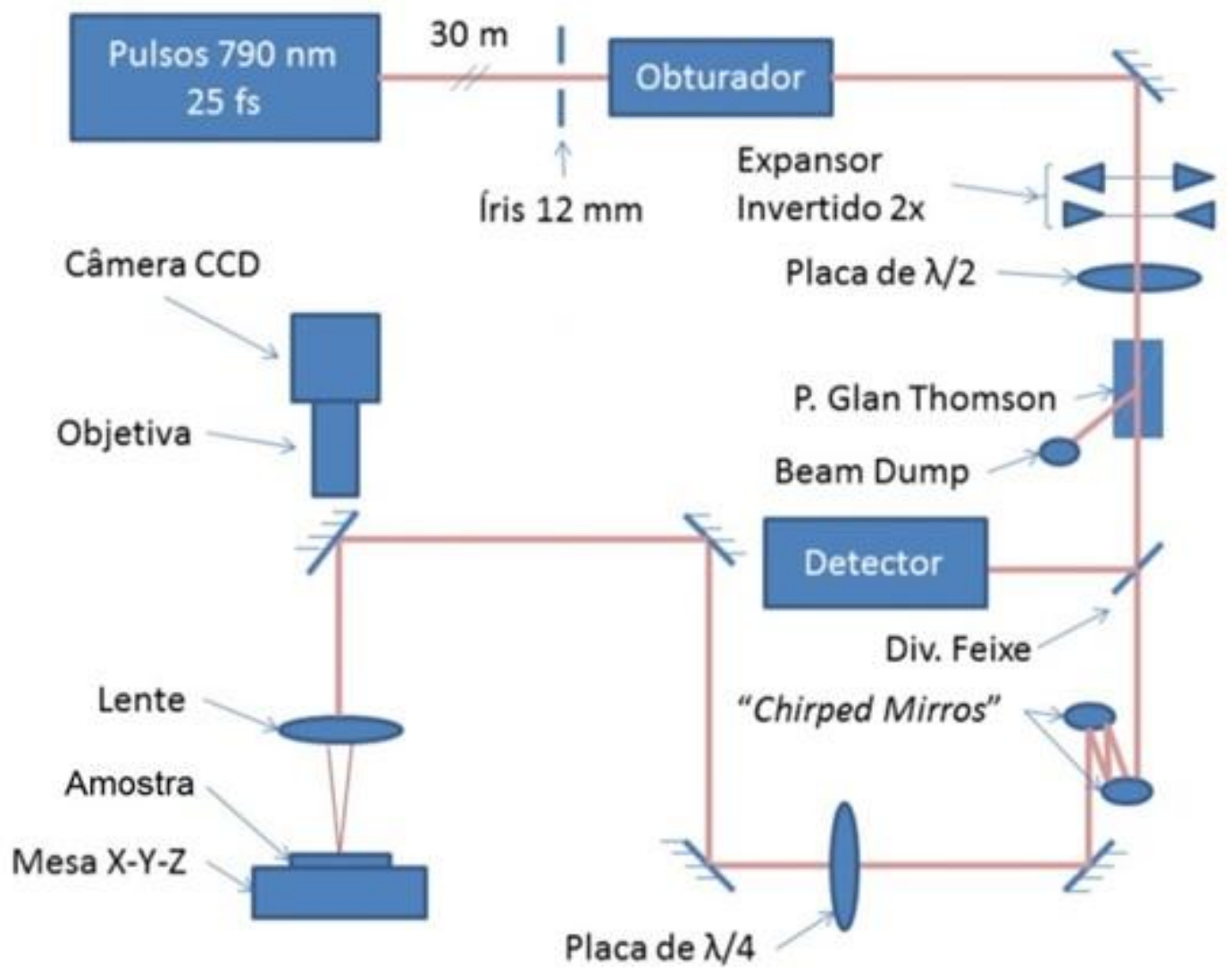

FIGURA 20 - Arranjo óptico do sistema de entrega do feixe [50].

Para realizar a varredura da amostra com o feixe de laser focalizado, a estação de trabalho conta com uma base para fixação de amostras, que possui um sistema de movimentação tridimensional (eixos x, y e z), com precisão submicrométrica controlado por computador, o que permite a execução de microusinagens com perfis complexos, por meio de programas de usinagem gerados por softwares específicos.

\subsection{Sistema LIBS para controle da ablação seletiva}

Para montagem e criação de um espectro de referência para o Ti no sistema LIBS, foi utilizada uma chapa de titânio grau 2 comercialmente puro (GR2CP) medindo $15 \times 10 \times 2 \mathrm{~mm}$, onde foram ablacionados quatro conjuntos de canais, variando-se a sobreposição de pulsos de um para outro, alterando também o posicionamento das lentes de captação do sinal do plasma de um canal para outro, podem estar perpendiculares ou paralelas ao sentido da ablação, no segundo caso, podendo ainda estar à frente (sentido -) ou atrás (sentido + ) do feixe. 
O conjunto 1 foi ablacionado com sobreposição de pulsos de $N=20$, enquanto que no conjunto 2 utilizou-se sobreposição de $\mathrm{N}=40$, ambos com a lente de captação paralela ao sentido de usinagem. Os conjuntos 3 e 4 seguiram a mesma variação na sobreposição de pulsos, alterando apenas 0 posicionamento das lentes, que ficaram perpendiculares ao trajeto do laser. Em cada conjunto a energia do laser foi reduzida a cada dois canais, conforme listado na TABELA 1, a fim de verificar se a sensibilidade do equipamento disponível seria suficiente para a aplicação em questão. Na FIGURA 21 são apresentados os canais ablacionados na chapa de titânio, além de uma representação do posicionamento das lentes para o teste de captação do sinal do plasma.

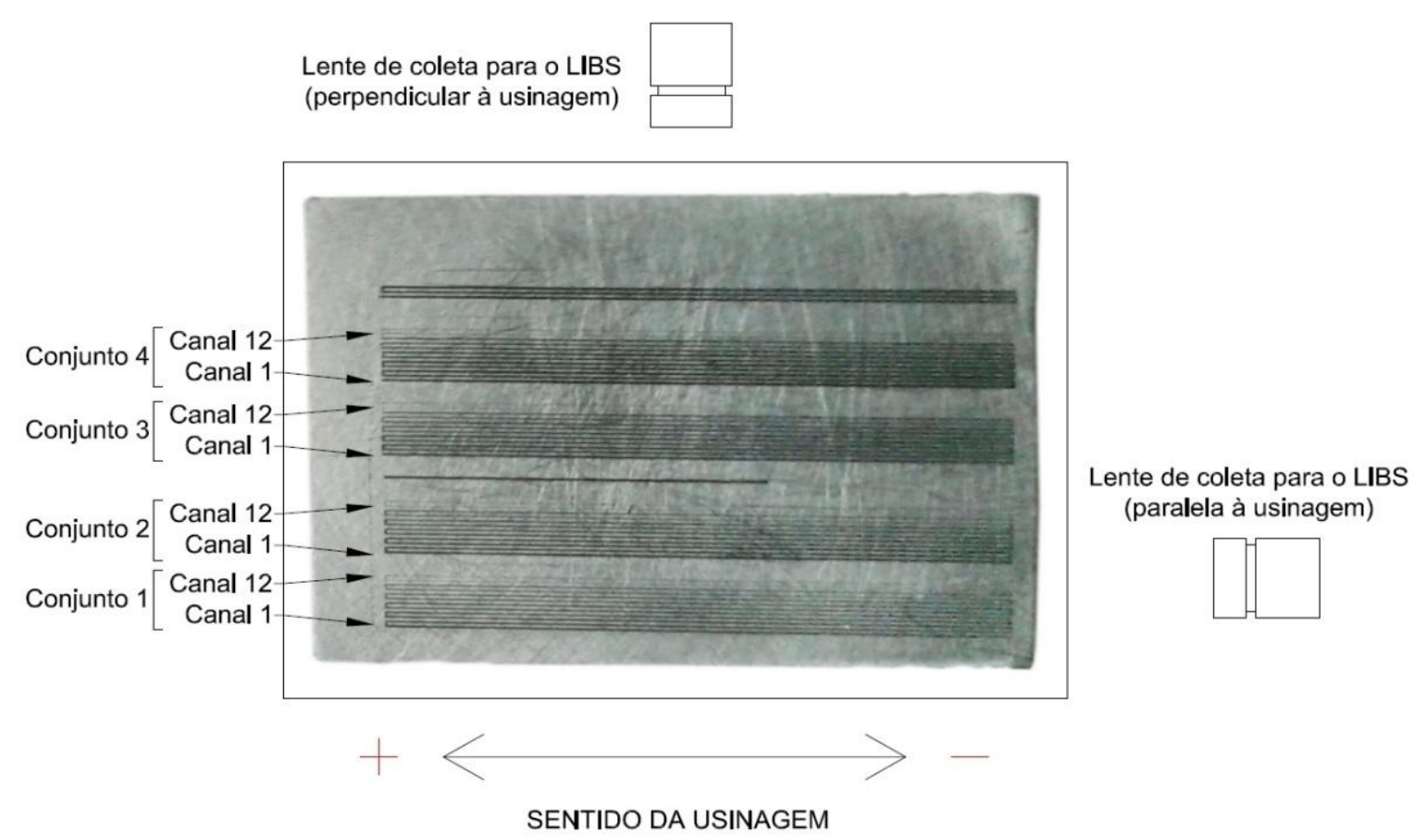

FIGURA 21 - Traços ablacionados na chapa de titânio GP2CP. Representação do posicionamento das lentes para teste de captação do sinal de emissão do plasma para o sistema LIBS. 
TABELA 1 - Variação de fluência e sentido de usinagem dos canais no teste de montagem do LIBS

\begin{tabular}{ccc}
\hline Canal & $\begin{array}{c}\text { Fluência por } \\
\text { pulso }\left(\mathbf{J} / \mathbf{c m}^{2}\right)\end{array}$ & $\begin{array}{c}\text { Sentido de usinagem } \\
(+/-)\end{array}$ \\
\hline 1 & 9,2 & + \\
2 & 9,2 & - \\
3 & 7,4 & + \\
4 & 7,4 & - \\
5 & 5,5 & + \\
6 & 5,5 & - \\
7 & 3,7 & + \\
8 & 3,7 & - \\
9 & 1,8 & + \\
10 & 1,8 & - \\
11 & 0,4 & + \\
12 & 0,4 & - \\
\hline
\end{tabular}

Para coletar o sinal do plasma para envio ao sistema LIBS foi confeccionado um dispositivo para acoplamento de um conjunto de lentes, com o objetivo de aumentar a quantidade de sinal luminoso enviado ao espectrômetro. $\mathrm{Na}$ FIGURA 22 tem-se uma representação do dispositivo montado com as lentes.

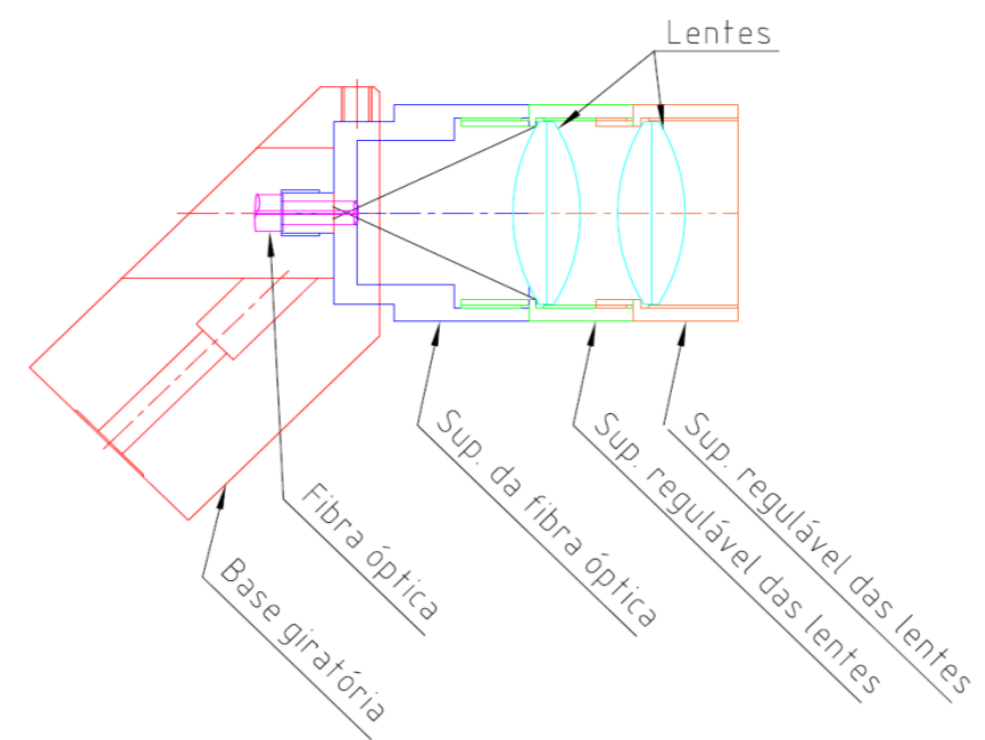

FIGURA 22 - Montagem das lentes para captação do sinal para o LIBS. 
A lente coletora possui diâmetro de $25 \mathrm{~mm}$, e distância focal de $50 \mathrm{~mm}$. O espectrômetro utilizado foi um modelo CCS100 fabricado pela Thorlabs, com uma faixa de medição de 350 à $700 \mathrm{~nm}$ de comprimento de onda, que gera os espectros num software próprio. Na FIGURA 23 pode-se ver a montagem do equipamento utilizado na estação de trabalho do laboratório de aplicações industriais.
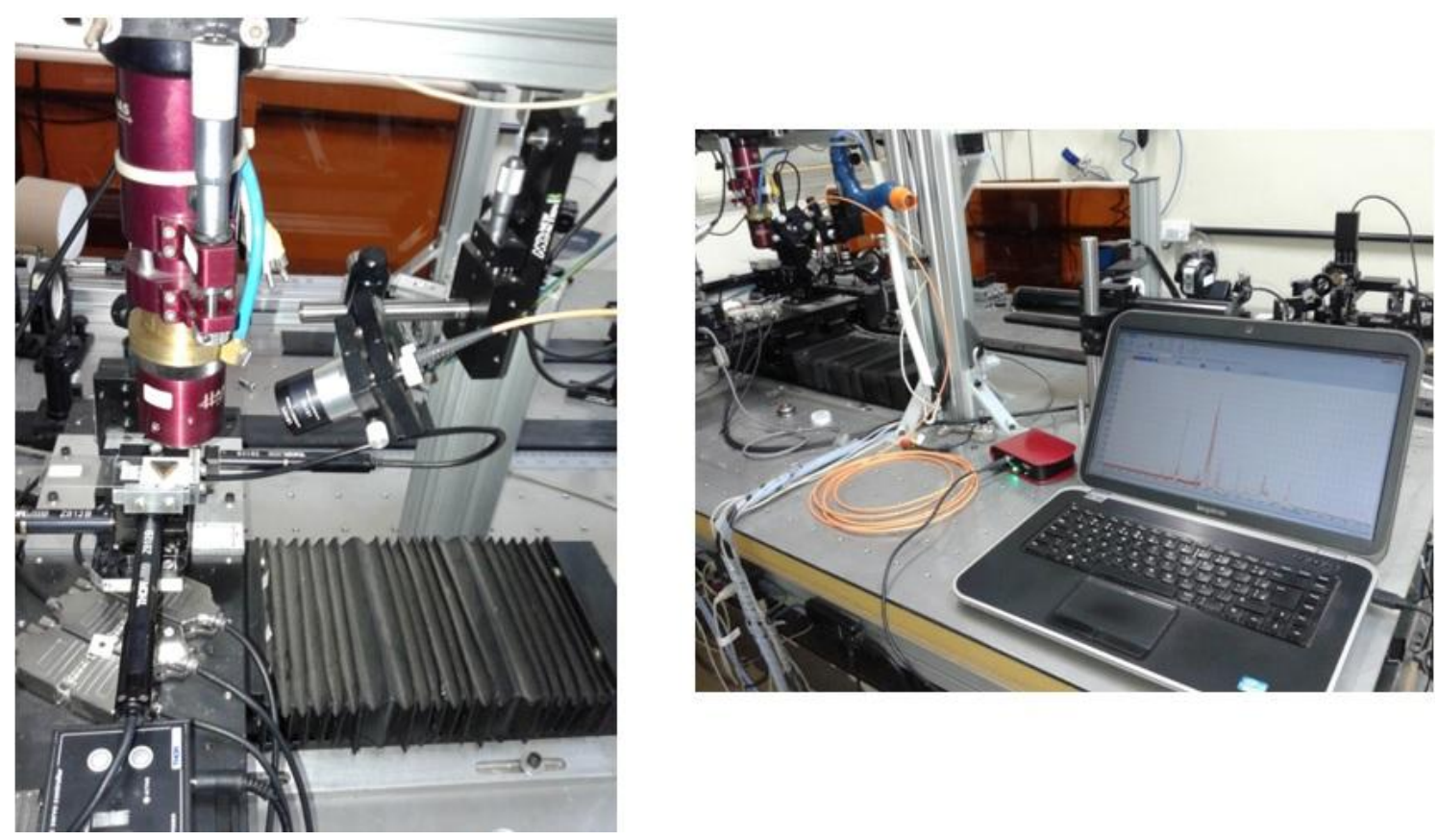

FIGURA 23 - Montagem do equipamento LIBS, à direita conjunto de lentes para captação do sinal do plasma e à esquerda espectrômetro e computador para tratamento dos dados.

O sinal coletado em cada um dos canais mostrou-se bem estável, mantendo os mesmos picos em todos os passes, apresentando apenas a variação já esperada de intensidade conforme a redução da energia do laser, uma vez que a qualidade do sinal analisado depende do sistema de coleta e da intensidade do plasma gerado. Na FIGURA 24 é apresentada uma imagem representativa da tela do software de análise utilizado para manipulação do sinal do plasma, os picos são referentes à ablação do canal 1 do conjunto 1 na chapa de titânio, e o espectro coletado para utilização como padrão para identificação do Ti no decorrer da ablação. 


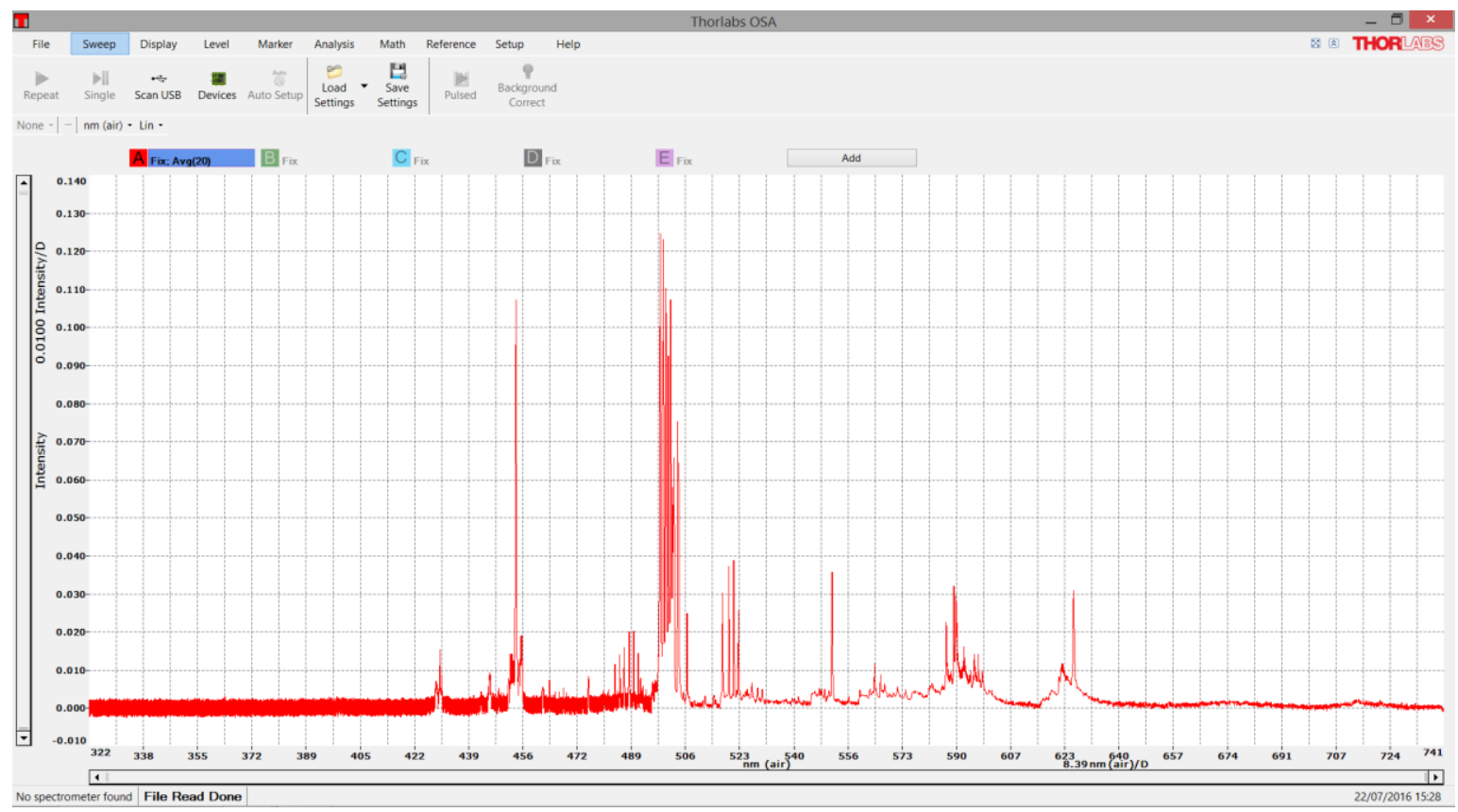

FIGURA 24 - Tela do software de análise espectral com os picos característicos do Ti coletados durante a ablação do canal 1 do Conjunto 1

\subsection{Teste do sistema LIBS numa pastilha triangular}

O sistema LIBS foi testado na ablação de uma pastilha triangular de metal duro com recobrimento de TiN fornecida por uma indústria metalúrgica de usinagem mecânica, objetivando verificar a capacidade do sistema LIBS utilizado de identificar a variação da concentração de determinado material no decorrer da ablação. Por tratar-se apenas de testes de sensibilidade do LIBS, não houve preocupação com a composição do filme e do substrato.

Foram ablacionados cinco rebaixos medindo $2 \times 4 \mathrm{~mm}$, mantendo todos os parâmetros de varredura constantes, variando-se apenas a quantidade de varreduras sobrepostas em cada rebaixo. No primeiro apenas um passe, no segundo dois passes, e assim por diante. Na FIGURA 25 é apresentada uma imagem da pastilha utilizada. 


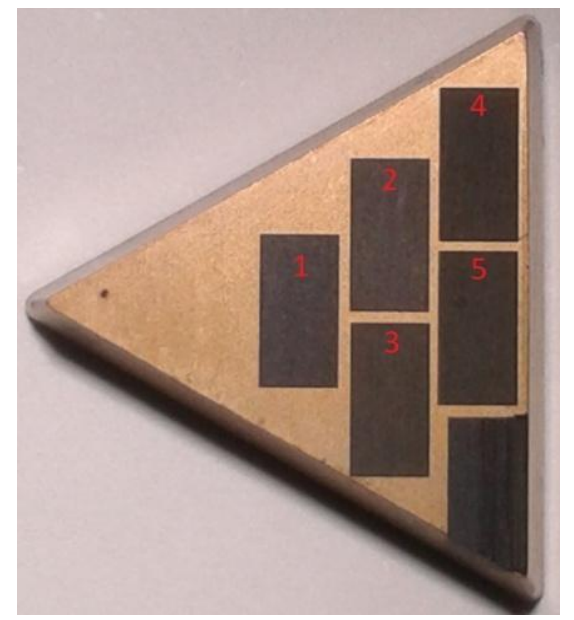

FIGURA 25 - Pastilha de usinagem utilizada para teste do sistema LIBS.

A ablação foi realizada com uma fluência por pulso de $5,5 \mathrm{~J} / \mathrm{cm}^{2}$ e uma sobreposição de pulsos de $N=20$, parâmetros definidos de acordo com os testes realizados anteriormente na chapa de titânio, condições onde conseguiu-se uma intensidade confiável de sinal para análise no LIBS, com a menor profundidade de ablação possível.

\subsection{Pastilha quadrada para os testes da ablação seletiva}

Para realização dos testes de ablação seletiva foram adquiridas 10 pastilhas de usinagem quadradas com filme de TiAIN e substrato de WC-Co, com designação geométrica ISO R210-14 05 12M-KM 1020 de fabricação da Sandvik, conforme a FIGURA 26, medindo 14,5 × 14,5 x 4,76 mm. Essa tipo de pastilha foi escolhida por não apresentar os mesmos elementos na composição do filme e do substrato, facilitando o controle do processo de ablação seletiva.

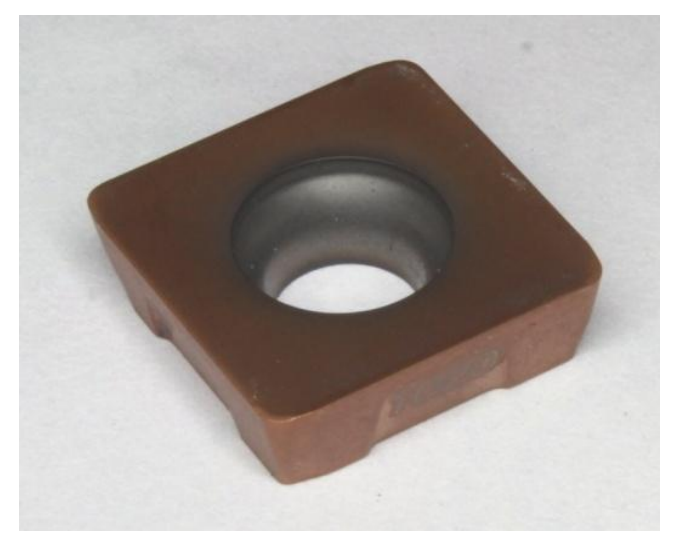

FIGURA 26 - Pastilha de mercado utilizada como amostra. 
A confirmação do material do filme e do substrato das pastilhas adquiridas para os testes da ablação seletiva foi feita por meio de Espectroscopia de raios $\mathrm{X}$ por dispersão de energia (EDS, do inglês: Energy-dispersive $X$-ray spectroscopy), num microscópio eletrônico de varredura (MEV) modelo TM3000 fabricado pela Hitachi. Para análise do substrato, uma das faces da pastilha foi lixada com lixa d'água grana 600 para remoção do filme superficial, deixando assim exposto o material do substrato.

A superfície do filme foi analisada no perfilômetro óptico a fim de avaliar sua rugosidade e uma das laterais da pastilha também foi lixada para que se pudesse realizar uma avaliação transversal da sua espessura.

\subsection{Limiar de ablação do filme de TiAIN}

O limiar de ablação do filme de TiAIN foi determinado pelo método DScan, processo realizado no Laboratório de Lasers de Altíssima Intensidade do CLA-IPEN, onde foram ablacionados 24 traços na superfície da pastilha de usinagem com energia do laser de $94 \pm 2 \mu \mathrm{J}$.

As imagens de cada perfil foram ampliadas utilizando-se o MEV e, posteriormente, as medidas da largura máxima foram registradas para determinar o limiar de ablação por meio das equações definidas no D-Scan.

Utilizando-se um perfilômetro óptico ZeGage Zemetric fabricado pela Zygo, munido de duas lentes objetivas, uma com magnificação de 20 vezes e outra com 50 vezes, foi possível também avaliar a variação da profundidade em cada traço no decorrer da varredura diagonal do D-Scan, associando a profundidade à fluência do feixe em cada momento da ablação. Essa informação será de grande importância para análise e definição dos parâmetros para ablação seletiva do filme, tendo em vista que o controle da profundidade é vital para a execução do trabalho.

Após o tratamento das dimensões de largura máxima dos perfis gravados, o limiar de ablação do filme foi calculado a partir das equações e ajustes definidos no D-Scan. 


\subsection{Limiar de ablação do substrato de WC-Co}

Para determinação do limiar de ablação do substrato, uma das faces da pastilha de usinagem foi lixada com lixa d'água grana 600 , para remoção do filme superficial, deixando assim exposto o material do substrato.

O procedimento do D-Scan foi realizado no Laboratório de Lasers de Altíssima Intensidade do CLA-IPEN, onde foram feitos 16 traços na superfície da amostra, obedecendo os mesmo critérios de varredura utilizados no filme, com energia do laser de $90 \pm 2 \mu \mathrm{J}$.

As imagens de cada perfil foram ampliadas utilizando-se o MEV e, posteriormente, as medidas da largura máxima foram registradas para determinar o limiar de ablação por meio das equações definidas no D-Scan.

\subsection{Determinação dos parâmetros para ablação seletiva}

Após a determinação dos limiares de ablação, tendo o filme limiar mais alto do que o substrato, outros aspectos foram avaliados para determinar os parâmetros necessários para a realização da ablação seletiva do filme, garantindo o menor dano possível ao substrato.

Observando-se o lado esquerdo dos traços, onde a superfície da pastilha encontra-se numa posição anterior à cintura do feixe e, portanto, está sendo irradiada por uma a fluência mais baixa, é possível verificar a transição do filme para o substrato, desde uma região onde estruturas periódicas induzidas pelo laser (LIPSS do inglês: Laser Induced Periodic Surface Structure) começam e se formar na superfície do filme, passando pela remoção progressiva de material até a chegada ao substrato. Na FIGURA 27 tem-se a imagem do traço 10, escolhido pela nitidez da transição do filme para o substrato, gravado com sobreposição de pulsos de $\mathrm{N}=18$ no D-Scan, com o detalhe da região de transição do filme para o substrato, onde a região mais clara na imagem refere-se ao substrato e a mais escura ao filme. 

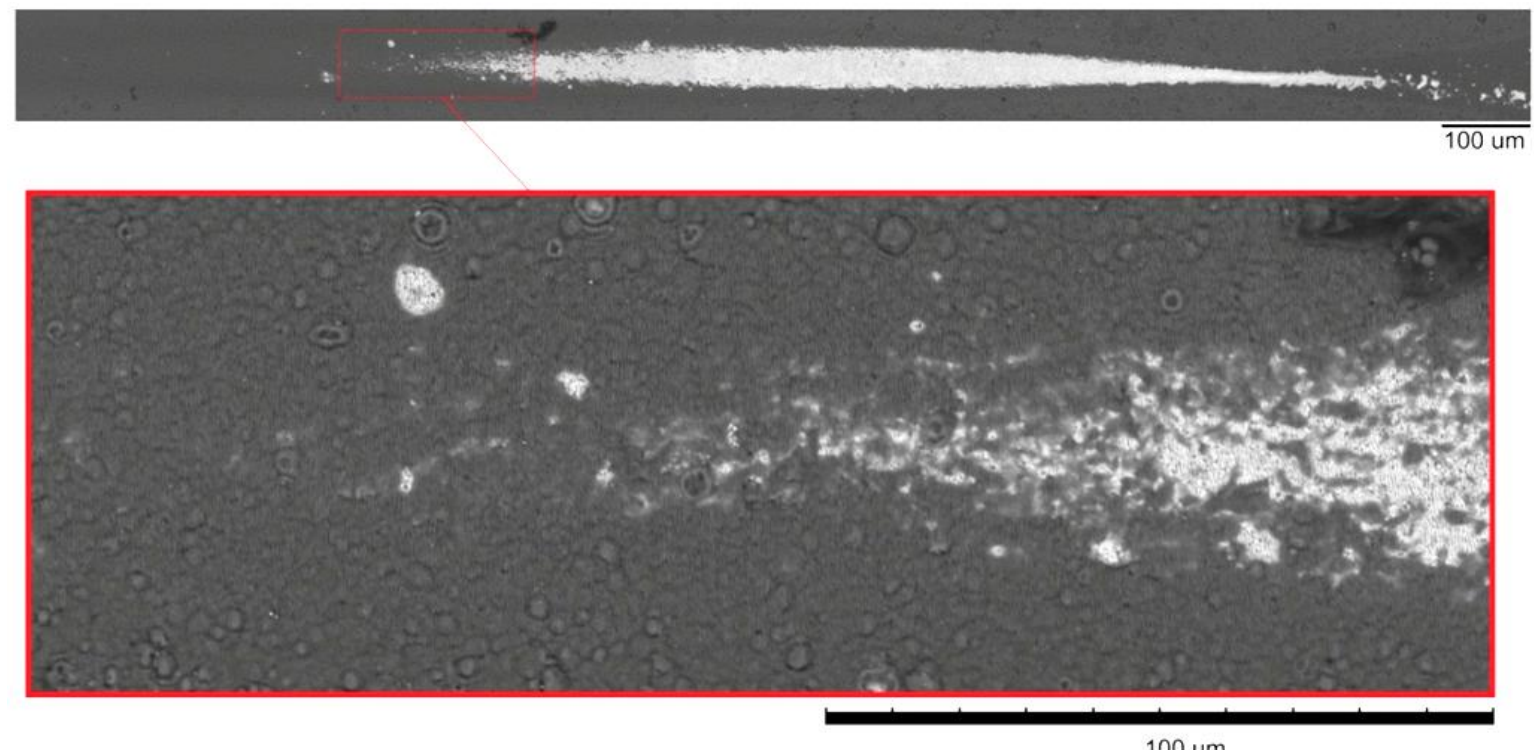

100 um

FIGURA 27 - Perfil do traço 10 ablacionado no filme com sobreposição de pulsos de $\mathrm{N}=18$. No detalhe, a região de transição do filme para o substrato no início do traço, desde a formação dos LIPSS até a remoção total do filme.

A partir da análise da sobreposição de pulsos, da energia do laser e do diâmetro teórico do feixe nessas regiões de transição, foi possível determinar a partir da Equação 6, a fluência necessária para reproduzir a formação dos LIPSS gerados durante o D-scan. Na FIGURA 28 é possível observar em detalhe os LIPSS formados pelo laser, indicando o início da ablação do filme.

Uma vez determinada a fluência e sobreposição necessária para a formação dessas micro estruturas, os parâmetros de varredura puderam ser variados a fim de determinar a condição ideal para remoção gradativa do filme. 


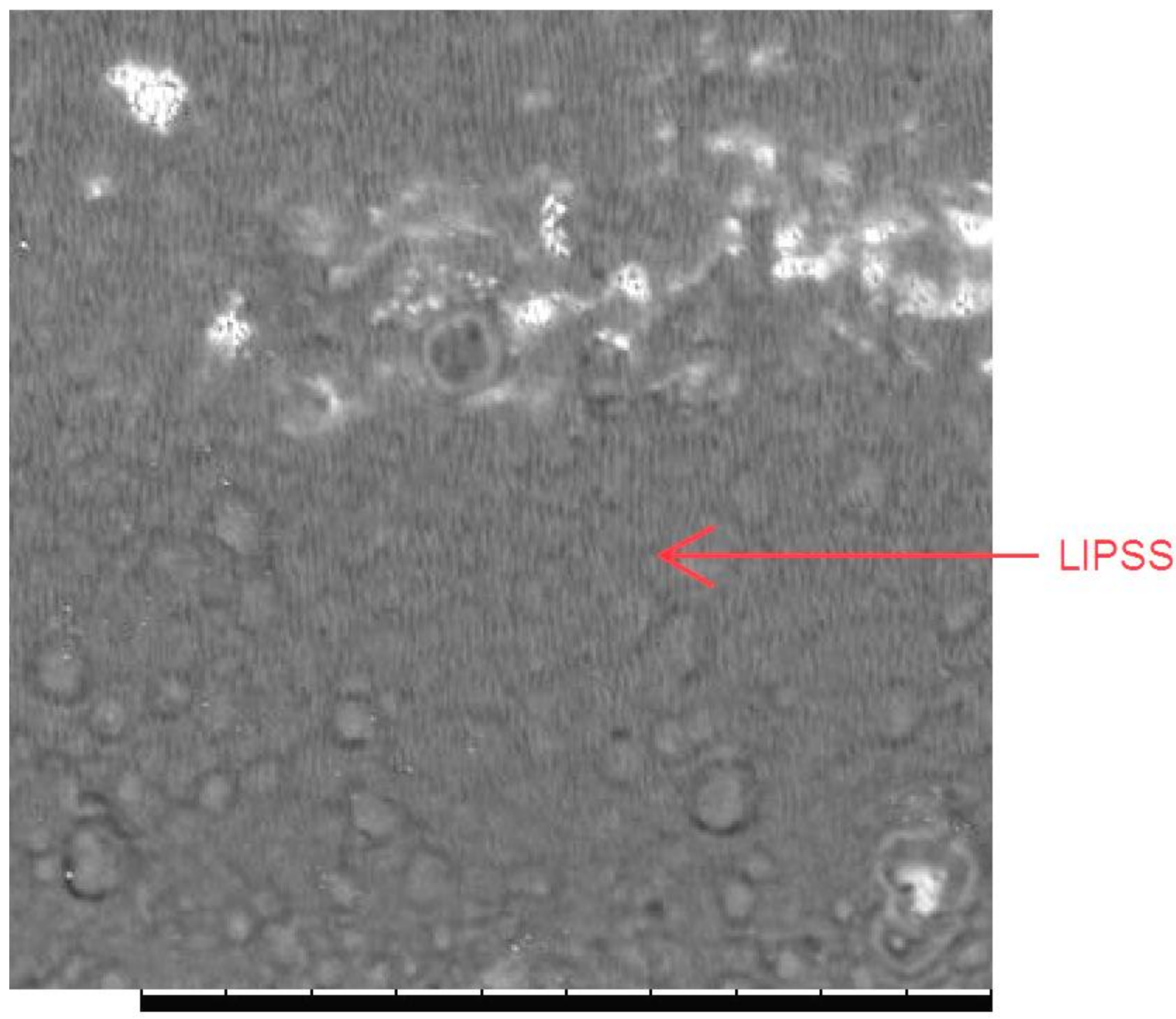

50 um

FIGURA 28 - Detalhe dos LIPSS formados pelo laser no filme, estruturas transversais ao traço no sentido vertical na imagem.

\subsection{Ablação por meio de baixa fluência no filme de TiAIN}

Analisando a distância (longitudinal ao traço) em que a região onde se iniciou a formação dos LIPSS se encontrava em relação ao centro do perfil gravado, correspondente à cintura do feixe na varredura diagonal, foi possível calcular o diâmetro teórico do feixe, e então determinar a fluência necessária para reproduzir a formação dos LIPSS.

Na FIGURA 29 é possível verificar uma representação da variação do diâmetro do feixe no decorrer da varredura diagonal referente ao traço 10 gravado no filme para o D-Scan. 


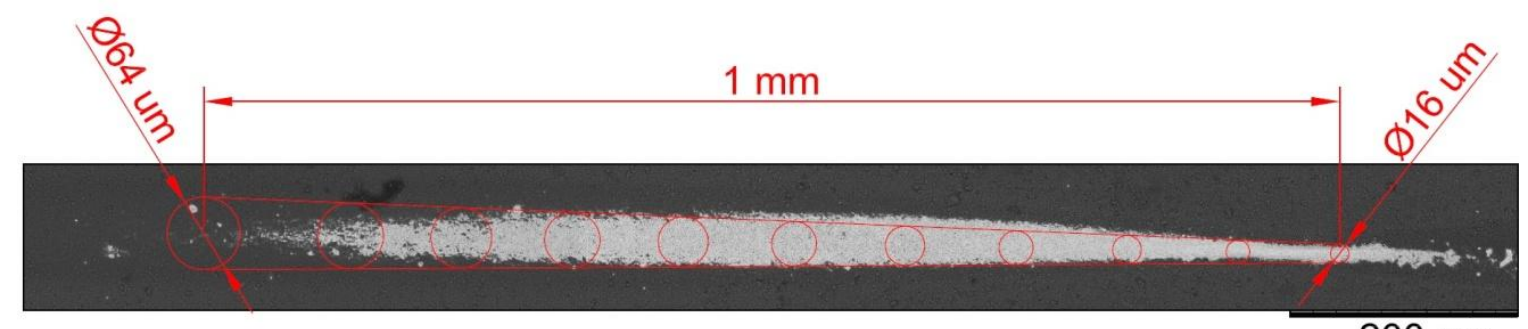

200 um

FIGURA 29 - Representação da variação do diâmetro do feixe no decorrer da varredura diagonal do traço 10 gravado para o D-scan.

A região de formação de LIPSS considerada encontrava-se a $1 \mathrm{~mm}$ da cintura do feixe, posição onde o laser atingiu um diâmetro teórico de $64 \mu \mathrm{m}$, calculado a partir da Equação 4. Considerando o diâmetro e a energia do feixe nesse ponto, foi possível determinar a partir da Equação 6, a fluência ideal por pulso para realização da varredura, obtendo o valor aproximado de $1 \mathrm{~J} / \mathrm{cm}^{2}$ com sobreposição de pulsos de $N=16$, o que corroborou com o valor de limiar obtido no D-scan.

Partindo da análise do gráfico da fluência de limiar em função da sobreposição de pulsos obtido no D-scan foram ablacionados 25 traços com fluência por pulso de $0,6 \mathrm{~J} / \mathrm{cm}^{2}$, referente à fluência de limiar para sobreposição de pulsos de $N=1000$, fazendo uma varredura em zig-zag com entre centros de $8 \mu \mathrm{m}$ entre os caminhos de ida e volta. A sobreposição de pulsos variou de $N=2340$ até $N=94$, para que se pudesse avaliar a evolução da formação dos LIPSS e a remoção parcial ou total do filme.

Para melhor compreensão do comportamento do processo, as profundidades de cada traço foram avaliadas utilizando-se um perfilômetro óptico.

\subsection{Teste de redução do limiar de ablação do filme de TiAIN a partir dos efeitos de incubação}

A partir da avaliação dos limiares de ablação do filme e do substrato, quatro traços foram gravados no regime de baixa fluência do substrato, portanto bem abaixo do limiar do filme, aplicando-se uma alta sobreposição de pulsos a fim de avaliar a viabilidade de se reduzir o limiar do filme aproveitando-se dos efeitos de incubação do mesmo.

A fluência utilizada foi de $0,3 \mathrm{~J} / \mathrm{cm}^{2}$ e a sobreposição de pulsos variou de um traço para outro, sendo $N=2340$ para o traço 1, 4679 para o 2, 7019 para 
o 3 e 9359 para o 4. Tais valores foram definidos a partir da observação do gráfico comparativos das fluência de limiar do filme e do substrato, conforme FIGURA 30.

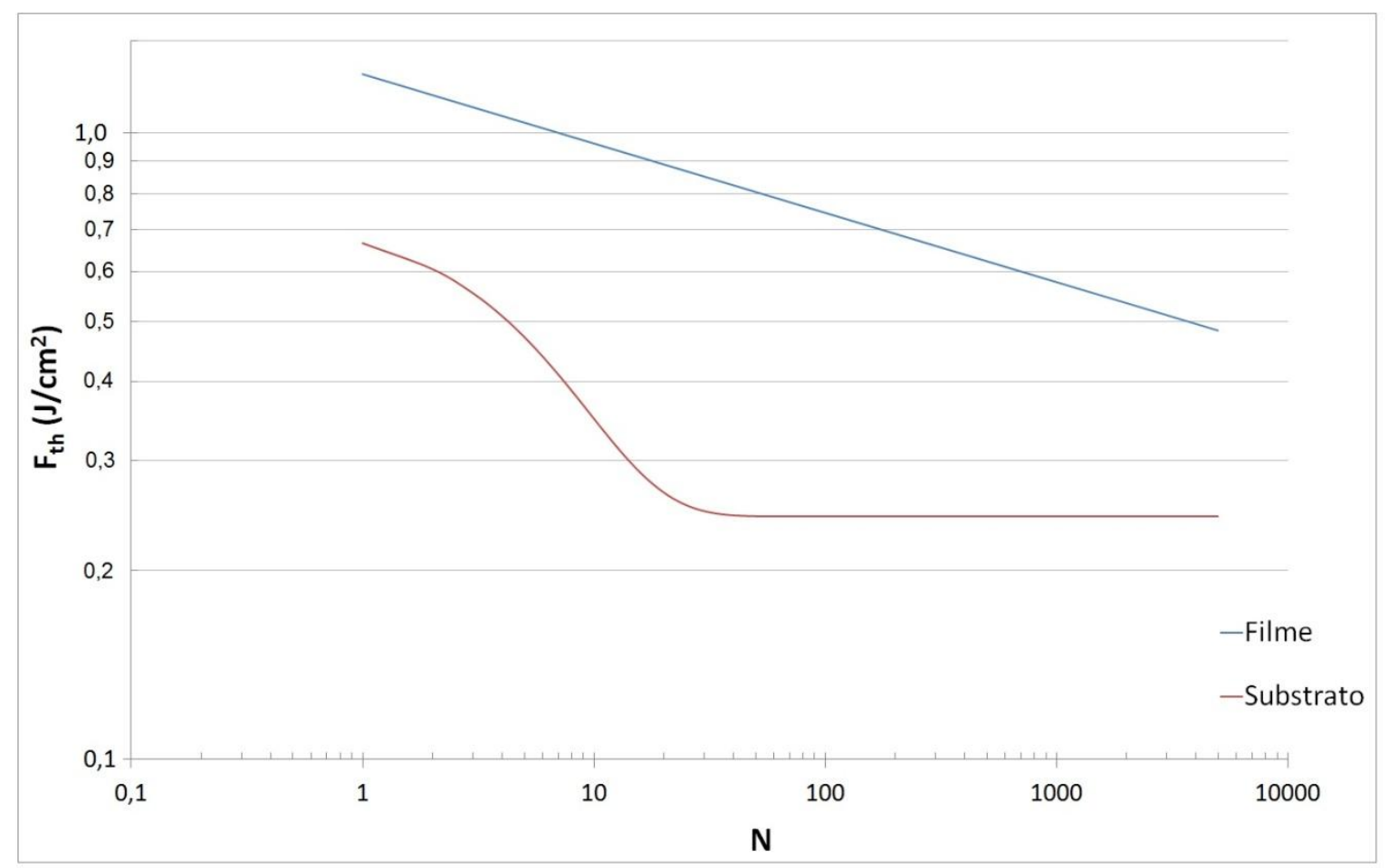

FIGURA 30 - Gráfico comparativo dos limiares de ablação do filme de TiAIN e do substrato de WC-Co em função da sobreposição de pulsos. 


\section{RESULTADOS E DISCUSSÃO}

\subsection{Sistema de controle da ablação (LIBS)}

O sinal coletado em cada um dos canais ablacionados na chapa de $\mathrm{Ti}$ mostrou-se bem estável, mantendo os mesmos picos em todos os passes, apresentando apenas a variação já esperada de intensidade conforme a redução da energia do laser, uma vez que a qualidade do sinal analisado depende do sistema de coleta e da intensidade do plasma gerado.

$\mathrm{Na}$ FIGURA 31 pode-se visualizar um modelo 3D gerado no perfilômetro óptico, referente ao perfil dos canais ablacionados no conjunto 1 , desde o canal 1 à esquerda ao canal 12 a direita.

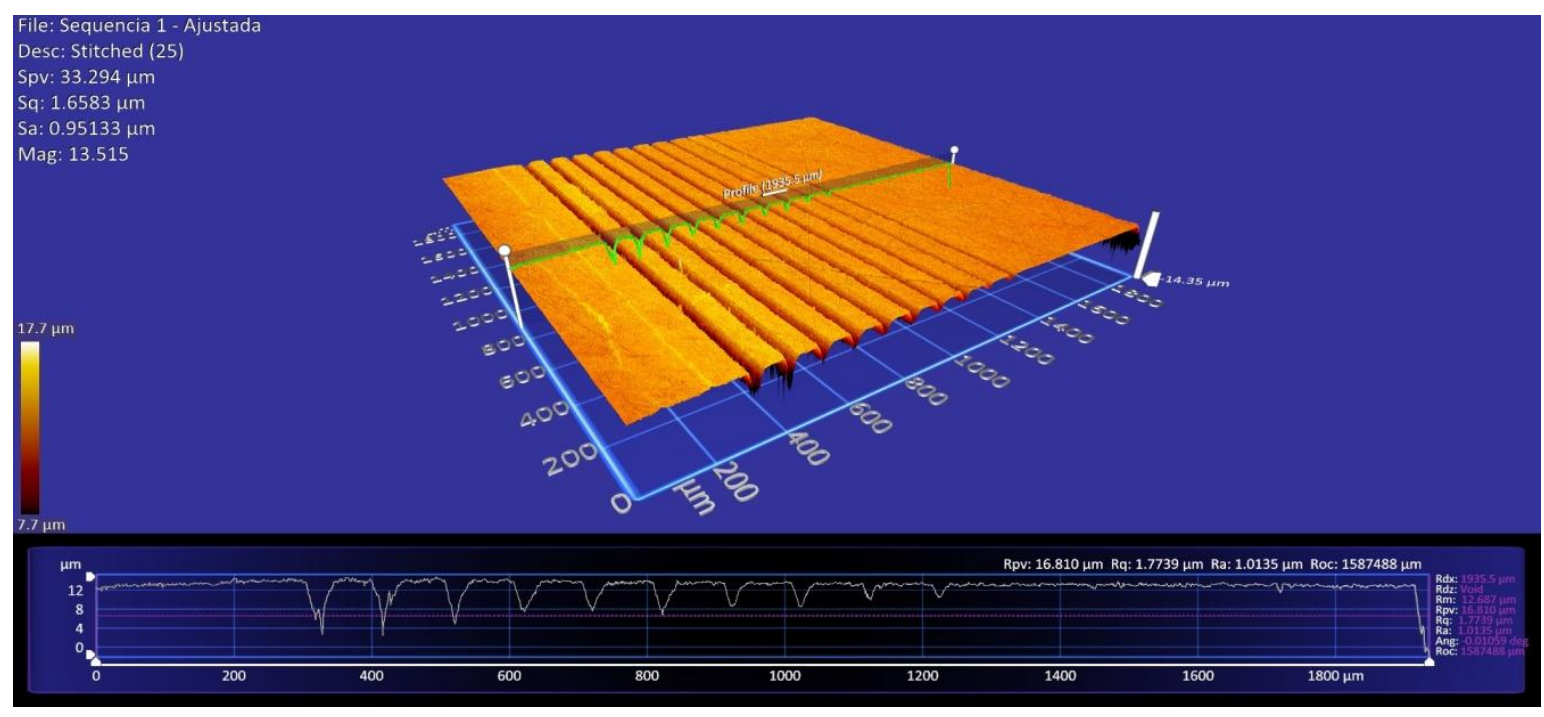

FIGURA 31 - Perfil 3D dos canais ablacionados no Conjunto 1

Conforme a redução na fluência dos pulsos, percebe-se a redução da profundidade dos canais, bem como a redução da intensidade do plasma e, consequentemente, na intensidade dos sinais captados pelo espectrômetro, que pode ser verificada no gráfico da FIGURA 32, desde o canal 12 ablacionado com fluência de $0,4 \mathrm{~J} / \mathrm{cm}^{2}$, até o canal 1 ablacionado com $9,2 \mathrm{~J} / \mathrm{cm}^{2}$. 


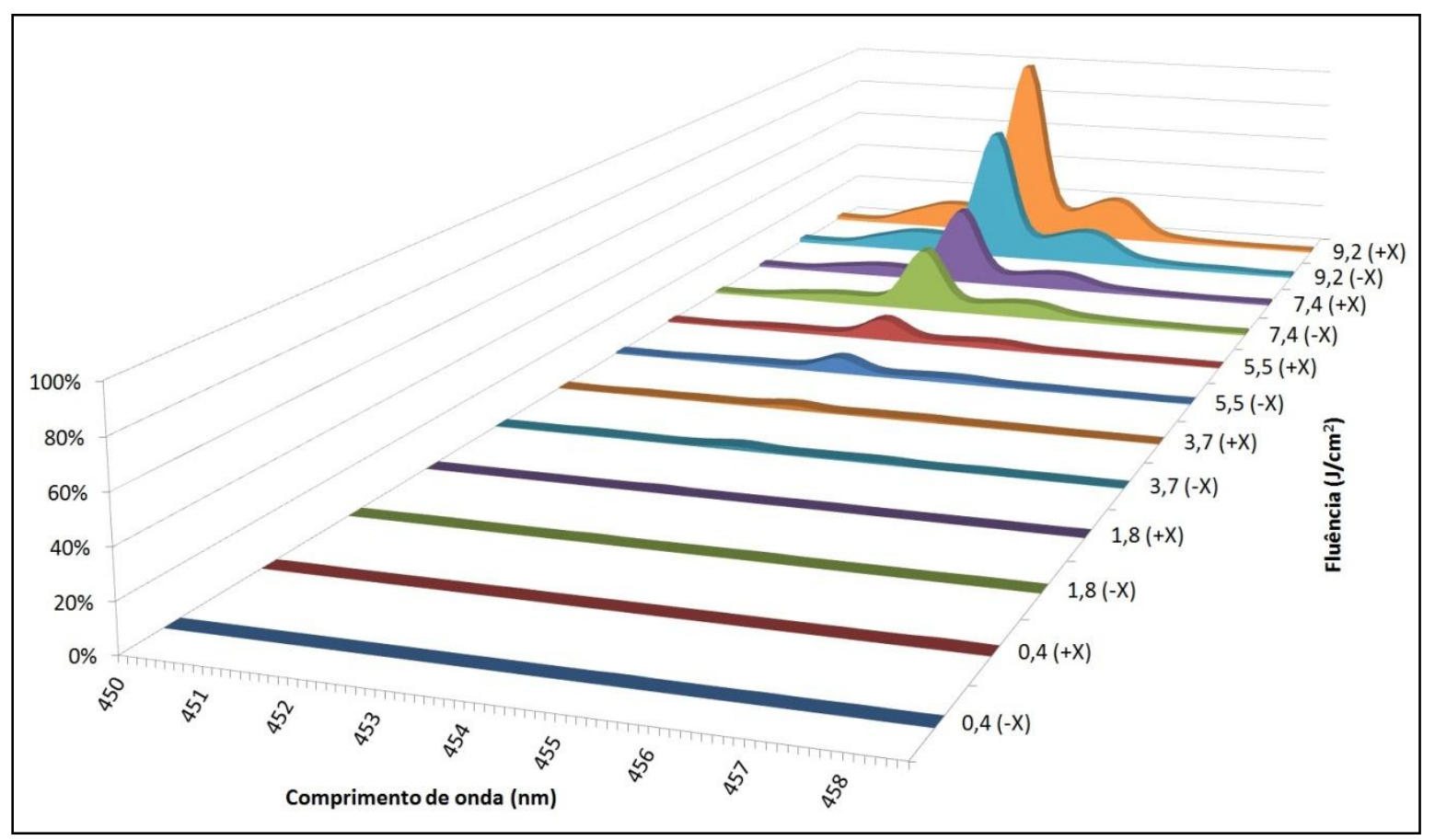

FIGURA 32 - Intensidades relativas dos sinais captados pelo espectrômetro de acordo com a redução da fluência do laser. Lentes de captação paralelas ao sentido de usinagem atrás do feixe.

Para facilitar a análise dos resultados, escolheu-se um pico característico e de boa intensidade do titânio, dispensando assim a necessidade de analisar o espectro inteiro. Na FIGURA 33 é apresentada uma comparação entre as intensidades relativas do sinal coletado para um pico característico do titânio centrado num comprimento de onda aproximado de 453,6 nm [51], mantendo-se todos os parâmetros de usinagem, exceto o posicionamento das lentes de coleta do sinal do plasma. 


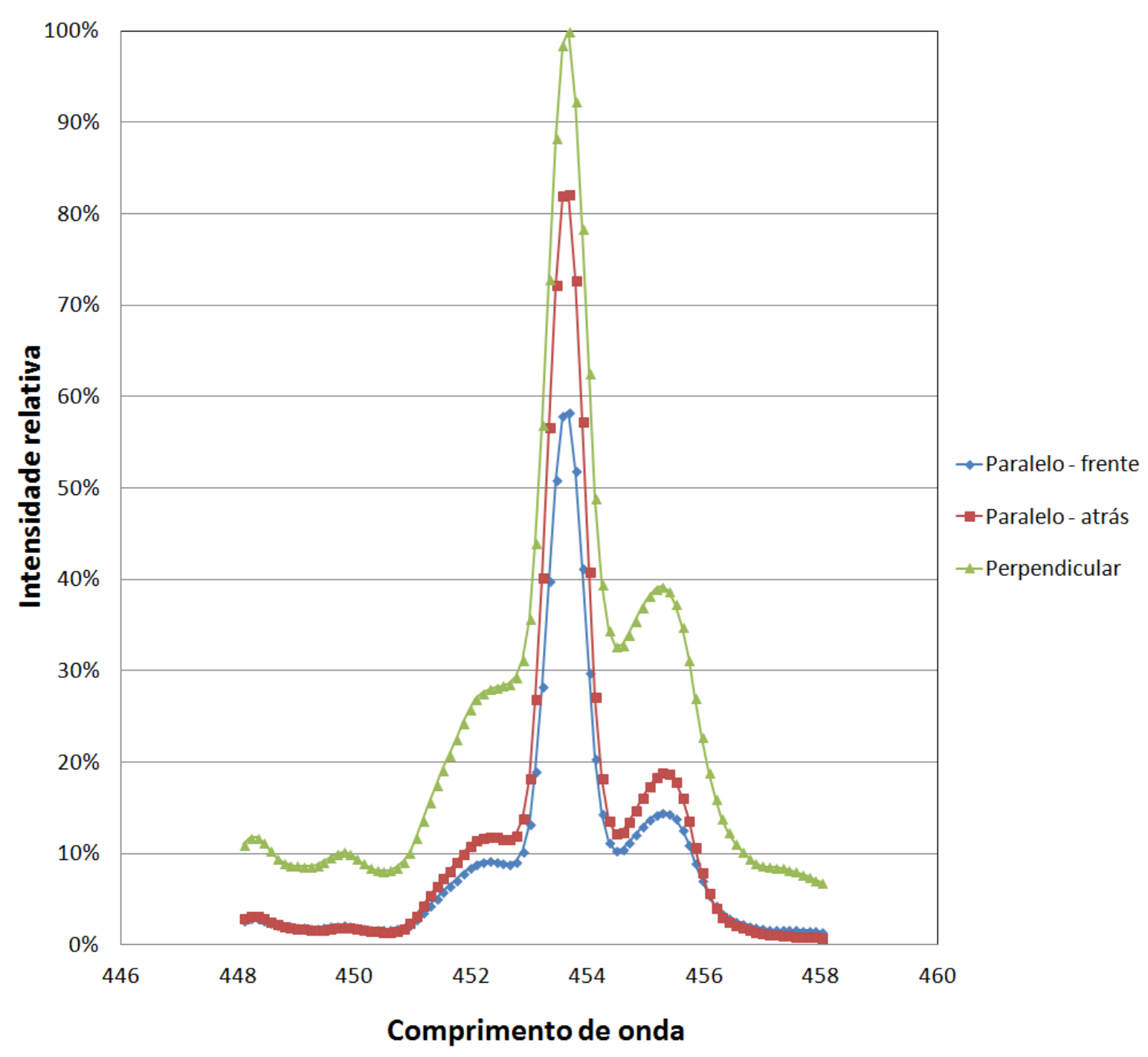

FIGURA 33 - Gráfico da intensidade relativa do sinal do plasma captada para cada configuração de posicionamento das lentes do LIBS.

Após a análise dos dados obtidos optou-se por posicionar o sistema de captação paralelo ao sentido da usinagem atrás do feixe, pois apesar de apresentar intensidade menor que a montagem perpendicular, permitiu grande redução do sinal de fundo, o que facilitaria no decorrer da varredura, a visualização do surgimento de novos picos de baixa intensidade referentes ao material de base.

Com relação à sensibilidade do equipamento, foi possível realizar medições apenas em plasmas gerados com fluências acima de $4 \mathrm{~J} / \mathrm{cm}^{2}$, e como os limiares do filme e do substrato encontram-se abaixo desse valor, seria necessária a utilização de um equipamento com maior sensibilidade, maior faixa 
de medição espectral ou maior ajuste de ganho no sinal, que fosse capaz de analisar plasmas com brilhos visíveis muito fracos.

\subsection{Teste do sistema LIBS na pastilha triangular}

No gráfico da FIGURA 34 apresenta-se a evolução das intensidades do sinal referentes ao pico característico do titânio, medidas pelo LIBS durante a ablação de cada passe na pastilha triangular de usinagem.

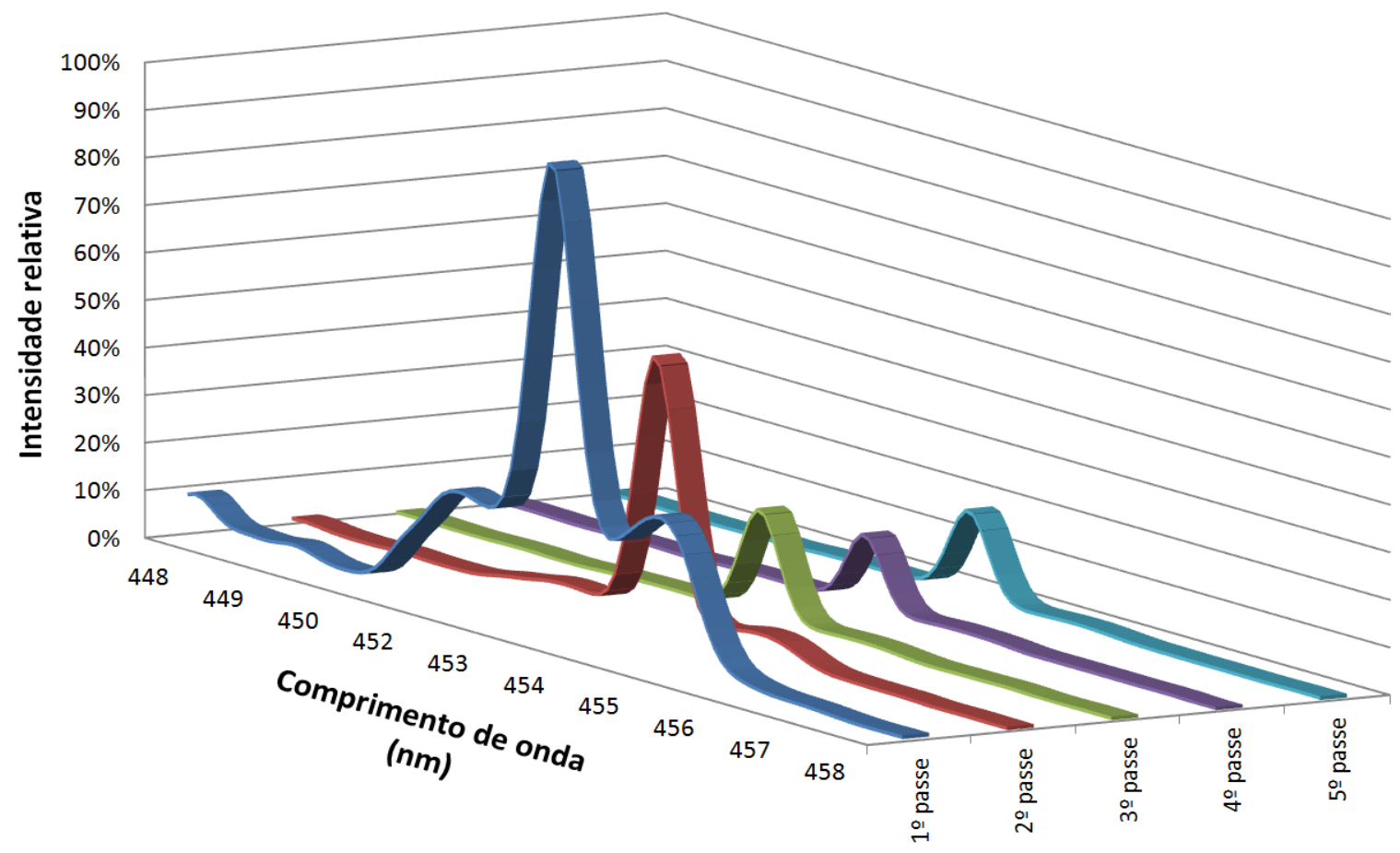

FIGURA 34 - Evolução da intensidade do pico referente ao titânio em cada passe ablacionado.

É possível verificar a redução do sinal do titânio do primeiro para 0 segundo passe, estabilizando-se a partir do terceiro, o que confirma que o LIBS é capaz de identificar o material que está sendo ablacionado, bem como evidenciar a redução da sua concentração, porém limitado pela sensibilidade do equipamento.

$\mathrm{Na}$ TABELA 2 e TABELA 3 são apresentados os materiais presentes no filme e no substrato, respectivamente, bem como suas concentrações relativas aproximadas avaliadas por meio de EDS. 
TABELA 2 - Composição do filme da pastilha utilizada para o teste do sistema LIBS.

\begin{tabular}{ccc}
\hline Elemento & $\begin{array}{c}\text { Concentração } \\
\text { relativa (\%) }\end{array}$ & Erro \\
\hline $\mathrm{Ti}$ & 87,193 & 0,141 \\
$\mathrm{~W}$ & 10,832 & 0,044 \\
$\mathrm{Co}$ & 0,968 & 0,011 \\
$\mathrm{Nb}$ & 0,879 & 0,006 \\
\hline
\end{tabular}

TABELA 3 - Composição do substrato da pastilha utilizada para o teste do sistema LIBS.

\begin{tabular}{ccc}
\hline Elemento & $\begin{array}{c}\text { Concentração } \\
\text { relativa (\%) }\end{array}$ & Erro \\
\hline $\mathrm{Ti}$ & 60,739 & 0,146 \\
$\mathrm{~W}$ & 32,521 & 0,087 \\
$\mathrm{Co}$ & 5,094 & 0,026 \\
$\mathrm{Nb}$ & 1,646 & 0,010 \\
\hline
\end{tabular}

A presença de grande quantidade de Ti na composição do substrato explica o fato do sinal ter estabilizado após certa profundidade. Como na pastilha quadrada adquirida para os testes finais não há Ti no substrato, esperava-se que o pico referente à este componente desapareça por completo após a remoção do filme.

A imagem gerada no perfilômetro óptico de cada rebaixo ablacionado podem ser visualizadas no APÊNDICE B, e na TABELA 4 são relacionadas as profundidades alcançadas em função da quantidade de passes sobrepostos, além da rugosidade do fundo de cada rebaixo. 
TABELA 4 - Profundidade e rugosidade, em função da quantidade de passes, dos rebaixos ablacionados para teste do sistema LIBS

\begin{tabular}{ccc}
\hline $\begin{array}{c}\text { Quantidade de } \\
\text { passes }\end{array}$ & $\begin{array}{c}\text { Profundidade } \\
\text { (um) }\end{array}$ & $\begin{array}{c}\text { Rugosidade } \\
\text { média - Ra }(\boldsymbol{\mu m})\end{array}$ \\
\hline 1 & 9,7 & 1,9 \\
2 & 20,5 & 3,1 \\
3 & 22,8 & 2,9 \\
4 & 30,3 & 4,7 \\
5 & 32,2 & 2,9 \\
\hline
\end{tabular}

Analisando os dados encontrados verificou-se que utilizando a fluência necessária para conseguir uma captação de sinal suficiente para análise no LIBS, a quantidade de material removido fica muito acima do necessário, chegando a uma profundidade de $10 \mu \mathrm{m}$ por passe, o dobro da espessura do filme da pastilha quadrada adquirida para os testes finais.

Para reduzir a profundidade da ablação seria necessário diminuir a fluência utilizada, o que consequentemente produziria um plasma com brilho menos intenso, que não seria detectado pelo equipamento LIBS disponível.

Decidiu-se então realizar os testes da ablação seletiva sem a utilização do sistema LIBS, aplicando-se os parâmetros determinados na análise dos traços do D-Scan e analisando os resultados posteriormente no MEV.

\subsection{Composição do filme e do substrato da pastilha quadrada}

$\mathrm{Na}$ TABELA 5 e TABELA 6 são apresentados os resultados das análises realizadas por EDS no filme e no substrato da pastilha quadrada. 
TABELA 5 - Composição do filme da pastilha de usinagem.

\begin{tabular}{ccc}
\hline Elemento & $\begin{array}{c}\text { Concentração } \\
\text { relativa (\%massa) }\end{array}$ & Erro \\
\hline $\mathrm{Ti}$ & 34,63 & 0,35 \\
$\mathrm{C}$ & 21,89 & 0,57 \\
$\mathrm{Al}$ & 19,82 & 0,18 \\
$\mathrm{~N}$ & 14,62 & 0,28 \\
$\mathrm{O}$ & 8,14 & 0,09 \\
\hline
\end{tabular}

TABELA 6 - Composição do substrato da pastilha de usinagem.

\begin{tabular}{ccc}
\hline Elemento & $\begin{array}{c}\text { Concentração } \\
\text { relativa (\%massa) }\end{array}$ & Erro \\
\hline W & 76,80 & 2,46 \\
C & 15,26 & 0,29 \\
Co & 3,19 & 0,01 \\
O & 2,95 & 0,01 \\
\hline
\end{tabular}

A partir dos resultados foi possível confirmar que as pastilhas estão de acordo com as especificações do fabricante, filme de TiAIN, e substrato de WCCo, facilitando a utilização do LIBS para controle do processo de ablação considerando esses materiais como referência [11].

A espessura do filme foi avaliada em aproximadamente $5 \mu \mathrm{m}$, conforme pode ser observado na FIGURA 35, juntamente com um mapa de cores para cada componente gerado pelo EDS. 


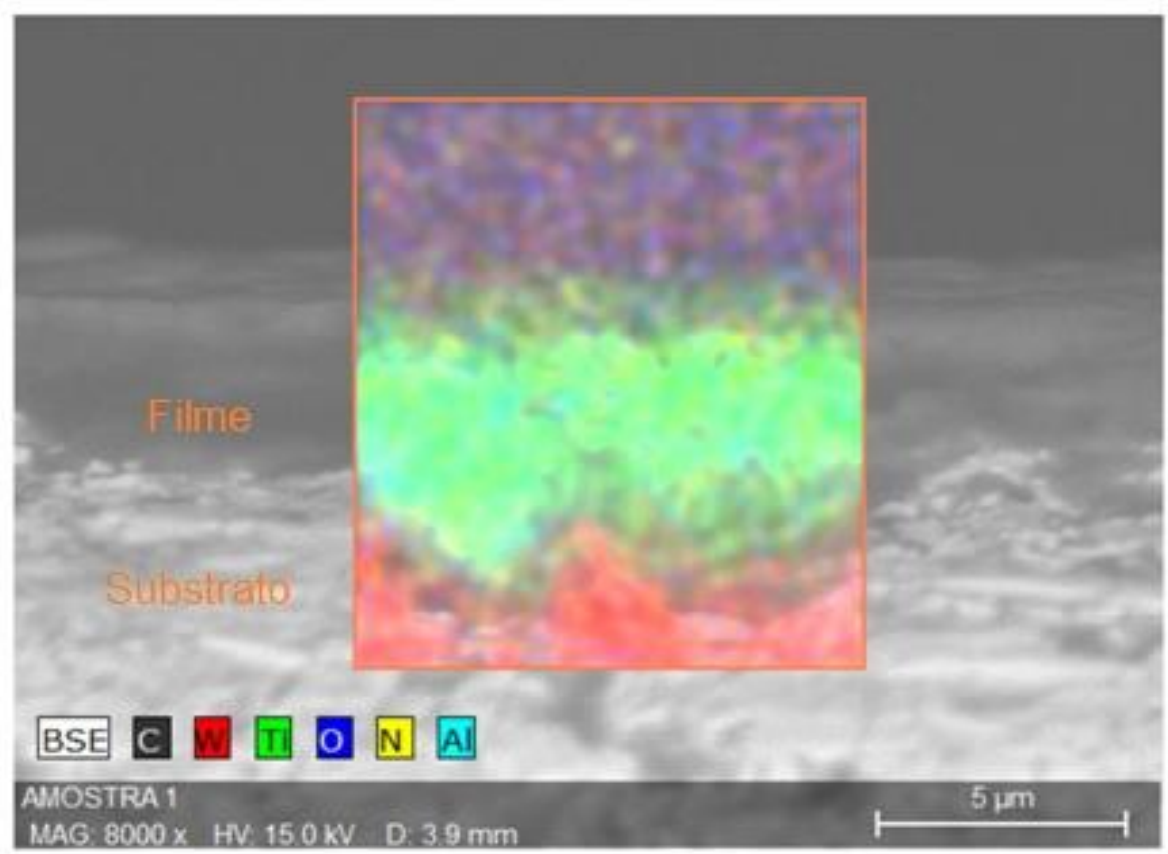

FIGURA 35 - Análise da espessura do filme de TiN.

Na FIGURA 36 é possível ver um mapa da superfície do filme gerado no perfilômetro óptico, sendo a rugosidade média $(\mathrm{Ra})$ de 0,2 $\mu \mathrm{m}$ e a rugosidade total (Rt - diferença entre o ponto mais alto e o mais baixo identificado) de 1,5 $\mu \mathrm{m}$. 


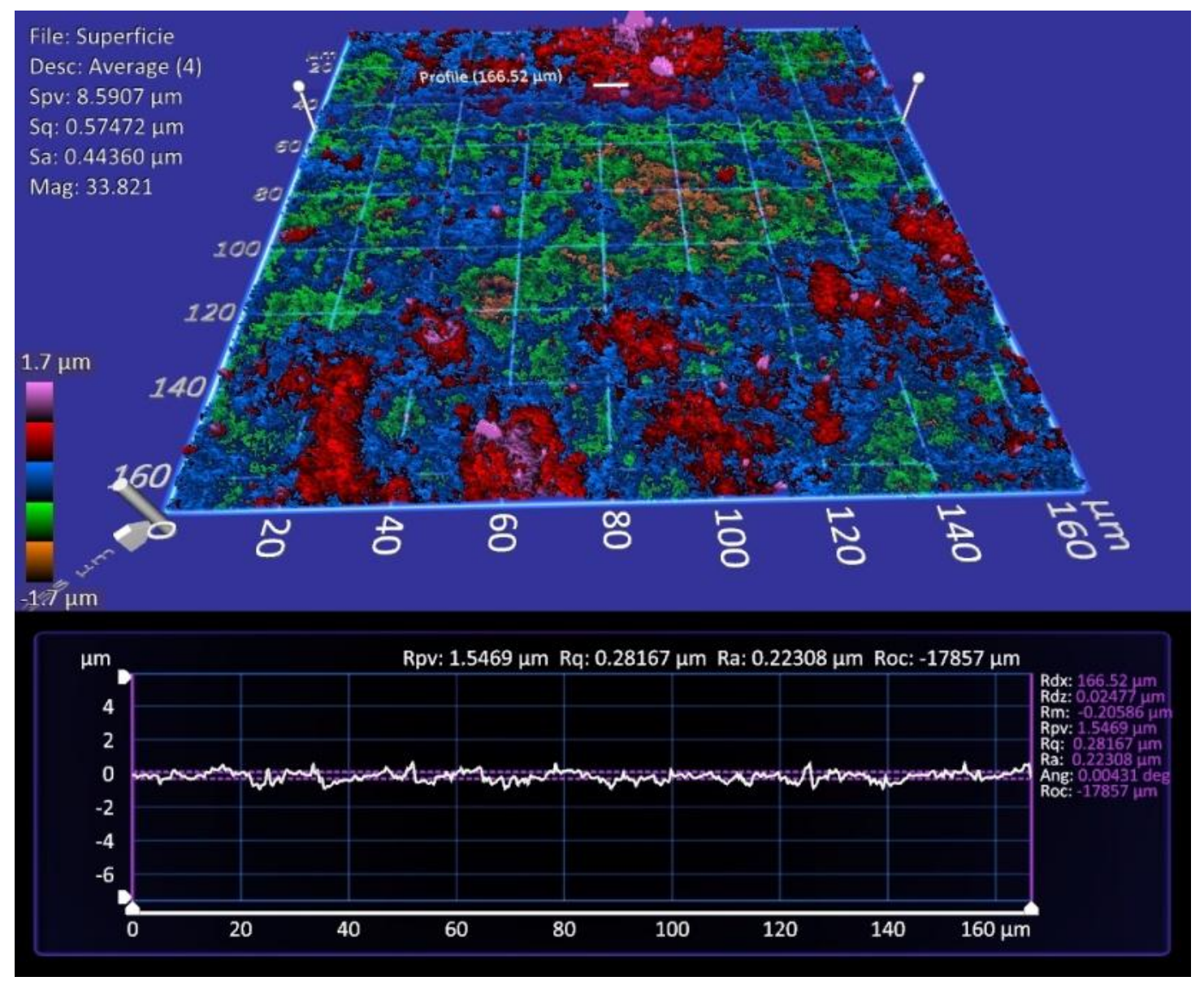

FIGURA 36 - Mapa de rugosidade da superfície da pastilha de usinagem.

\subsection{Limiar de ablação do filme de TiAIN}

Na FIGURA 37 são apresentados os perfis dos 24 traços ablacionados para determinação do limiar de ablação do filme pelo método D-Scan.

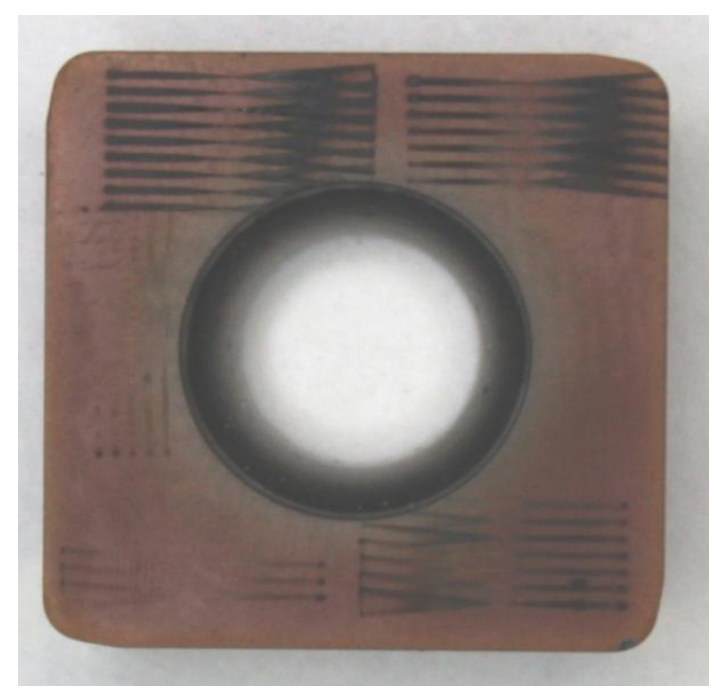

FIGURA 37 - Perfis gravados na pastilha de usinagem pelo método D-Scan, para determinação do limiar de ablação do filme de TiAIN. 
Na FIGURA 38 é possível observar uma montagem das imagens obtidas dos onze primeiros traços gravados, organizados em ordem decrescente de sobreposição de pulsos, variando de $\mathrm{N}=4913$ à $\mathrm{N}=8$, conforme velocidades de varredura pré-determinadas no equipamento, único parâmetro variado no processo.

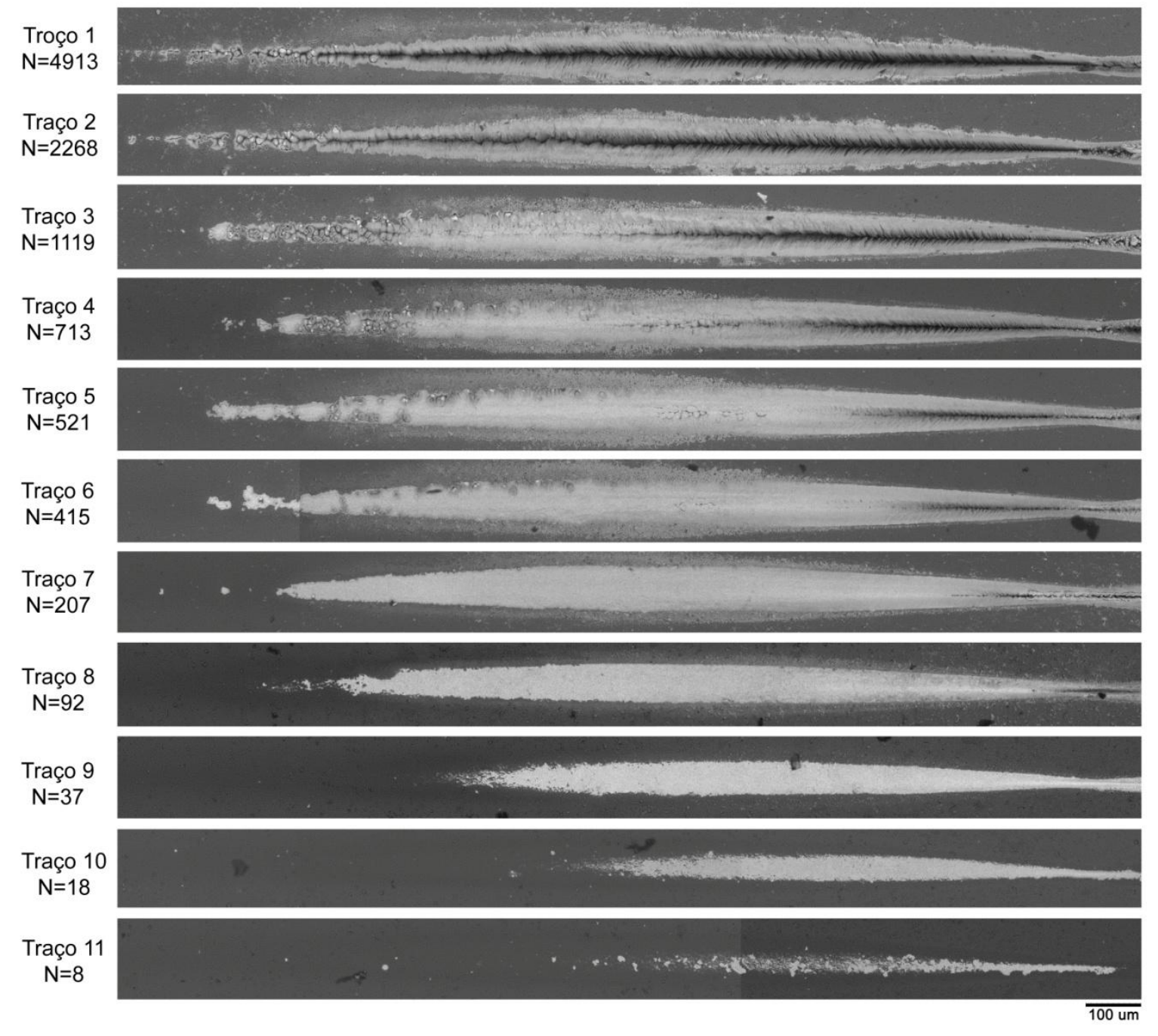

FIGURA 38 - Onze primeiros traços gravados no D-Scan para determinação do limiar de ablação do filme de TiAIN.

Na FIGURA 39 pode-se observar a ampliação do traço 9, gravado com sobreposição de 37 pulsos, e o detalhe da região de maior largura. Este traço foi escolhido pela boa definição da imagem e das bordas bem definidas. 


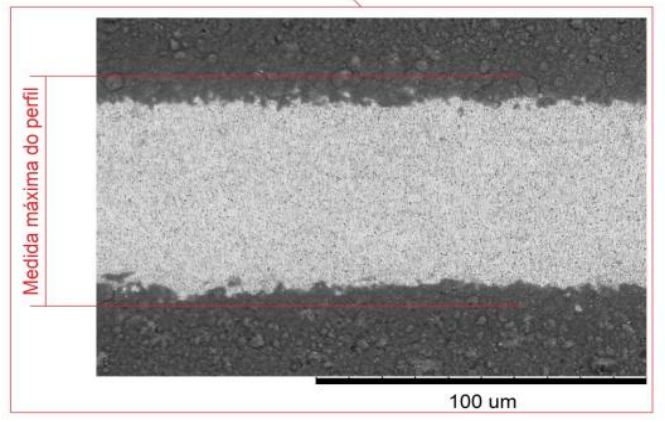

FIGURA 39 - Perfil do traço 9 gravado na superfície da pastilha para determinação do limiar de ablação pelo método D-Scan. No detalhe, região da largura máxima do perfil.

Na FIGURA 40 tem-se um modelo da variação de profundidade do traço 9 gravado para o D-Scan, onde é possível avaliar a profundidade atingida durante a varredura diagonal.

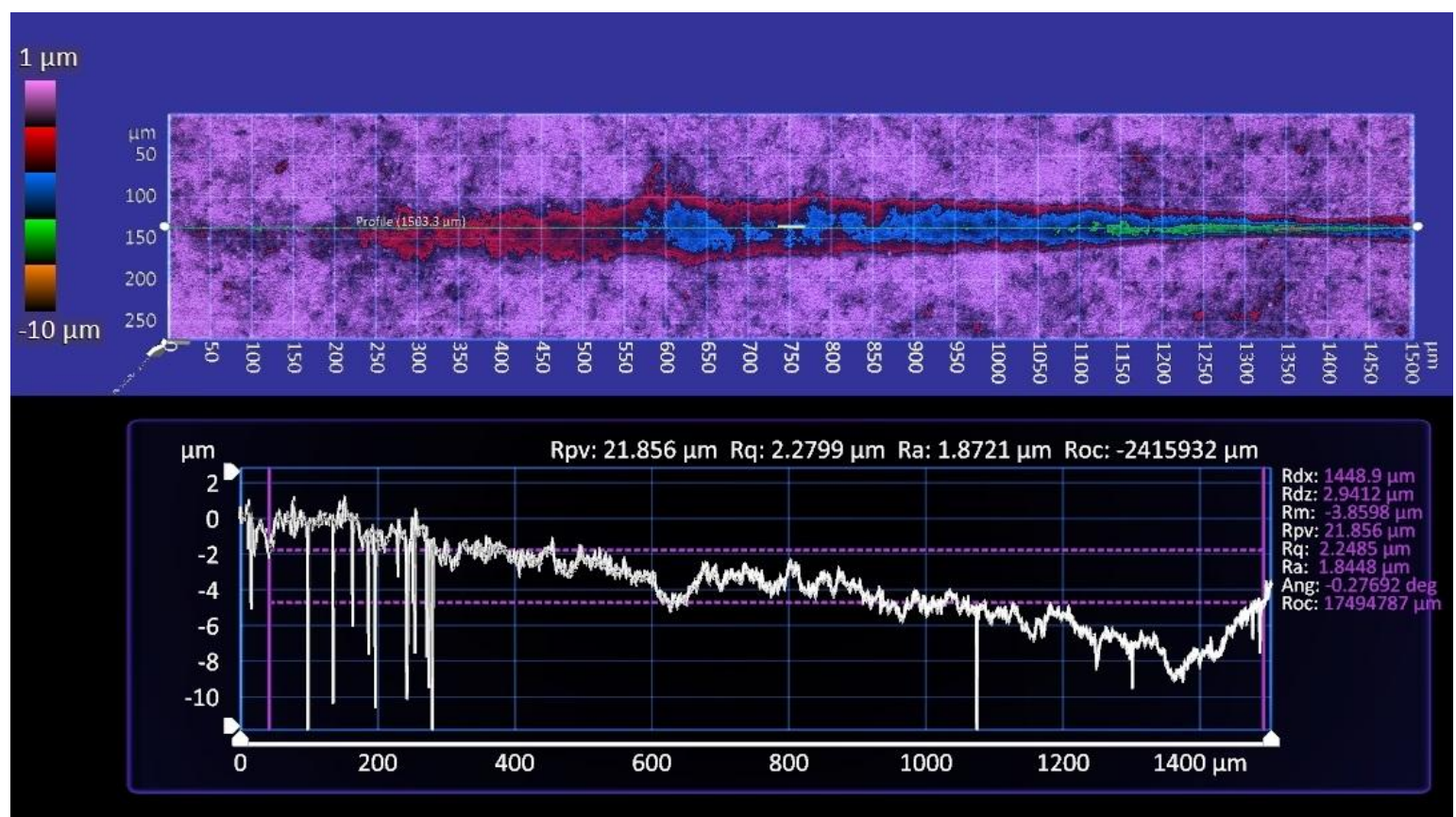

FIGURA 40 - Acima, vista frontal com escala de profundidade do traço 9 ablacionado para realização do D-Scan no filme de TiAIN. Abaixo, secção longitudinal no centro do traço.

Analisando o gráfico da FIGURA 41, tem-se que o limiar de ablação para $\mathrm{N}=1$ e para $\mathrm{N}=5000$ do filme de TiAIN é de aproximadamente $1,23 \mathrm{~J} / \mathrm{cm}^{2}$ 
e $0,48 \mathrm{~J} / \mathrm{cm}^{2}$ respectivamente, ajustando-se ao modelo de incubação referente à materiais metálicos.

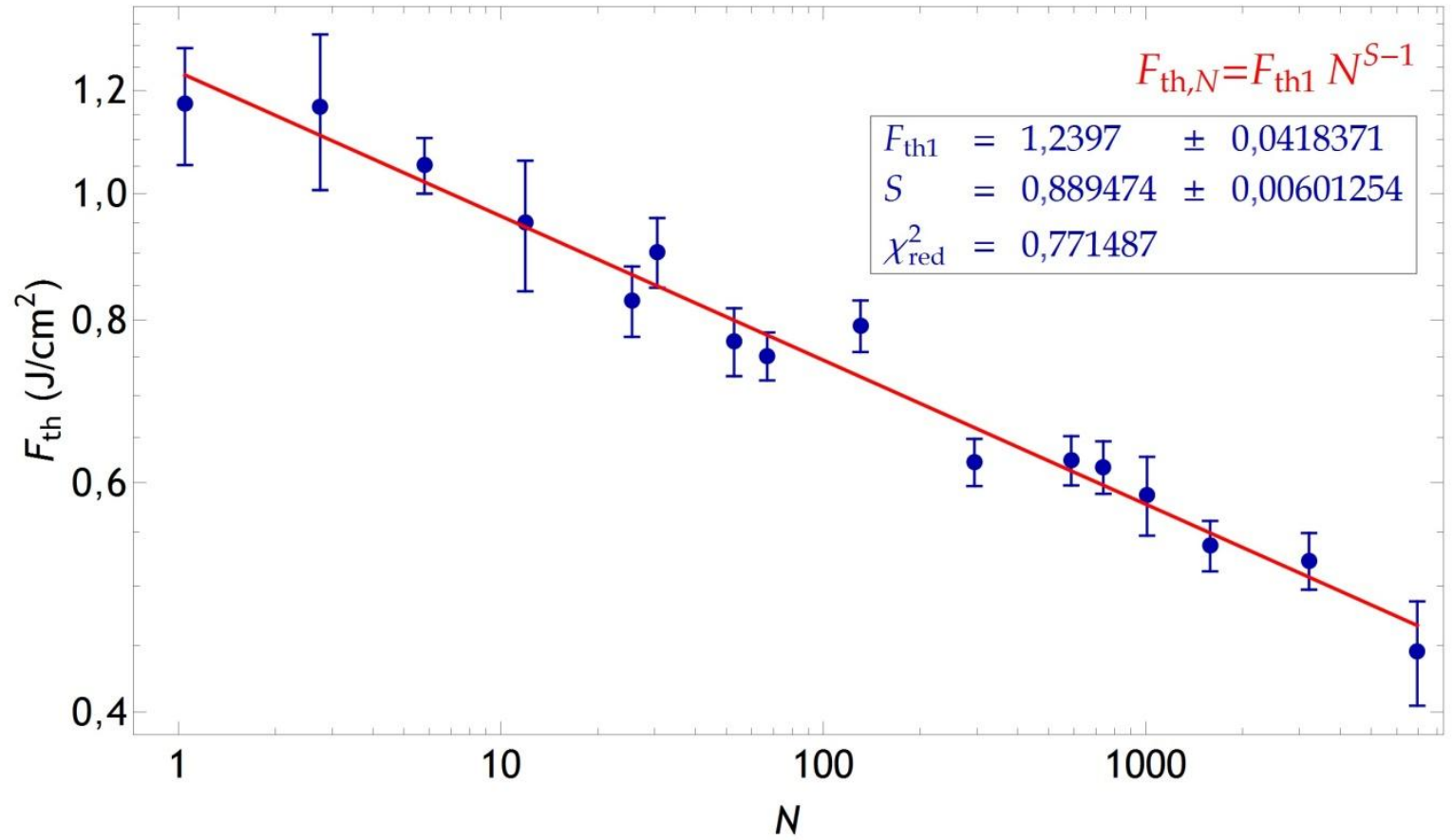

FIGURA 41 - Gráfico do limiar de ablação em função da sobreposição de pulsos para o filme de TiAIN, obtido pelo método de D-Scan.

\subsection{Limiar de ablação do substrato de WC-Co}

Na FIGURA 42 são apresentados os perfis gravados no substrato para determinação de seu limiar de ablação pelo método D-Scan.

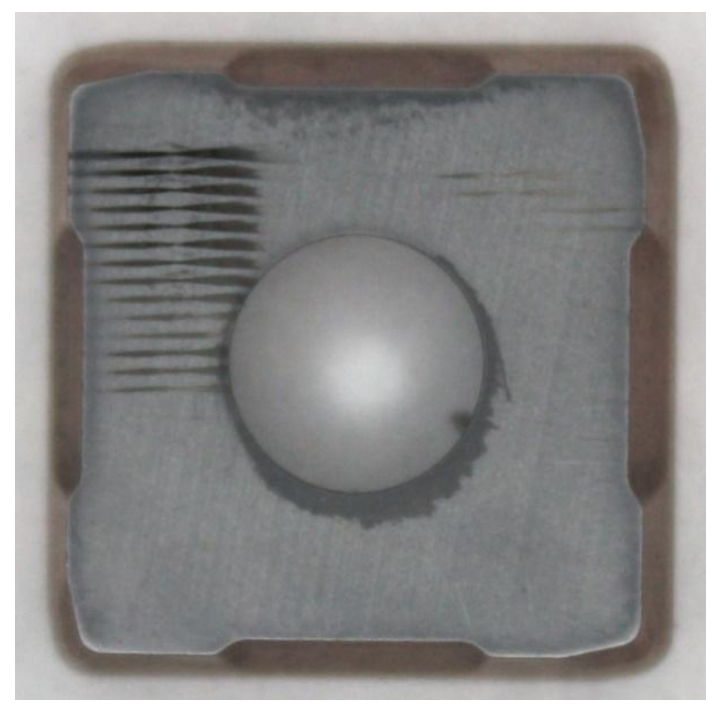

FIGURA 42 - Perfis gravados no substrato da pastilha quadrada pelo método DScan para determinação do limiar de ablação. 
Na FIGURA 43 é possível ver a ampliação do traço 13, gravado com sobreposição de 32 pulsos, e o detalhe da região de maior largura. Este traço foi escolhido pela boa definição da imagem e das bordas bem definidas.

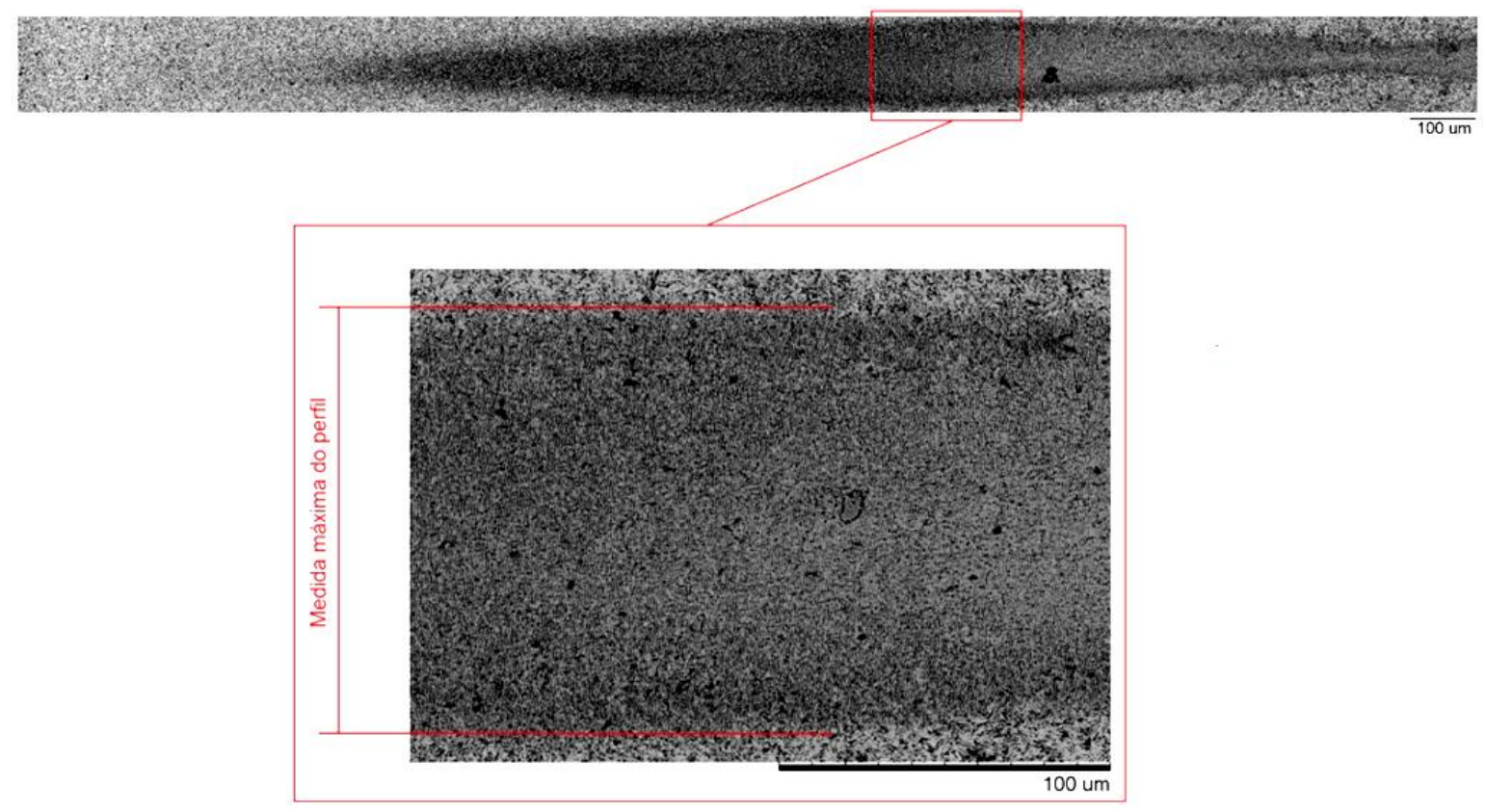

FIGURA 43 - Perfil do traço 13 gravado na superfície da pastilha para determinação do limiar de ablação pelo método D-Scan. No detalhe, região de largura máxima do perfil.

Analisando-se o gráfico da FIGURA 44, tem-se que o limiar de ablação para $\mathrm{N}=1$ e para $\mathrm{N}=5000$ do substrato é de aproximadamente $0,66 \mathrm{~J} / \mathrm{cm}^{2} \mathrm{e}$ $0,24 \mathrm{~J} / \mathrm{cm}^{2}$ respectivamente, ajustando-se ao modelo de incubação referente à materiais dielétricos. 


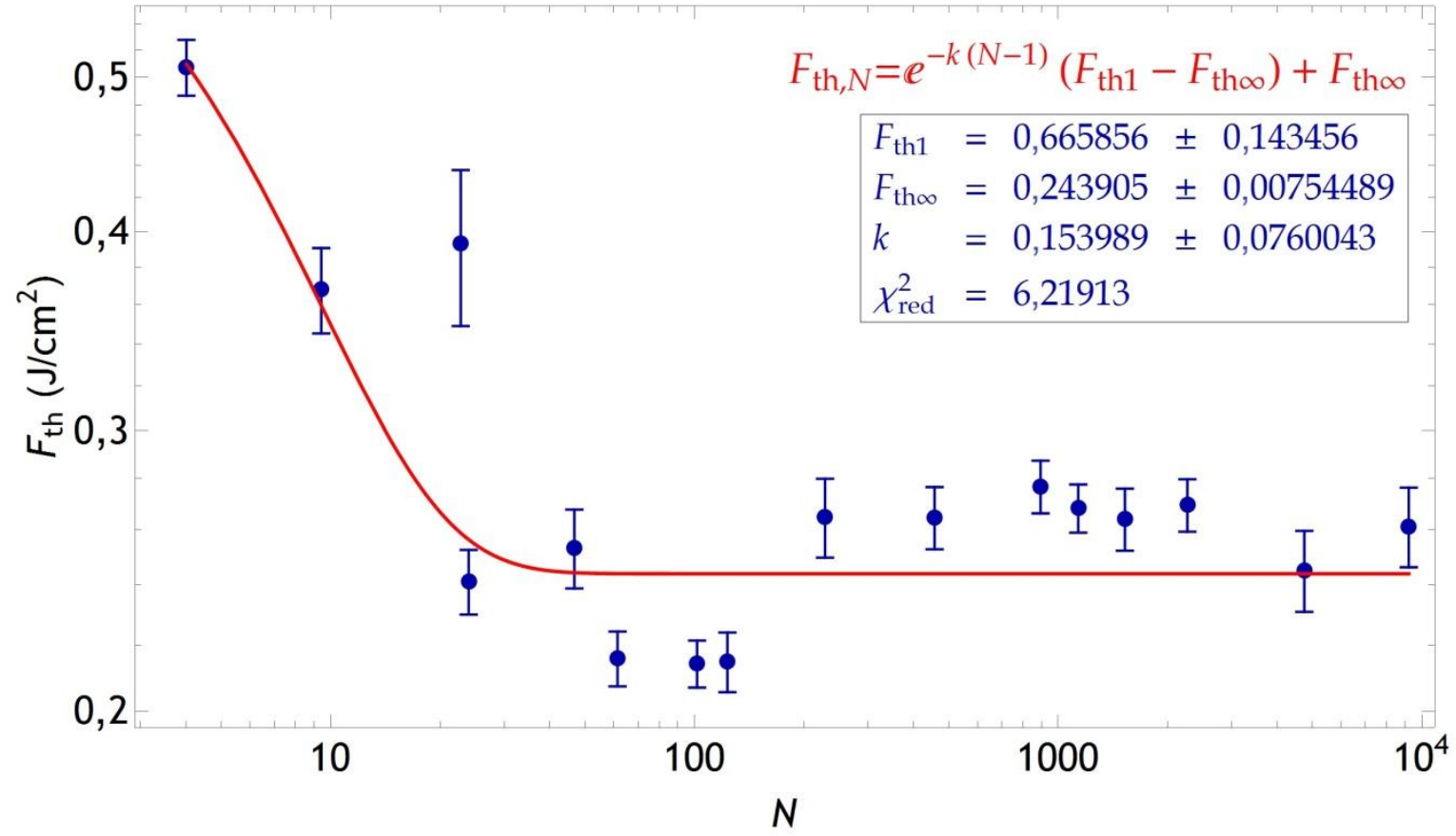

FIGURA 44 - Gráfico do limiar de ablação em função da sobreposição de pulsos para o substrato de WC, obtido pelo método de D-Scan.

\subsection{Ablação por meio de baixa fluência no filme de TiN}

$\mathrm{Na}$ FIGURA 45 tem-se uma imagem dos canais ablacionados com $0,6 \mathrm{~J} / \mathrm{cm}^{2}$ para o teste de ablação no regime de baixa fluência do filme, variando a sobreposição de pulsos de um traço para outro.

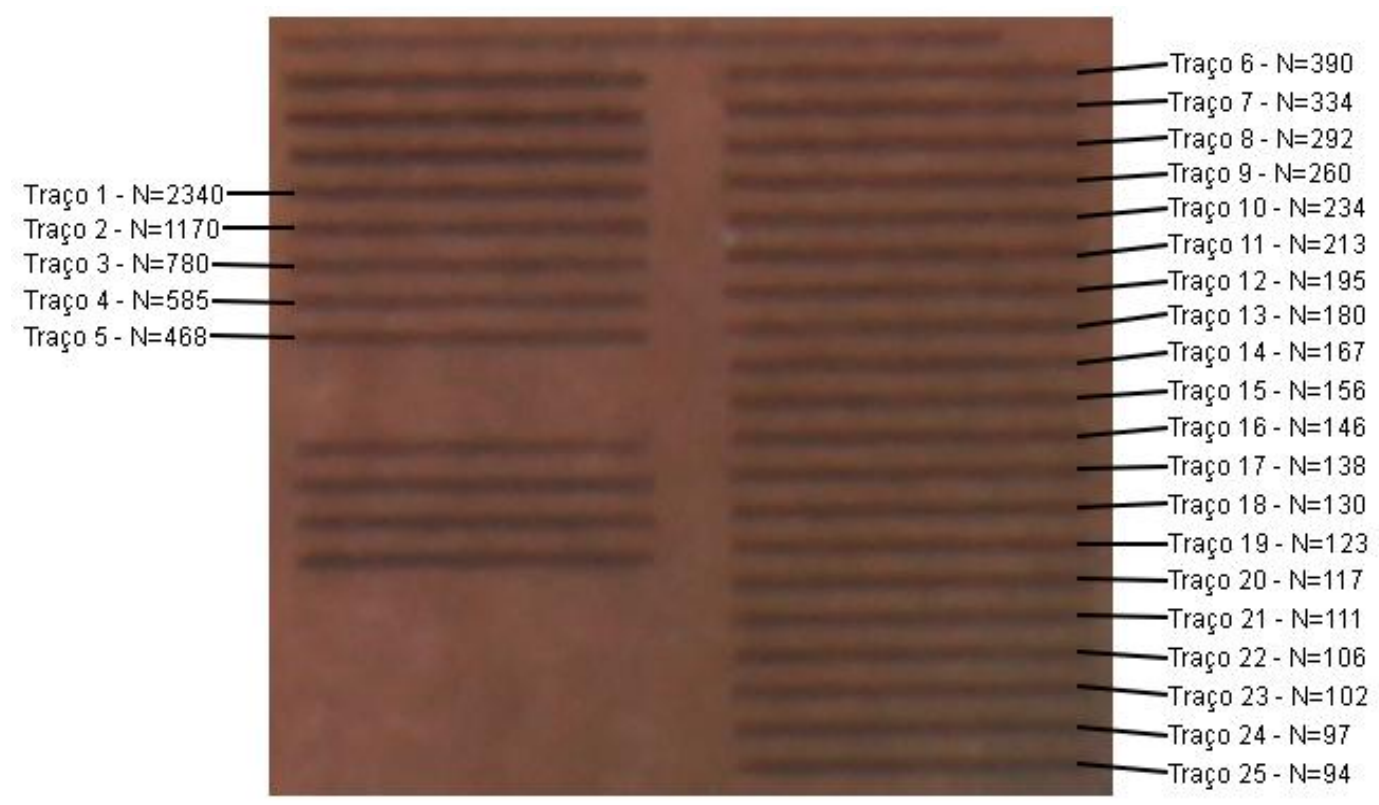

FIGURA 45 - Traços gravados para teste de ablação com fluência próxima à de limiar do filme de TiAIN. 
Na FIGURA 46 é possível ver uma imagem gerada no MEV do traço 21, gravado com sobreposição de pulsos de $N=111$, onde pode-se perceber com clareza o percurso de varredura do laser, linha vermelha, e a região onde foi realizada a análise EDS para identificação dos elementos presentes, linha amarela. $\mathrm{Na}$ imagem as superfícies mais escuras referem-se ao filme de TiAIN, enquanto que as partes mais claras são referentes ao substrato de WC-Co.

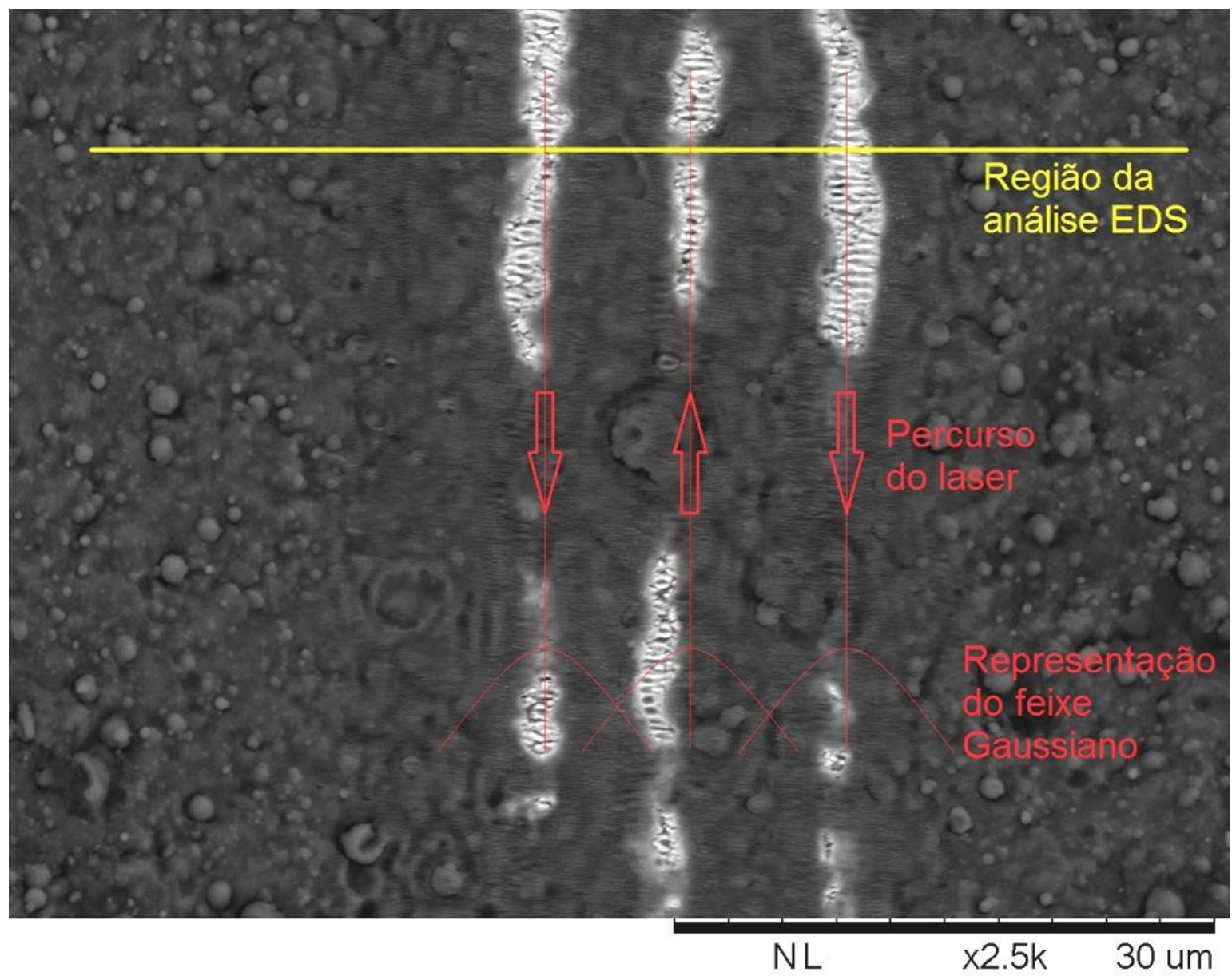

FIGURA 46 - Imagem do traço 21 com indicação do percurso do laser, linha vermelha, e da região transversal ao traço onde foi realizada uma análise por EDS, linha amarela.

Na FIGURA 47 apresenta-se a análise EDS do traço 21, onde foi possível verificar que no centro do feixe, onde se concentrou a maior parte da energia na propagação Gaussiana, houve uma redução brusca nas quantidades de Ti, Al e $\mathrm{N}$ que são os principais componentes do filme, linhas azul e verde, enquanto que a presença de $\mathrm{W}$ aumentou, linha rosa, indicando que o filme foi totalmente removido deixando o substrato exposto. 


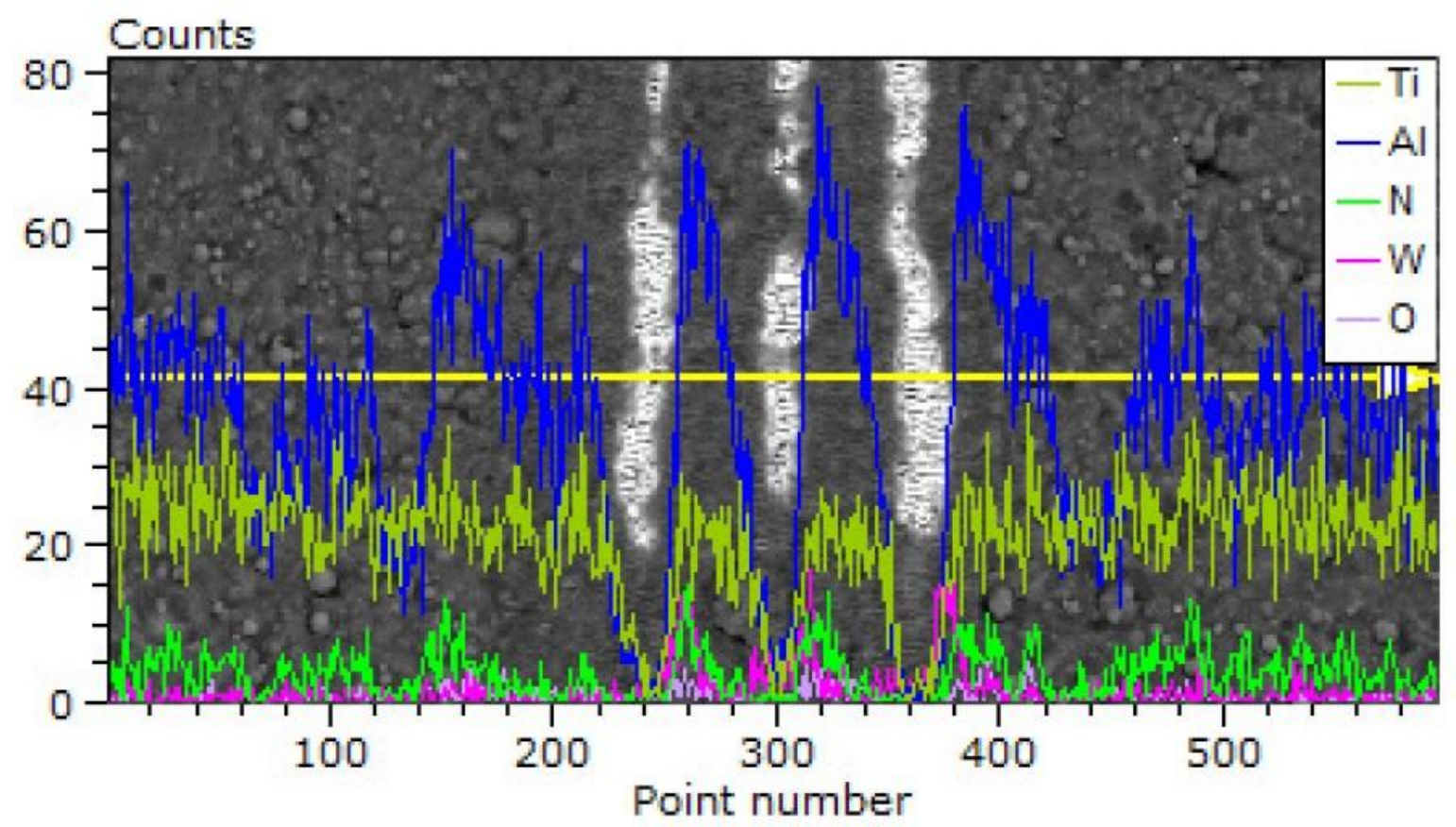

FIGURA 47 - Detalhe da análise EDS realizada no traço 21, onde é possível identificar a redução dos componentes do filme na região de varredura do laser.

A FIGURA 48 apresenta as imagens geradas no MEV dos canais 1, 5, $10,15,20$, e 25 , para que se pudesse ter uma ideia da evolução do perfil em função da variação da quantidade de pulsos sobrepostos. Cada traço encontra-se na vertical no centro de cada quadro, onde é possível verificar que o $\mathrm{W}$, partes mais claras, não está visível em todos os traços, principalmente naqueles gravados com maior sobreposição de pulsos onde esperava-se maior remoção de material.

Observando-se ainda a FIGURA 48, pode-se perceber que a remoção do filme não mostrou-se uniforme num mesmo traço, variando numa mesma passagem do feixe entre regiões claras (substrato de WC-Co) e escuras (filme de TiAIN). Uma explicação para tal comportamento seria uma possível falta de uniformidade do filme que, caso fosse mais fino ou mesmo absorvesse melhor o comprimento de onda do laser em determinadas regiões, ocasionaria uma variação no perfil dos canais ablacionados. 

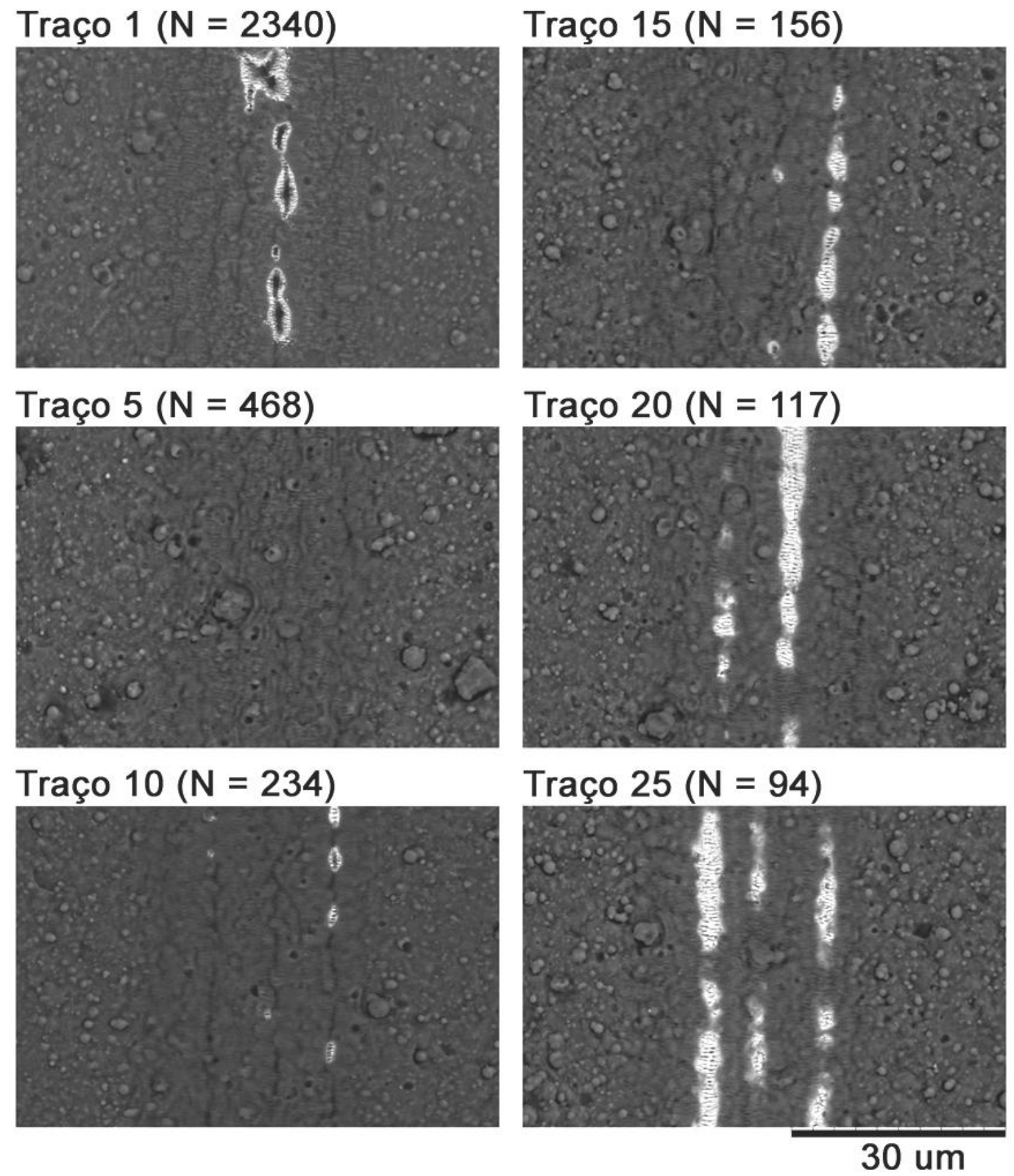

FIGURA 48 - Imagens geradas no MEV dos canais ablacionados em função da variação da sobreposição de pulsos.

Na FIGURA 49 é apresentada uma imagem do canal 21, onde é possível verificar o perfil gerado pelo feixe durante a varredura além de estimar a profundidade do canal. 


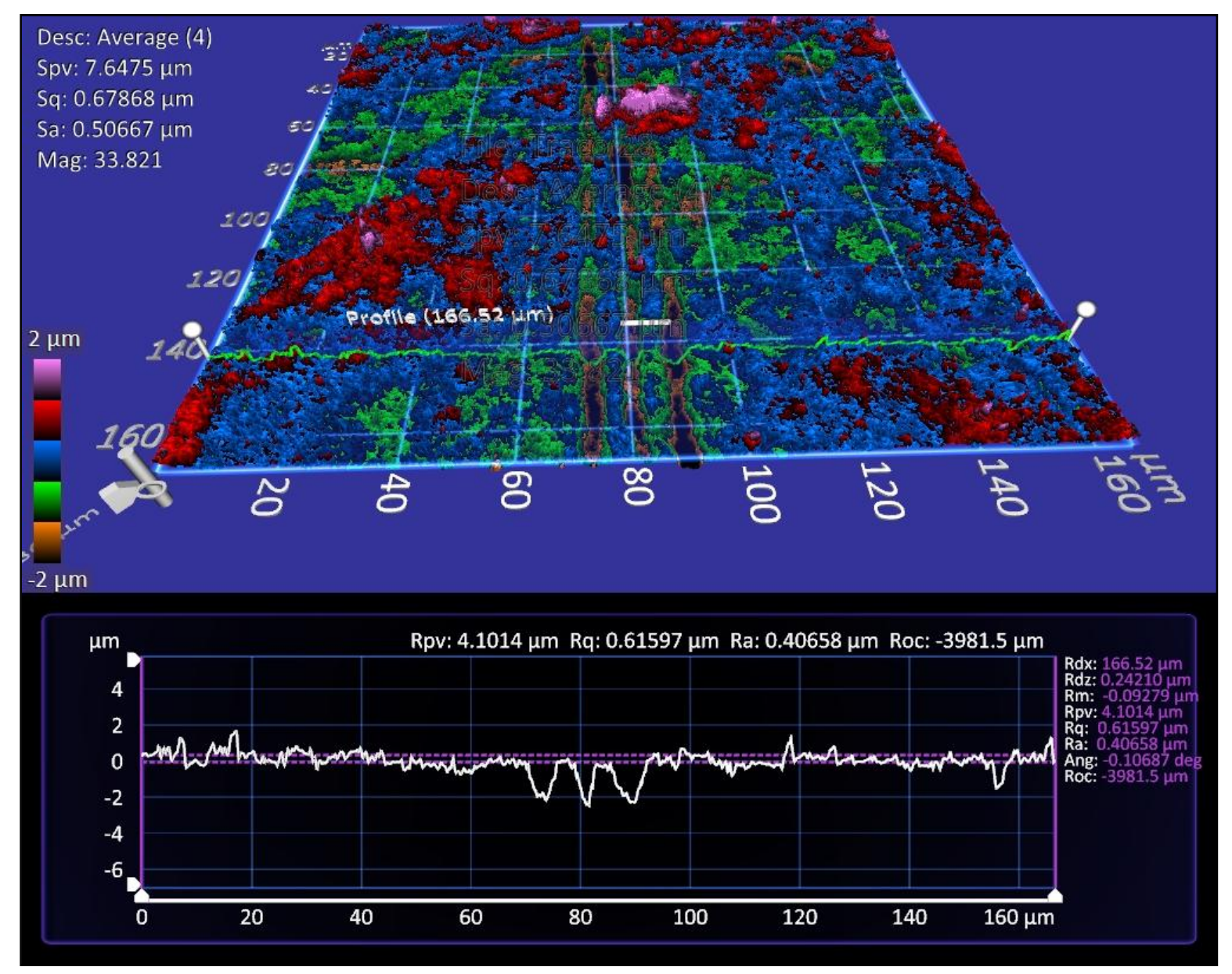

FIGURA 49 - Perfil gerado no perfilômetro óptico referente ao traço 21 ablacionado com fluência por pulso de $0,6 \mathrm{~J} / \mathrm{cm} 2$ e sobreposição de $\mathrm{N}=111$. Imagem 3D da superfície (acima), e seção transversal do traço com o perfil de profundidades (abaixo).

Analisando a FIGURA 47 é possível confirmar que houve maior remoção de material no centro do feixe, fato que indica ser necessário rever os parâmetros utilizados para se conseguir uma superfície de varredura mais uniforme.

No gráfico da FIGURA 50 pode-se verificar a profundidade estimada de cada um dos canais ablacionados no filme, aproximadas após análise das imagens geradas no perfilômetro óptico. 


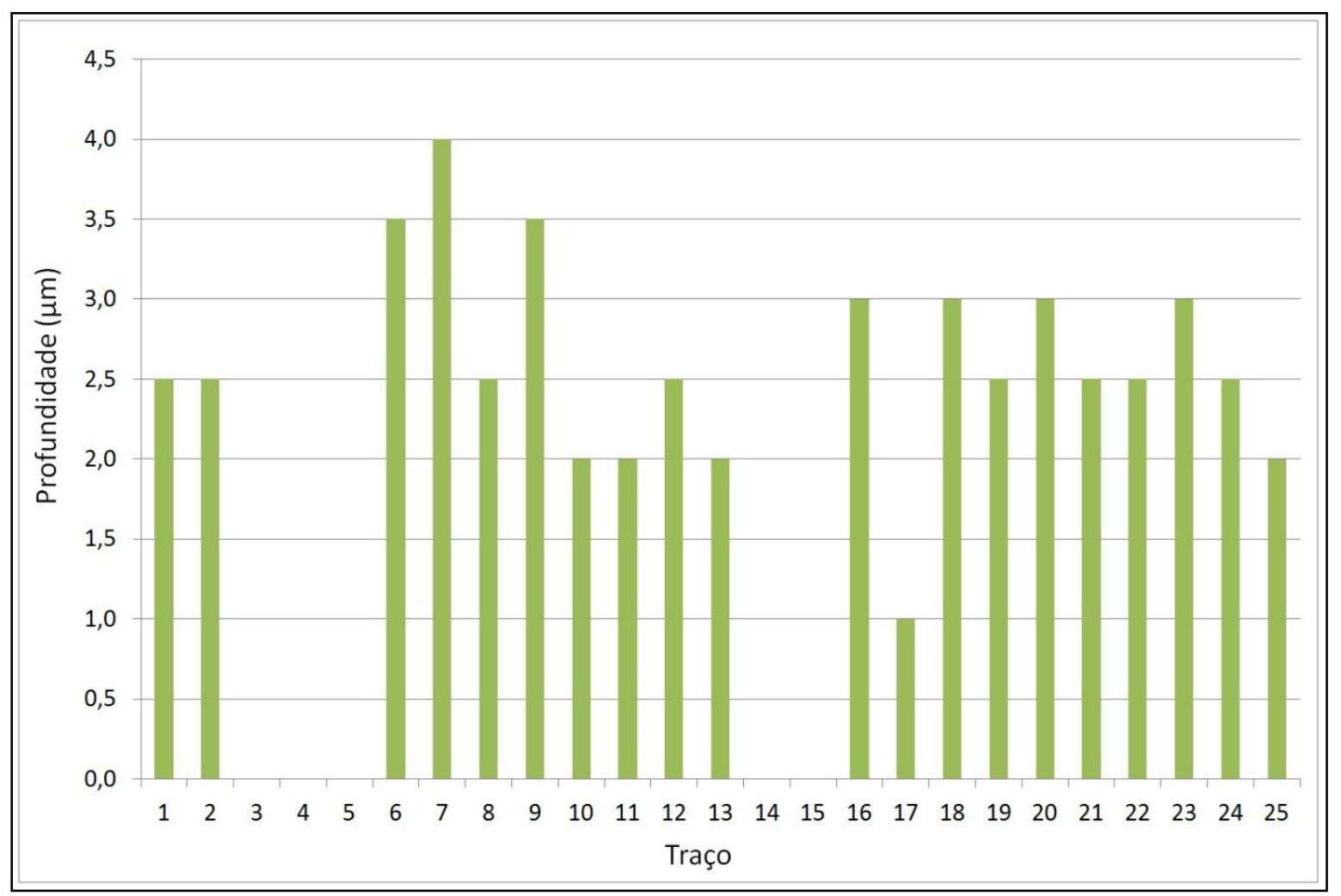

FIGURA 50 - Gráfico das profundidades em cada um dos 25 canais ablacionados no filme de TiAIN, com sobreposição de pulsos variando de $\mathrm{N}=2340$ (traço 1) até $\mathrm{N}=94$ (traço 25).

Com exceção dos canais $3,4,5,14$ e 15, onde foi identificada a formação isolada de LIPSS porém não verificou-se uma profundidade mensurável do traço, todos os demais canais apresentaram profundidades variando de 1 à $4 \mu \mathrm{m}$. Tanto a variação das profundidades quanto os traços que não chegaram a um perfil mensurável, podem ser decorrentes de diversos fatores envolvidos na realização dos testes, porém acreditou-se que a fator mais impactante para essa condição foi a falta de homogeneidade do filme, indicada pela visualização do substrato em traços com diferentes profundidades.

Considerando uma profundidade média de $2 \mu \mathrm{m}$, cerca de $40 \%$ da espessura do filme, pode-se assumir que a fluência utilizada para o processo foi suficiente para desencadear a remoção gradativa do filme, sendo necessária a análise e ajustes de outros parâmetros para se conseguir uma superfície de varredura plana e uniforme.

Apesar da variação da quantidade de pulsos sobrepostos, não percebeu-se grandes mudanças nos perfis gravados, o que pode ser atribuído ao fato de que a variação na sobreposição dos pulsos não foi suficiente para que os 
efeitos de incubação provocassem mudanças consideráveis no limiar de ablação do filme. Tal conclusão levou à realização de um novo teste utilizando maior sobreposição, a fim de avaliar a quantidade de pulsos necessária para desencadear efeitos de incubação suficientes para promover a redução do limiar de ablação do filme.

\subsection{Teste de redução do limiar de ablação do filme de TiN a partir dos efeitos de incubação}

$\mathrm{Na}$ FIGURA 51 tem-se a imagem dos traços gravados com fluência de $0,3 \mathrm{~J} / \mathrm{cm}^{2}$ e alta sobreposição de pulsos.

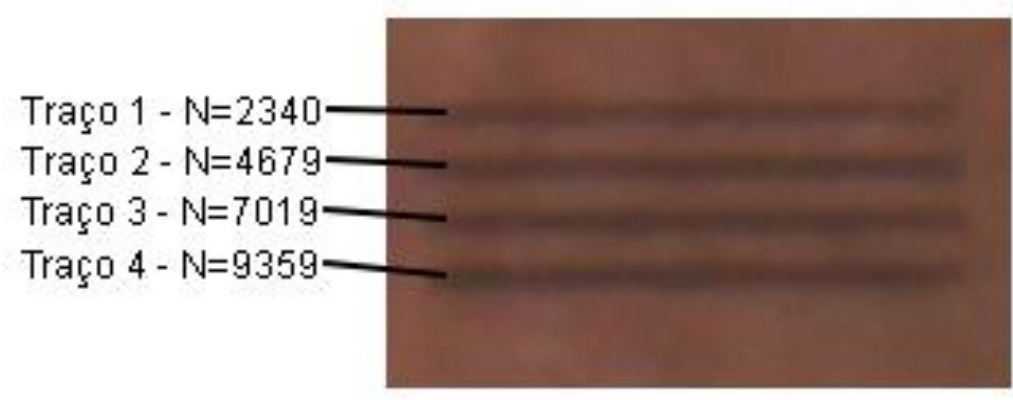

FIGURA 51 - Traços gravados utilizando fluência abaixo do limiar de ablação do substrato, portando muito abaixo do limiar do filme, porém com alta sobreposição de pulsos.

Na FIGURA 52 são apresentados os detalhes vistos no MEV de cada um dos traços, onde percebe-se pouca evolução das estruturas geradas pelo laser conforme o aumento da quantidade de pulsos sobrepostos. 
Traço $1(\mathrm{~N}=2340)$

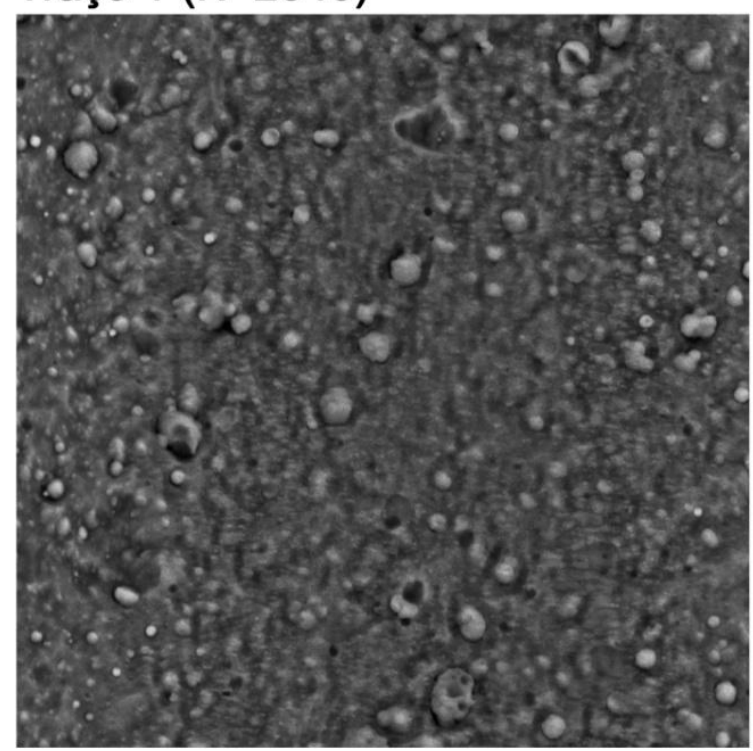

Traço $2(\mathrm{~N}=4679)$

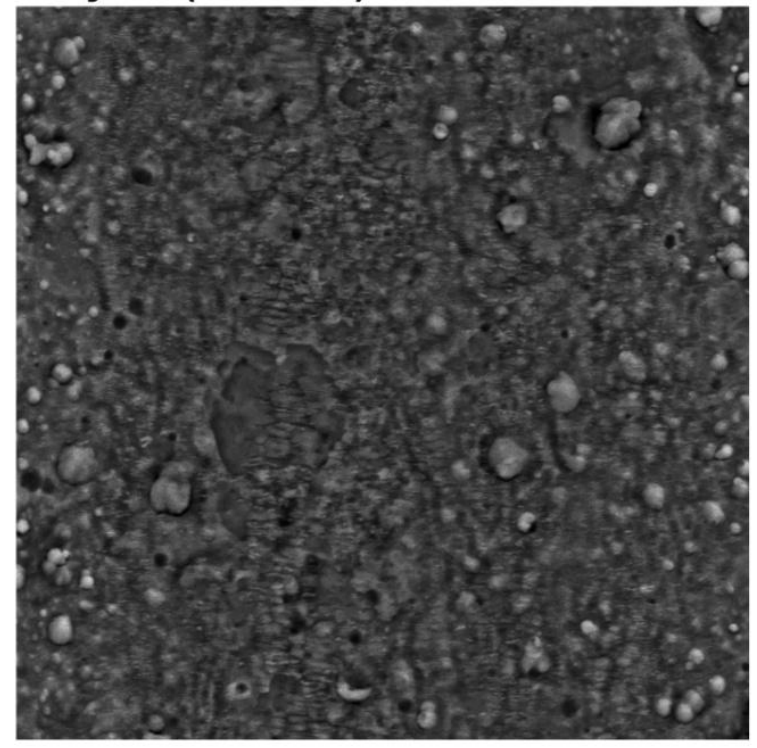

Traço $3(\mathrm{~N}=7019)$

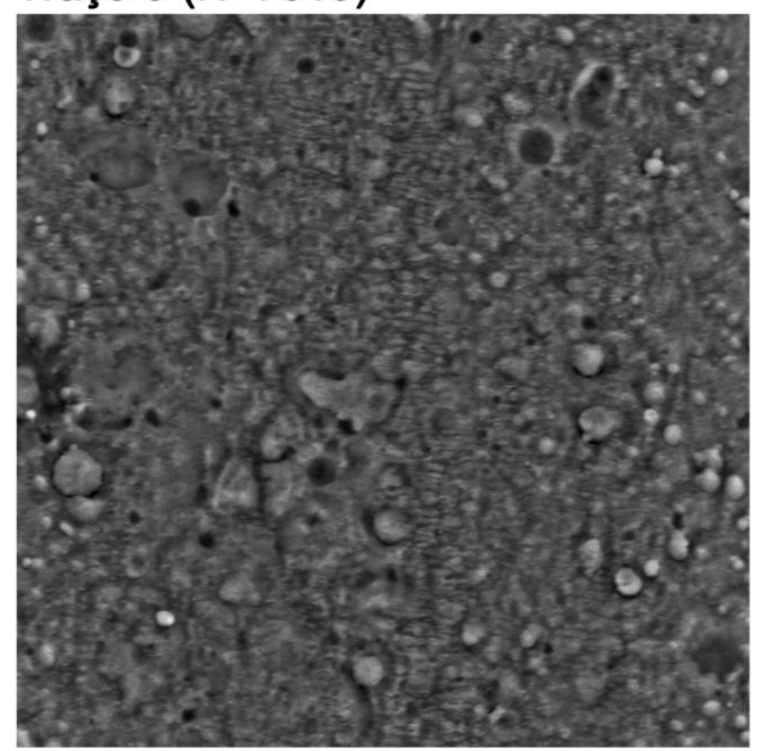

Traço $4(\mathrm{~N}=9359)$

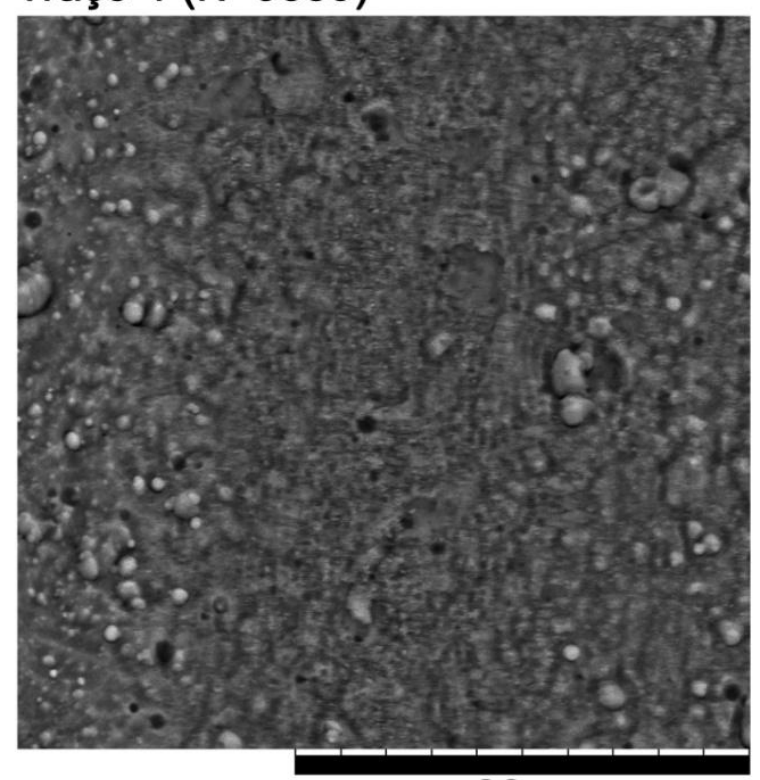

30 um

FIGURA 52 - Traços para teste de ablação com alta sobreposição de pulsos.

No perfilômetro óptico não foi possível detectar alterações na superfície, ficando claro que as estruturas que se pôde observar nas imagens, mais aparentes no traço 4, são LIPSS muito superficiais, não chegando a evoluir para remoção de material, ou tratando-se apenas de alterações nanométricas que não puderam ser detectadas pelo equipamento.

Por ter sido utilizada uma fluência muito abaixo do limiar do filme, $0,3 \mathrm{~J} / \mathrm{cm}^{2}$, possivelmente não houve energia suficiente para gerar os efeitos de incubação esperados e posterior redução do limiar de ablação. 
Com a sobreposição próxima de 10.000 pulsos efetuada no traço 4 , provavelmente atingiu-se a saturação dos efeitos de incubação, assim sendo, para que o processo de ablação evoluísse para efetiva remoção de material, seria necessário aumentar gradativamente a fluência do laser e repetir os testes até o ponto onde o filme pudesse ser efetivamente removido. 


\section{CONCLUSÕES}

A partir dos resultados obtidos nos traços realizados para remoção seletiva do filme de TiAIN, conclui-se que o presente trabalho não foi suficiente para estabelecer um processo confiável para realização de tal tarefa. No entanto, devido à quantidade de informações coletadas referentes ao processo de remoção do filme pelo laser, principalmente àquelas provenientes da análise dos traços ablacionados para determinação dos limiares de ablação pelo método DScan, foi possível vislumbrar novas estratégias que podem de fato, resultar num procedimento para realização da ablação seletiva proposta.

\subsection{Sugestões de trabalhos futuros}

Com base nos resultados presentes neste trabalho, a seguinte linha de investigação é sugerida:

- Redução do limiar de ablação de filme de TiAIN a partir da indução de efeitos de incubação provocados por alta taxa de sobreposição de pulsos laser ultracurtos com baixa fluência. 
APÊNDICE A - Traços gravados no filme de TiN para determinação do limiar de ablação pelo método D-Scan. Sobreposição decrescente de pulsos de cima para baixo, variando de $\mathrm{N}=4913$ à $\mathrm{N}=1$.

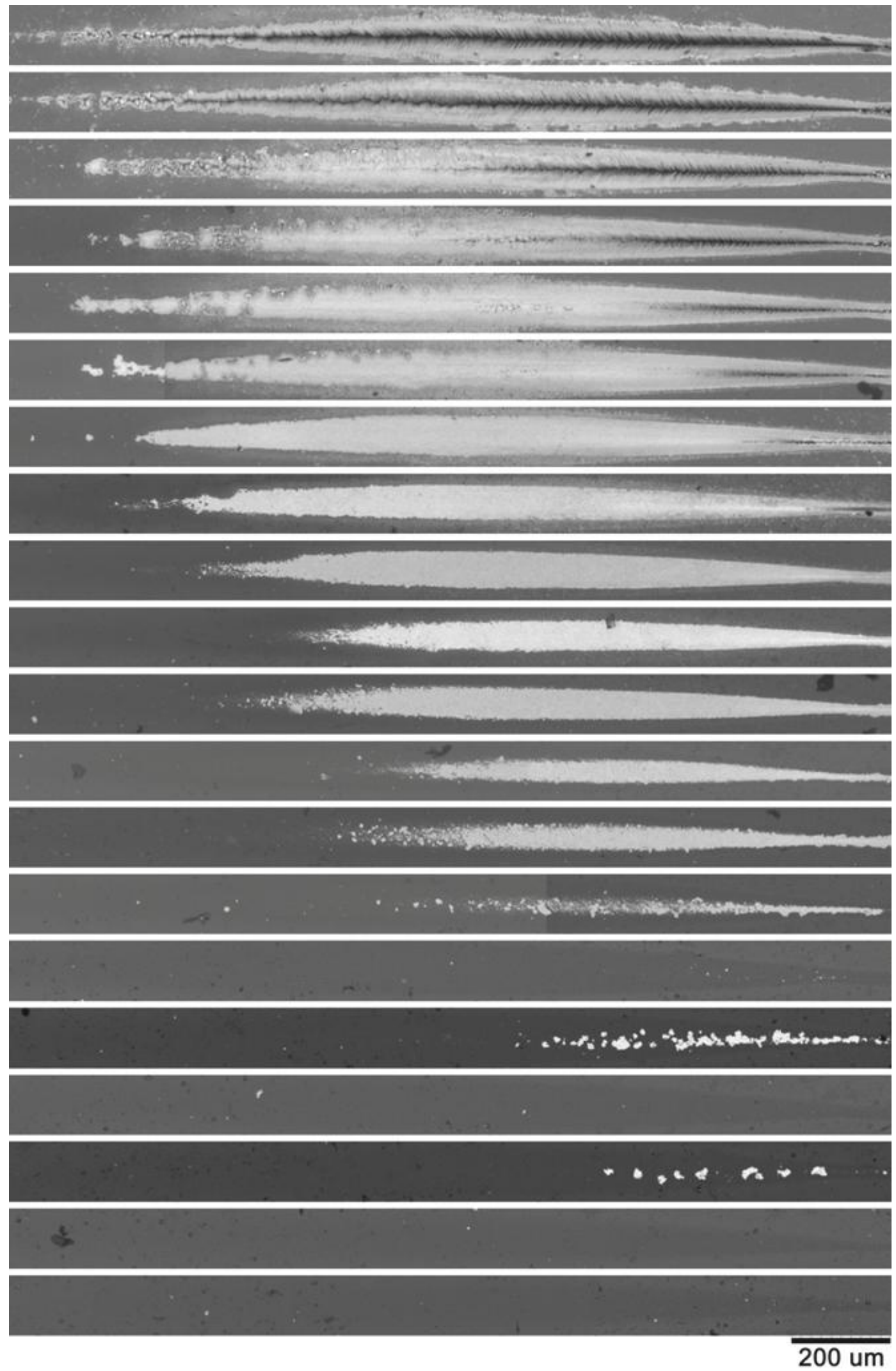


APÊNDICE B - Rebaixos ablacionados para teste do sistema de LIBS

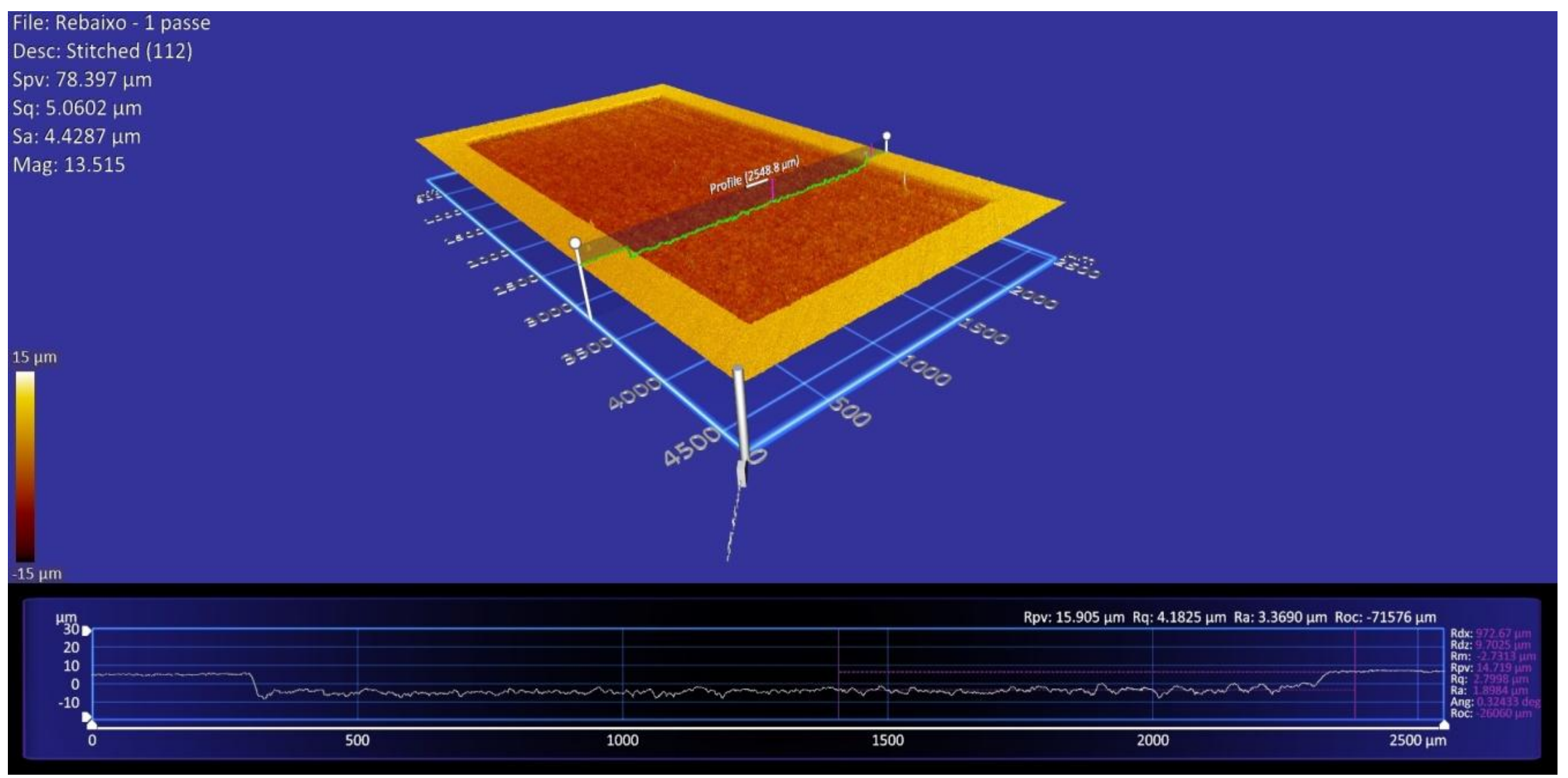

FIGURA 53 - Rebaixo ablacionado em 1 passe numa pastilha de usinagem para teste do sistema de LIBS. 


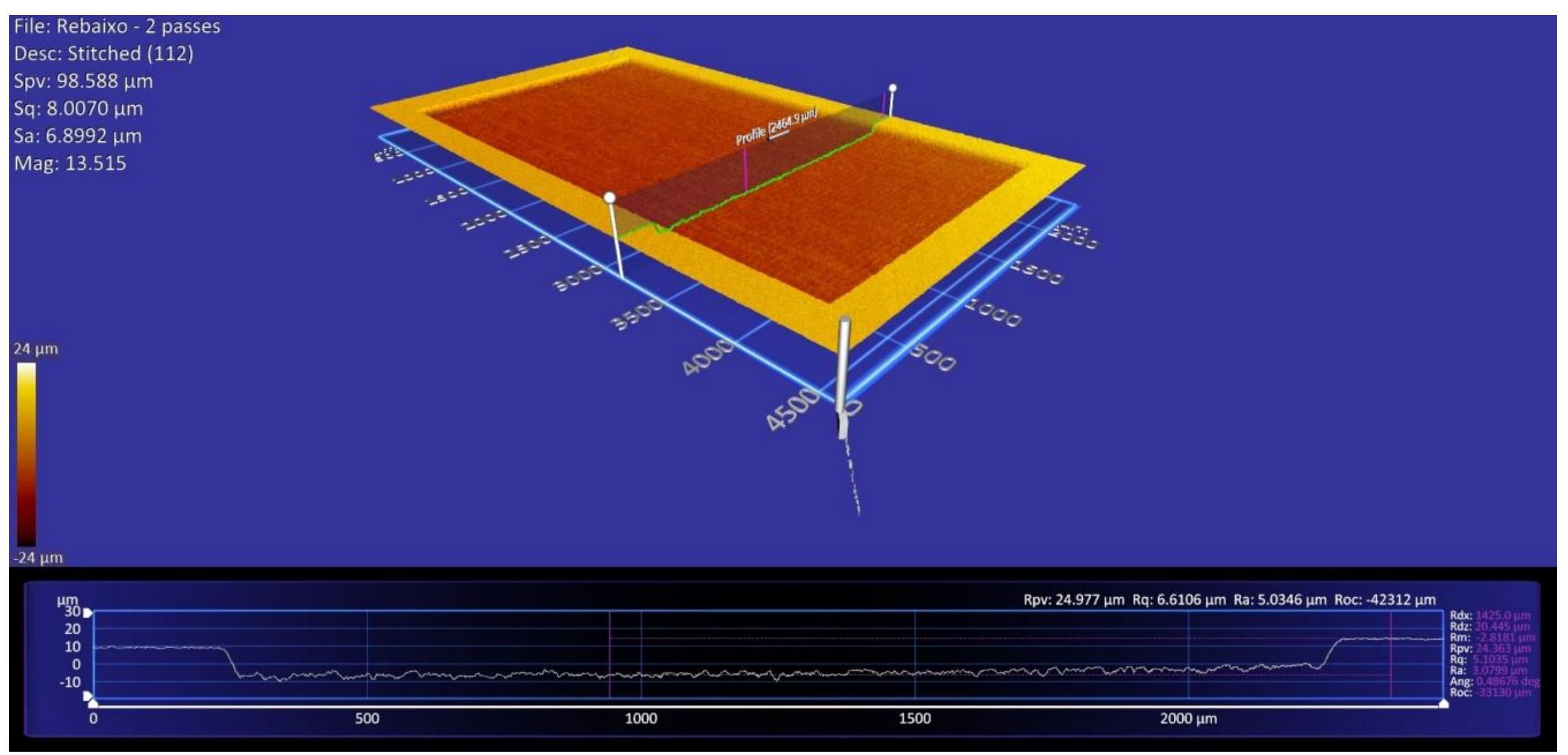

FIGURA 54 - Rebaixo ablacionado em dois passes numa pastilha de usinagem para teste do sistema de LIBS. 


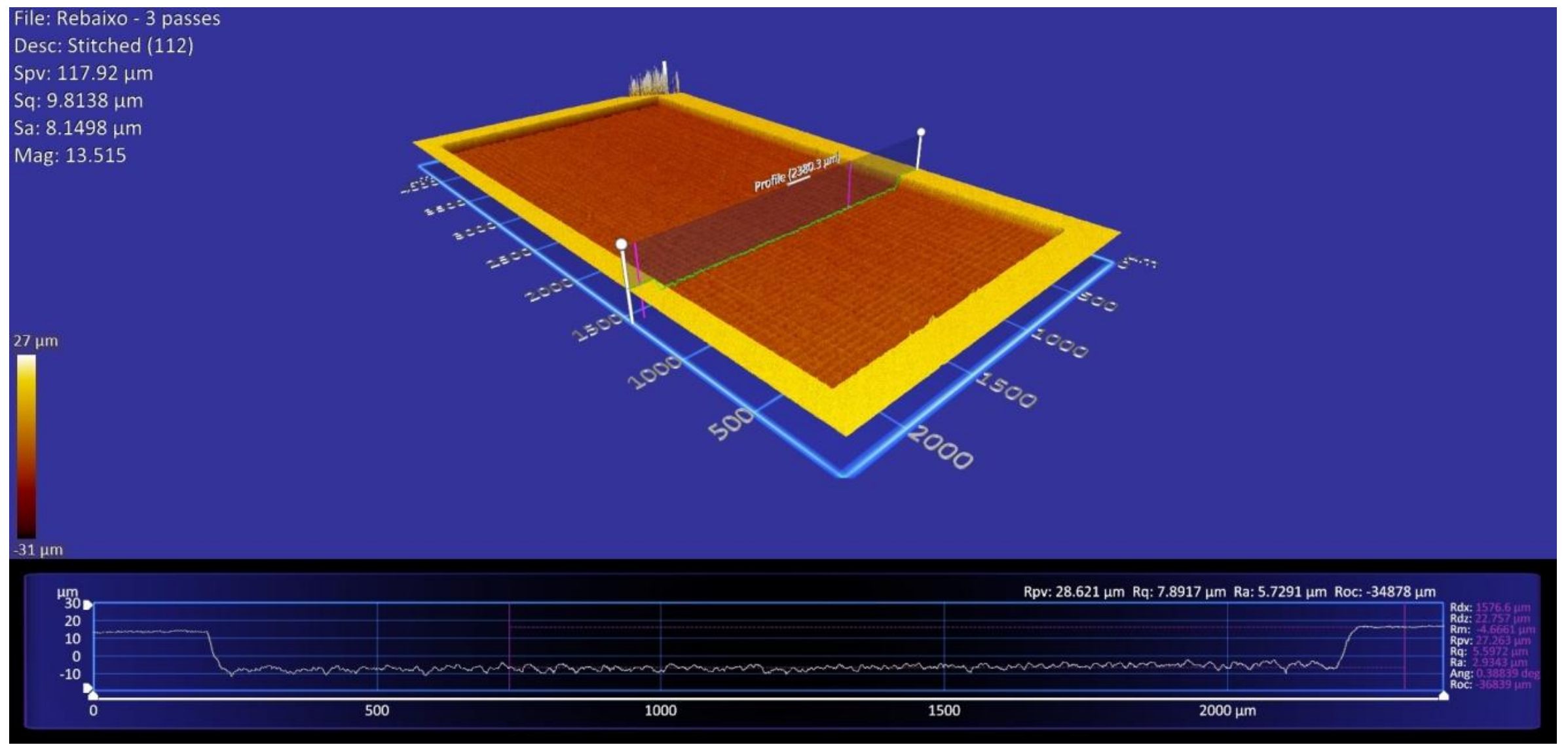

FIGURA 55 - Rebaixo ablacionado em três passes numa pastilha de usinagem para teste do sistema de LIBS. 


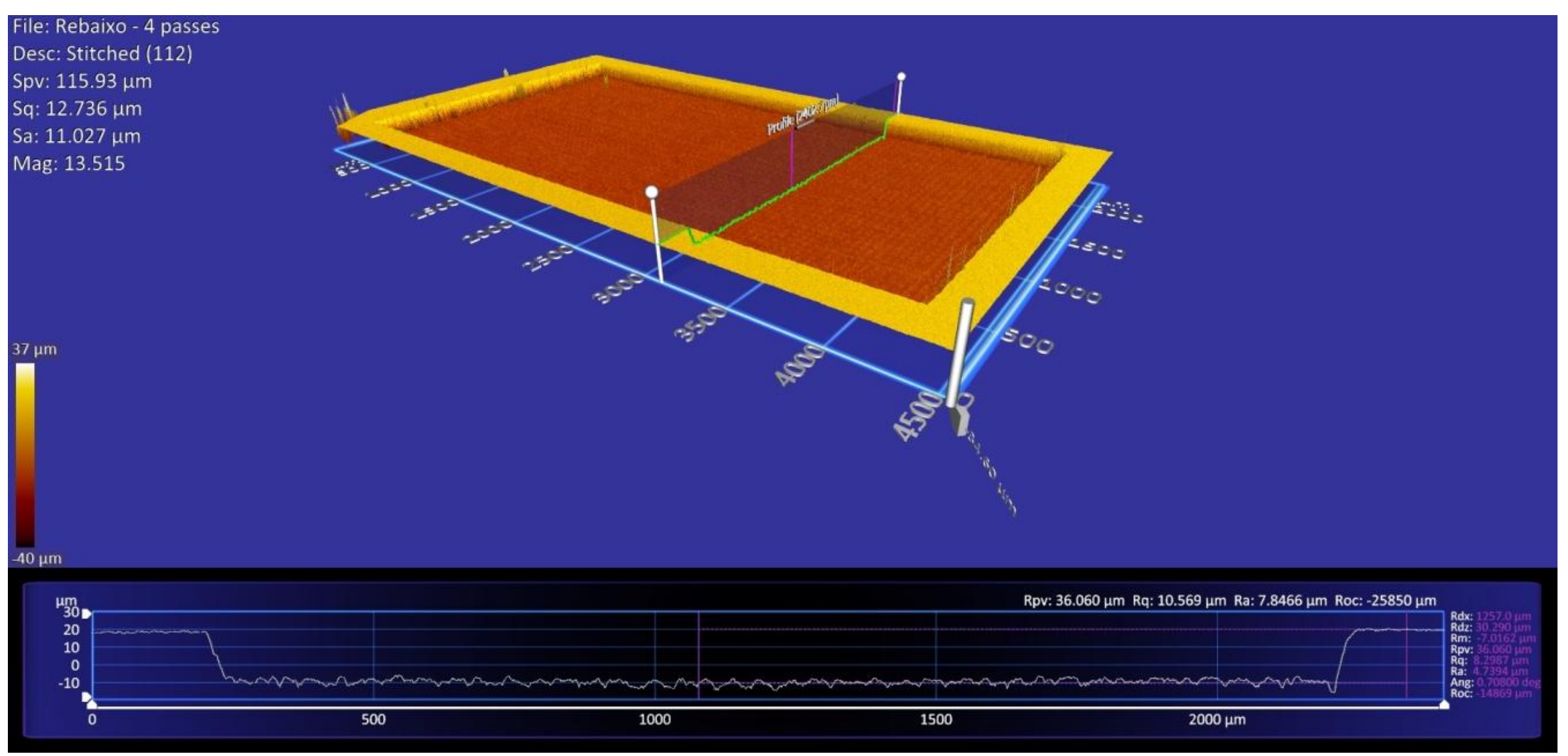

FIGURA 56 - Rebaixo ablacionado em quatro passes numa pastilha de usinagem para teste do sistema de LIBS. 


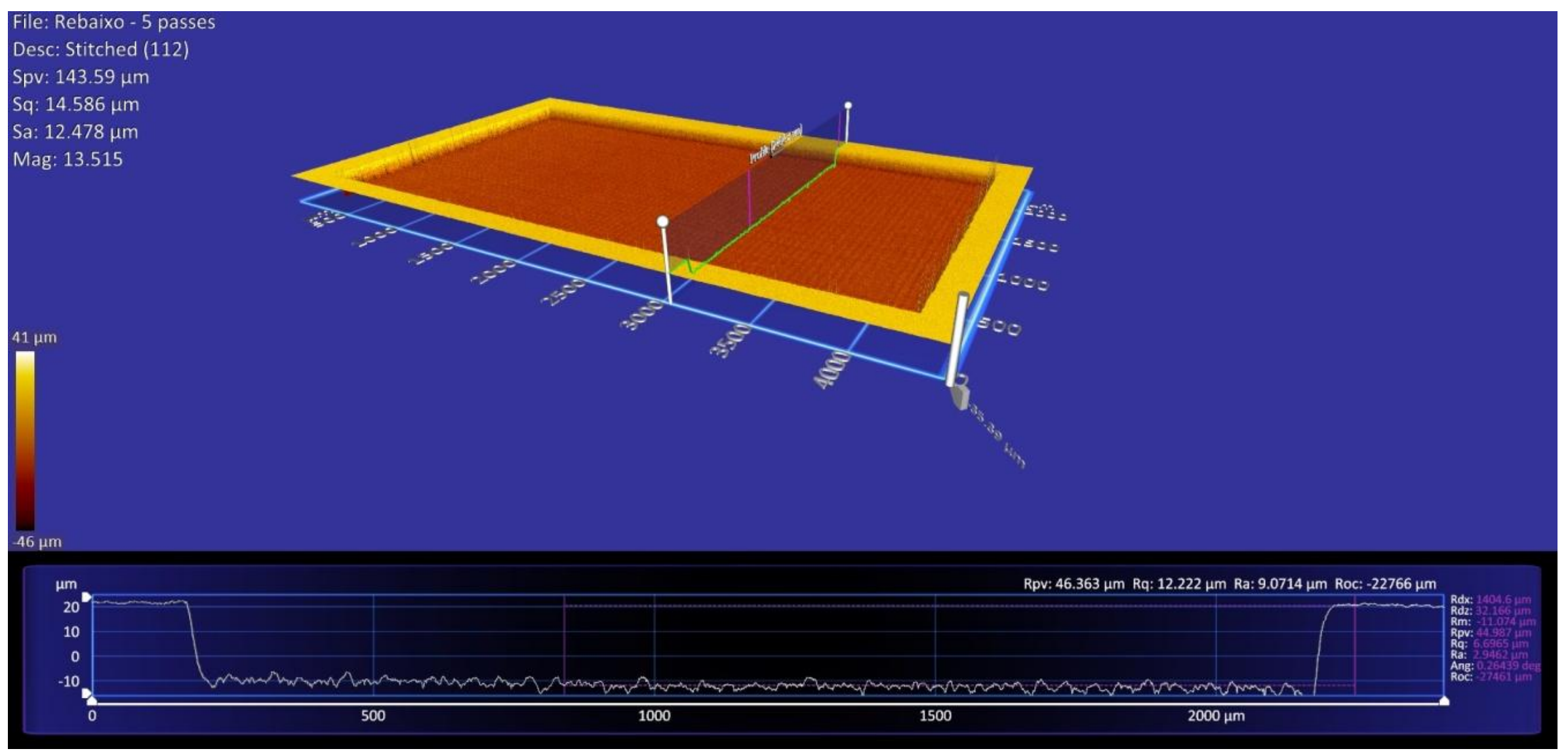

FIGURA 57 - Rebaixo ablacionado em cinco passes numa pastilha de usinagem para teste do sistema de LIBS. 


\section{REFERÊNCIAS BIBLIOGRÁFICAS}

[1] OHRING, M. Materials science of thin films: deposition and structure. 2nd ed. San Diego, CA: Academic Press, 2002.

[2] JUNIOR, A. R. F.; PINEDO, C. E.; TSCHIPTSCHIN, A. P. Utilização da nitretação sob plasma como pré-tratamento ao revestimento TiN-PVD na geração de superfícies duplex no aço AISI H13. Tecnologia em Metalurgia e Materiais, vol. 5, no. 3, 2009.

[3] LAKSHMANAN, S.; XAVIOR, M. A. Performance of Coated and Uncoated Inserts during Intermittent Cut Milling of AISI 1030 Steel. Procedia Engineering, vol. 97, pp. 372-380, 2014.

[4] KNOTEK, O.; LÖFFLER, F.; KRÄMER, G. Cutting performance of multicomponent and multilayer coatings on cemented carbides and cermets for interrupted cut machining. International Journal of Refractory Metals and Hard Materials, vol. 14, no. 1, pp. 195-202, 1996.

[5] EZUGWU, E. O.; OKEKE, C. I. Tool life and wear mechanisms of TiN coated tools in an intermittent cutting operation. Journal of Materials Processing Technology, vol. 116, no. 1, pp. 10-15, 2001.

[6] RUBLACK, T.; HARTNAUER, S.; KAPPE, P.; SWIATKOWSKI, C.; SEIFERT, G. Selective ablation of thin SiO 2 layers on silicon substrates by femto- and picosecond laser pulses. Materials Science \&amp; Processing, vol. 103, no. 1, pp. 43-50, 2011.

[7] MALINAUSKAS, M.; DANILEVIČIUS, P.; JUODKAZIS, S. Threedimensional micro-/nano-structuring via direct write polymerization with picosecond laser pulses. Optics express, vol. 19, no. 6, pp. 5602-5610, 2011.

[8] HERMANN, J. et al. Selective ablation of thin films with short and ultrashort laser pulses. Applied Surface Science, Article; Proceedings Paper vol. 252, no. 13, pp. 4814-4818, 2006.

[9] XIAO, S. Z.; SCHOPS, B.; OSTENDORF, A. Selective Ablation of Thin Films by Ultrashort Laser Pulses. Laser Assisted Net Shape Engineering 7 (Lane 2012), Proceedings Paper vol. 39, pp. 594-602, 2012.

[10] MATEO, M. P.; CTVRTNICKOVA, T.; FERNANDEZ, E.; RAMOS, J. A.; YANEZ, A.; NICOLAS, G. Laser cleaning of varnishes and contaminants on brass. Applied Surface Science, Article vol. 255, no. 10, pp. 5579-5583, Mar 2009.

[11] POULI, P.; MELESSANAKI, K.; GIAKOUMAKI, A.; ARGYROPOULOS, V.; ANGLOS, D. Measuring the thickness of protective coatings on historic metal objects using nanosecond and femtosecond laser induced breakdown spectroscopy depth profiling. Spectrochimica Acta Part B- 
Atomic Spectroscopy, Article; Proceedings Paper vol. 60, no. 7-8, pp. 1163-1171, 2005.

[12] DUMITRU, G.; LUSCHER, B.; KRACK, M.; BRUNEAU, S.; HERMANN, J.; GERBIG, Y. Laser processing of hardmetals: Physical basics and applications. International Journal of Refractory Metals \& Hard Materials, Article; Proceedings Paper vol. 23, no. 4-6, pp. 278-286, 2005.

[13] URECH, L.; LIPPERT, T.; WOKAUN, A.; MARTIN, S.; MÄDEBACH, H.; KRÜGER, J. Removal of doped poly( methylmetacrylate) from tungsten and titanium substrates by femto- and nanosecond laser cleaning. Applied Surface Science, vol. 252, no. 13, pp. 4754-4758, 2006.

[14] SEMEROK, A. F. et al. Femtosecond, picosecond, and nanosecond laser microablation: laser plasma and crater investigation. Laser and Particle Beams, Cambridge University Press, 2001.

[15] ZOPPEL, S.; HUBER, H.; REIDER, G. A. Selective ablation of thin Mo and TCO films with femtosecond laser pulses for structuring thin film solar cells. Applied Physics a-Materials Science \& Processing, Article vol. 89, no. 1, pp. 161-163, 2007.

[16] VANKO, G. et al. Bulk micromachining of SiC substrate for MEMS sensor applications. Microelectronic Engineering, Article vol. 110, pp. 260-264, 2013.

[17 NATIONAL MUSEUMS LIVERPOOL. Disponível em: <http://www.liverpoolmuseums.org.uk/conservation/departments/sculpture/ laser_cleaning.aspx>. Acesso em: 09 mar. 2017.

[18] MAIMAN, T. H. The Laser Odyssey. Laser Press, 1 ed, 2000.

[19] EINSTEIN, A. Zur Quantentheorie der Strahlung. ed. Zürich: Physikalische Zeitschrift, vol. 18, pp. 121-128, 1917.

[20] PATEL, C. K. N. Continuous-Wave Laser Action on Vibrational-Rotational Transitions of C O 2. Physical review, vol. 136, no. 5A, p. A1187, 1964.

[21] TRÄGER, F. Handbook of lasers and optics. New York: Springer, 2007.

[22] CSELE, M. Fundamentals of light sources and lasers. Hoboken, N.J.: J. Wiley, 2004.

[23] MCCLUNG, F. J.; HELLWARTH, R. W. Giant Optical Pulsations from Ruby. Applied Optics, vol. 1, no. S1, pp. 103-105, 1962/01/01 1962.

[24] SHI, W.; LEIGH, M.; ZONG, J.; JIANG, S. Single-frequency terahertz source pumped by $Q$-switched fiber lasers based on difference-frequency generation in GaSe crystal. Optics Letters, vol. 32, no. 8, pp. 949-951, 2007. 
[25] RP PHOTONICS. Disponível em: <https://www.rpphotonics.com/q_switching.html> Acesso em: 09 mar 2017.

[26] HARGROVE, L. E.; FORK, R. L.; POLLACK, M. A. Locking of he-ne laser modes induced by synchronous intracavity modulation. Applied Physics Letters, vol. 5, no. 1, pp. 4-5, 1964.

[27] KRUEGER A.; FÉRU, P. Getting Practical: New materials such as Yb:KGW yield simpler, more versatile femtosecond systems. Oemagazine, 30 May 2004. doi: 10.1117/2.5200405.0006 Available:

<http://spie.org/newsroom/getting-practical?ArticleID=x17070>

[28] SAMAD, R. E. Desenvolvimento de um amplificador de pulsos ultracurtos de Cr:LiSAF para um sistema laser híbrido de alta potência. 2006. Tese (Doutorado) - Universidade de São Paulo, São Paulo.

[29] WIKIPEDIA. Disponível em:

<https://es.wikipedia.org/wiki/Amplificaci\%C3\%B3n_de_pulso_gorjeado>. Acesso em: 09 mar 2017.

[30] WIKIPEDIA. Disponível em:

<https://en.wikipedia.org/wiki/Gaussian_beam>. Acesso em: 09 mar 2017.

[31] STEEN W. M.; MAZUMDER, J. Laser Material Processing. 4th Edition. ed. London: Springer, 2010.

[32] LASER FOCUS WORLD. Disponível em:

<http://www.laserfocusworld.com/articles/2010/02/beam-

characterization.html>. Acesso em: 09 mar 2017.

[33] SALEH B. E. A.; BAHAA, E. A. S. Fundamentals of photonics. Hoboken, N.J: Hoboken, N.J Wiley-Interscience, 2007.

[34] STEFAN, N. Micromachining, in Ultrafast Lasers, FERMANN, M. E.; GALVANAUSKAS, A.; SUCHA, G. Eds. CRC Press, 2002.

[35] DULEY, W. W. UV Lasers: effects and applications in materials science. Cambridge University Press, 2005.

[36] VON DER LINDE, D.; SOKOLOWSKI-TINTEN, K.; BIALKOWSKI, J. Lasersolid interaction in the femtosecond time regime. Applied Surface Science, vol. 109-110, pp. 1-10, 1997.

[37] FOSSA, J. Desenvolvimento de um sistema óptico para microperfuração de materiais cerâmicos, metálicos e poliméricos utilizando laser nanopulsado de Nd:YAG. 2007. Dissertação (Mestrado) - Universidade de São Paulo, São Carlos.

[38] STUART, B. C.; FEIT, M. D.; HERMAN, S.; RUBENCHIK, A. M.; SHORE, B. W.; PERRY, M. D. Nanosecond-to-femtosecond laser-induced 
breakdown in dielectrics. Physical Review B, vol. 53, no. 4, pp. 1749-1761, 1996.

[39] SLIDEPLAYER. Disponível em: <http://slideplayer.com.br/user/6293042/>. Acesso em: 09 mar 2017.

[40] LIU, J. Simple technique for measurements of pulsed Gaussian-beam spot sizes, Optics letters, vol. 7, no. 5, pp. 196-198, 1982.

[41] SAMAD, R. E.; MACHADO, L. M.; VIEIRA JUNIOR, N. D.; ROSSI, W. D. Ultrashort Laser Pulses Machining, in Laser Pulses - Theory, Technology, and Applications. PESHKO, I. Ed. InTech, pp. 143-174, 2012.

[42] ASHKENASI, D.; LORENZ, M.; STOIAN, R.; ROSENFELD, A. Surface damage threshold and structuring of dielectrics using femtosecond laser pulses: the role of incubation. Applied Surface Science, vol. 150, no. 1-4, pp. 101-106, 1999.

[43] JEE, Y.; BECKER, M. F.; WALSER, R. M. Laser-induced damage on single-crystal metal surfaces. Journal of the Optical Society of America B, vol. 5, no. 3, pp. 648-659, 1988/03/01 1988.

[44] SAMAD R. E.; VIEIRA JR, N. D. Geometrical method for determining the surface damage threshold for femtosecond laser pulses. Laser physics, vol. 16, no. 2, pp. 336-339, 2006.

[45] MACHADO, L. M.; SAMAD, R. E.; ROSSI, W. D.; VIEIRA JR., N. D. D-Scan measurement of ablation threshold incubation effects for ultrashort laser pulses. Optics Express, Article vol. 20, no. 4, pp. 4114-4123, 2012.

[46] HALL D. R.; JACKSON, P. E. The physics and technology of laser resonators. Adam Hilger, Bristol: CRC Press, 1989.

[47] CREMERS D. A.; RADZIEMSKI, L. J. Handbook of laser-induced breakdown spectroscopy. Chichester, West Sussex, England, Hoboken, NJ: John Wiley \& Sons, 2006, pp. xviii, 283 p.

[48] RADIVOJEVIC, I. Spectrochemical Analysis of Solid Samples by Laserinduced Plasma Spectroscopy. Technische Universität München, 2004.

[49] GUREVICH, E.; HERGENRODER, R. Femtosecond laser-induced breakdown spectroscopy: physics, applications, and perspectives. Applied spectroscopy, vol. 61, no. 10, p. 233A, 2007.

[50] MACHADO, L. M. Microusinagem de dielétricos com pulsos laser de femtossegundos. 2012. Tese (Doutorado) - Universidade de São Saulo, São Paulo.

[51] KRAMIDA, A.; RALCHENKO, Y.; READER, J. NIST Atomic Spectra Database (ver. 5.3), [Online]. Disponível em: <http://physics.nist.gov/asd>. Acesso em: 09 mar. 2017. 